\title{
Wear Reduction Systems Liquid Piston Ring
}

\section{Final Report}

\author{
R.J. Raymond \\ T-N. Chen \\ L. DiNanno
}

September 1990

Work Performed Under Contract No.: DE-AC21-88MC25035

For

U.S. Department of Energy

Office of Fossil Energy

Morgantown Energy Technology Center

Morgantown, West Virginia

By

Tecogen, Inc.

Waltham, Massachusetts 


\section{DISCLAIMER}

This report was prepared as an accoont of work sponsored by an agency of the United States Government. Neigher the United States Government nor any agency thereof. nor any of their employees, makes any' warranty, express or implied, or assurnes any lepal liability or responsibility for the eccuracy, complateness, or usefulness of any information, apparatus, product, or process discloced, or represents that its use would not initringe privutely owned rights. Reference herein to any specific commercial product, process. or service by trade name, traderrark, manufacturer, or otherwise dues not necessarily consitute or imply its endorsement, recomunendation. or favoring by the United States Governnient or any agency thereof. The views and opinions of authors expressed herein do not necessarily state or refrect those of the United Siates Government or any agency thereof.

This report has been reproduced directly from the best available copy.

A vailable to DOE and DOE contractors from the Office of Scientific and Technical Information, P.O. Box 62, Oak Ridge. TN 37831; prices available from (615)576-8401, FTS 626.8401.

Available to the public from the National Technical Information Servise, U. S. Department of Commerce, 5285 Port Royal Rd., Springfield, VA 22161. 


\title{
Wear Reduction Systems \\ Liquid Piston Ring
}

\author{
Final Report
}

\author{
R.J. Raymond \\ T-N. Chen \\ L. DiNanno
}

Work Performed Under Contract No.: DE-AC21-88MC25035

\author{
For \\ U.S. Department of Energy \\ Office of Fossil Energy \\ Morgantown Energy Technology Center \\ P.O. Box 880 \\ Morgantown, West Virginia 26507-0880 \\ By \\ Tecogen, Inc. \\ 45 First Avenue \\ P.D. Box 9046 \\ Waltham, Massachusetts 02254-9046
}

September 1990 


\section{ACKNOWLEDGEMENT}

Tecogen Inc., a subsidiary of Thermo Electron Corporation, extends its thanks to Mr. Nelson F. Rekos. Jr., Project Manager, and Wllliam Gary Smith. Project Manager, Morgantown Energy Technology Center. U.S. Department of Energy, for their assistance and guldance throughout the duration of this project. 


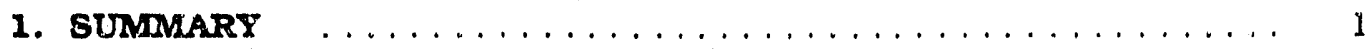

2. INTRODUCTION AND OBUECTIVES $\ldots \ldots \ldots \ldots \ldots \ldots \ldots \ldots$

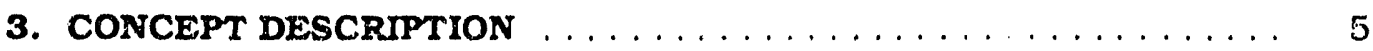

4. PROGRAM DESCRIPTION $\ldots \ldots \ldots \ldots \ldots \ldots \ldots \ldots \ldots \ldots \ldots \ldots$

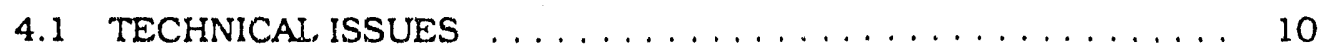

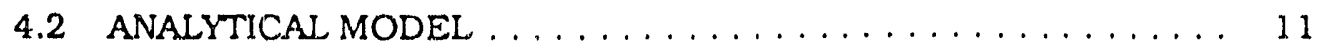

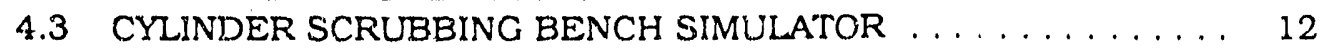

4.4 SINGLE-CYLINDER LIQUID PISTON RING TEST RIG . . . . . . . 13

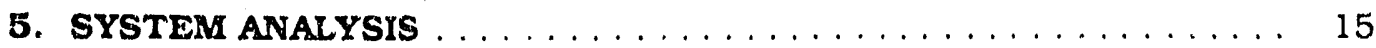

5.1 RECIRCULATED LIQUID RING SYSTEM $\ldots \ldots \ldots \ldots \ldots \ldots \ldots$

5.2 ONCE-THROUGH LIGUID SYSTEM $\ldots \ldots \ldots \ldots \ldots \ldots \ldots \ldots 18$

5.3 A.SH SYSTEM PARTICLE LOADING $\ldots \ldots \ldots \ldots \ldots \ldots \ldots 20$

5.1 DYNAMICS OF THE LIQUID RING $\ldots \ldots \ldots \ldots \ldots \ldots \ldots \ldots 21$

5.5 EFFECT OF HEAT TRANSFER $\ldots \ldots \ldots \ldots \ldots \ldots \ldots \ldots \ldots$

6. BENCH SCRUBBING SIMUILATION STUDY $\ldots \ldots \ldots \ldots \ldots \ldots, 30$

6.1 LABYRINTH GEOMETRY $\ldots \ldots \ldots \ldots \ldots \ldots \ldots \ldots \ldots \ldots$

6.2 BENCH SCRUEBING SIMULATOR $\ldots \ldots \ldots \ldots \ldots \ldots \ldots \ldots, 30$

6.3 FLOW VISUALIZATION SYSTEM $\ldots \ldots \ldots \ldots \ldots \ldots \ldots \ldots \ldots \ldots$

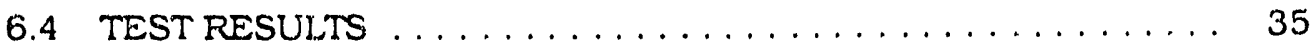

7. SINGLE-CYLINDER TEST RIG $\ldots \ldots \ldots \ldots \ldots \ldots \ldots$

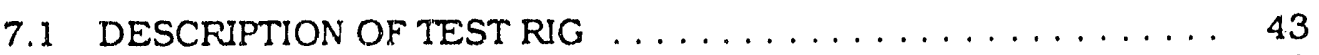

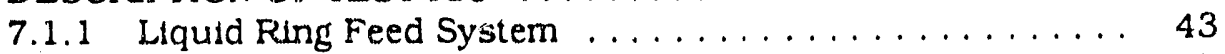

7.1 .2 Solid Particles Feed System $\ldots \ldots \ldots \ldots \ldots \ldots \ldots \ldots 47$

7.1 .3 Exhaust System . . . . . . . . . . . . . . . 49

7.1 .4 Test Cylinder Lube Oll System $\ldots \ldots \ldots \ldots \ldots \ldots . . \ldots 9$

7.2 TEST CONDITIONS ..................... 50

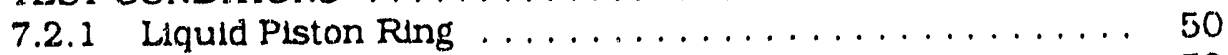

7.2 .2 Solids Particle Feed Rate $\ldots \ldots \ldots \ldots \ldots \ldots \ldots \ldots$

7.2 .3 Liquid Piston Ring Flow Rate . . . . . . . . . . . 51

7.2 .4 Water/Surfactant Mixture . . . . . . . . . . . . 51

7.2 .5 Top Piston Ring Design $\ldots \ldots \ldots \ldots \ldots \ldots \ldots \ldots \ldots$

7.2 .6 Cylinder Pressure . . . . . . . . . . . . . 52

7.3 TEST RESULTS AND DISCUSSION $\ldots \ldots \ldots \ldots \ldots \ldots \ldots \ldots 52$

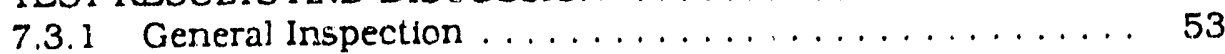

7.3 .2 Piston Ring and Liner wear $\ldots \ldots \ldots \ldots \ldots \ldots \ldots$

8. CONOLUSIONS AND RECOMDIENDATIONS $\ldots \ldots \ldots \ldots$. 1

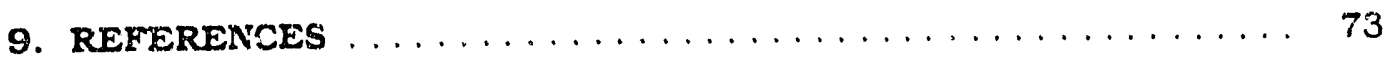




\section{LIST OF TABLES}

7.1 Wear Data for the Liquid Piston Ring Test Rig . 


\section{LIST OF IILUSTRATIONS}

3.1 Liquid Piston Ring Concept Schematic

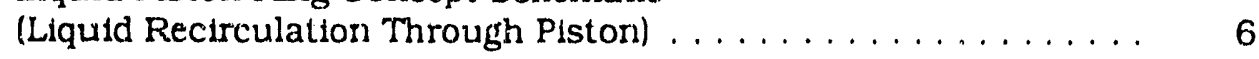

3.2 Liquid Piston Ring Concept Schematic

(Liquid Recirculation Through Cylinder Liner) . . . . . . . . . 7

3.3 Liquid Piston Ring Concept Schematic

(Once-Through System) .................. 8

5.1 Flow Dlagram for Reclrculated Liquld System . . . . . . . . 17

$5.2 \quad$ Flow Dlagram for Once-Through Liquid System . . . . . . . . . 19

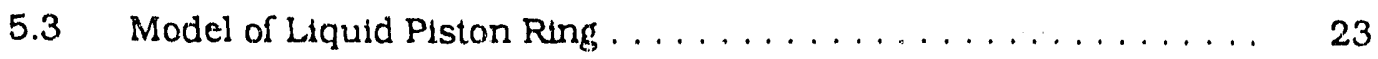

$5.4 \quad\left(P_{1}-P_{0}\right)$ versus Crank Angle - Medium Speed Engine

9.0-in. Bore, 10.5-in. Stroke . . . . . . . . . . . . . . 24

$5.5 \quad\left(P_{1}-P_{0}\right)$ versus Crank Angle - Low Speed Engine

13-in. Bore, 16-in. Stroke .................. 26

5.6 Two-Piece Piston Design with Thermal Barrier to the Labyrinth . . 29

6.1 Labyrunth Geometry $\ldots \ldots \ldots \ldots \ldots \ldots \ldots \ldots \ldots \ldots \ldots$

$6.2 \quad$ Bench Scrubbing Simulator $\ldots \ldots \ldots \ldots \ldots \ldots \ldots \ldots \ldots$

6.3 Bench Scrubbing Simulator $\ldots \ldots \ldots \ldots \ldots \ldots \ldots \ldots \ldots$

6.4 Flow Visualtzation Lighting Syrstem $\ldots \ldots \ldots \ldots \ldots$

6.5 Flow Visualization System for Stationary Camera . . . . . . . . 37

6.6 Flow Tracer Picture of Bench Slmulator Test . . . . . . . . . . 38

6.7 Observation of Flow Pattern in Labyrinth Channeis . . . . . . . . . 39

7.1 Wear Reduction System Test Rig Schematic $\ldots \ldots \ldots \ldots \ldots 4$

7.2 Single-Cylunder Test $\mathrm{Ng} \ldots \ldots \ldots \ldots \ldots \ldots \ldots \ldots$

7.3 Piston/Cylizder Arrangement for Wear Reduction Test Rig . . . . . 46

7.4 Particle Feed Apparatus for Wear Reduction Systern Test Rig . . . 48

7.5 Test Components After Test $1 \ldots \ldots \ldots \ldots \ldots \ldots$

7.6 Test Components After Test $2 \ldots \ldots \ldots \ldots \ldots \ldots$ 


\section{IIST OF ILIUSTRATIONS (Continued)}

7.7 Test Components After Test $2 \ldots \ldots \ldots \ldots \ldots \ldots \ldots$

7.8 Test Components After Test $2 \ldots \ldots \ldots \ldots \ldots$

7.9 Test Components Arter Test $3 \ldots \ldots \ldots \ldots$

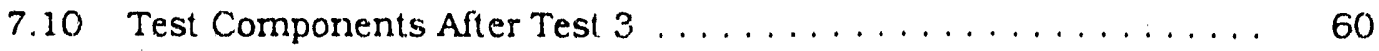

7.11 Test Components After Test $3 \ldots \ldots \ldots \ldots 6 \ldots$

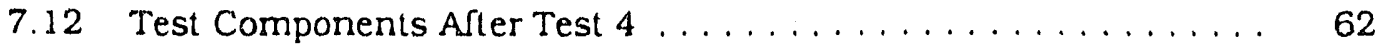

7.13 Test Components After Test $4 \ldots \ldots \ldots \ldots \ldots \ldots \ldots \ldots \ldots$

7.14 Test Components Arter Test $4 \ldots \ldots \ldots \ldots \ldots$

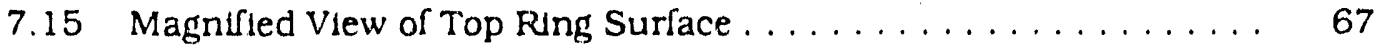

7.16 Magnifled View of Top Ring Surface $\ldots \ldots \ldots \ldots \ldots 6$

7.17 Magnified View of Top Ring Surface . . . . . . . . . . . . . 69 


\section{SUMOMARY}

The overall objective of the program was to demonstrate the technical feasibility of achieving an acceptable wear rate for the cylinder liner, piston, and piston rings in a coal/water-slurry-fueled engine that utilized the concept of a liquid piston ring above the conventional piston rings and to identify technical barriers and required research and development.

The study included analytical modeling of the syste.n, a bench study of the fluid motion in the liquid pist on ring, and a single-cylinder test rig for wear comparison. A system analysis made on the different vartations of the liquid supply system showed the desirability of the once-through version from the standpoint of system simplicity. The dynamics of the liquid ring were modeled to determine the important design parameters that influence the pressure fuctuation in the liquid ring during a complete engine cycle and the integrity of the liquid ring. This analysis indicated the importance of controlling heat transfer to the liquid ring through piston and liner to avold bolling the liquid. A conceptual piston design for minimizing heat transfer is presented in this report.

A bench simulator was bullt with a flow visualization system to study the fluid motion in the labyrinth area of the liquid piston ring when it is moved with the piston in reciprocaling motion. A. $90^{\circ}$ saw-tooth labyrinth was chosen based on the flow study to provide high shear rate at the wall and constant agitation in the channel to prevent solid accumulation.

A single-cylinder test rig was constructed using a commercial diesel engine as a base. The test piston was driven by the piston of the diesel engine, which was in turn driven by a variable speed motor. A fluidized-bed solid-particle delivery system was developed for the test rig to simulate ash loading on the cylinder wall. The test rig was used to test various conigurations with solld particles feeding into the cylinder so that relative wear rates of piston ring and liner could be measured. Results showed that the liquid piston ring effectively reduced the solid particles on the wall by scrubbing, especially in the case where a surfactant was added to the water. The wear rates were reduced by a factor of 2 with the liquid ring. However. leakage of the contaminated liquid ring material past the top ring limited ti, effectiveness of the liquid ring concept.

On the basis of this study, it was concluded that the liquid piston ring concept has significant technical merit in reducing the wear of piston ring and liner in a coal/water slurry-fuel engine. The research and development to be carried out next is to design and develop improved piston ring seals and a liquid buffer system to prevent the leakage of the liquid ring material past the piston ring. 


\section{INTRODUCTION AND OBJECTIVES}

There are three major technical questions to address in burning a solid fuel contaminated with solid noncombustibles (ash) in a rectprocating engine. The first question concerns combustion time. Is there sufficient time to burn the fuel efficiently for the desired fuel particle stze and engine speed? This question has been answered in the affirmative for slow-speed engines burning coal/water slurries where the coal particle sizes are in the 5 to $15 \mu \mathrm{m}$ range. ${ }^{1}$ Current DOEsponsored work in this area with medium-speed diesel engines has also shown that medium-speed engines can burn somewhat smaller particle sizes eflicienily. ${ }^{2}$

The second question rtates to cismponent wear rates. How can economically acceptable wear rates be malntained in the mechanical components of the engine that come into contact with the ash contained in the fuel?

The third question relates to the first cost of an engine developed to burn coal. What is the cost of an engine that burns coal with an acceplable efficiency and acceptable wear rates?

In answering all of these questions there are obvious trade-offs to be evaluated, such as: fuel cost vs wear rate (ash removal) and engine first cost vs wear rate (how much complexity and/or exotic materjals are bull into the engine to give an "acceptable" wear rate). Developing an economically viable reciprocating engine/coal fuel system is a process of examining a large number of alternatives and synthesizing a solution. The resulting engine/fuel system can then be compared to other types of prime mover/fuel systems capable of performing the same function to determine if it is a viable solution.

This report covers the control of wear rates in a reciprocating. coal-fueled engine: specifically, wear in the cylinder, piston ring, and liner area. The approach investigated here was developed on the idea that an engine designed to burn coal will resemble an oil-fueled engine in all respects not directly related to burning coal: i.e., it will have a conventional valve train, trunk-piston arrangement, etc. This idea is based on the trends found in reports detalling DOE-sponsored work that indicate that the major contractors are modifying engines from their existing product line to malie them compatible with burning coal.

The concept examined here, then, is an attempt to at'ack the problem of cylinder liner and ring wear in a reciprocating, coal-fueled engine by providing a solution that will have minimum impact on engine design and materials of construction. 
There are two approaches to dealing with the ash present in the engine cylinder after combustion. The first approach, favored by most firms currently active in the area, is to use in the construction of the engine component materials that can operate with ash present at rubbing surfaces and retain acceptable wear rates. The second approach is to prevent the ash from coming into contact with surfaces that are in relative motion, thereby allowing the use of conventional materials.

Most firms currently engaged in coal-fueled engine work are pursuing the approach of using hard materials in the rubbing components of the cylinder and piston assembly to reduce wear rates to an economically acceptable level. Alumina. silica, and iron oxide, the major components of most coal ash, are among the hardest materials known to man, and thus cause difficulties and uncertainties in this approach.

The question also arises: What happens to the ash particles once they work their way past the piston rings and liner? in the case of a trunk-type piston engine, the ash must find its way into the sump where it will mix with the lubricating oil. Once mixed with the lube oll, the ash could concelvably be removed before the oil is fed to the bearings. However, oll contaminated with ash dripping from the piston and liner would splash onto surfaces such as cams, cam followers, and gears before ever reaching the sump. What this really means is that if the approach is to allow ash to come into contact with the rubbing surfaces, not only will the piston rings and liner require ash-compatible materials but so will many, if not all, of the remaining rubbing surfaces in the engine.

The approach of preventing the ash from ever getting between rubbing surfaces in the engine is attractive be a ause it would allow conventional materials to be used, thereby potentlally reducing development time and the ultimate cost of the engine. The most direct way of achieving this would be to prevent the ash from ever depositing on the cylinder bore. This is not considered to be a practical alternative. The next way wuuld be to remove the ash from the bore in advance of the top piston ring, which is the approach taken in the concept evaluated in this report.

The overall objective of the program described in this report was to demonstrate the technical feasibility of achleving an acceptable wear rate fur the cylinder liner, piston, and piston ring in a coal/water-slumy-fueled engine utilizing the concept of a liquid piston ring above the conventional piston rings to scrub ash particles from the cylinder walls and remove them from the engine. The definition of what constltutes an acceptable wear rate will be left to the engine manufacturer responsible for the complete coal-fired engine, since the first cost of the engine, 
the fuel cost, and the maintenance cost (which is related to wear rate) are interrelated. Obviously, a very cheap fuel (relative to oll) can allow higher first cost and maintenance costs: therefore, it would be unrealistic to expect piston ring life in an engine runining on coal fuel to be equtvalent to that of an engine operating on Number 2 diesel fuel. For example, higher liner wear is tolerated in many modern. medium-speed diesels in order to burn a less expensive fuel.

The work described in this report includes analytical modeling. proof-ofconcept bench tests, and the conceptual design of a full-scale piston. Firing tests were not carried out in this phase of the program. The work scope is conceived as a series of logical steps culminating in a decision as to whether or not the concept is worthy of a single-cylinder firing engine test. 


\section{CONCEPT DESCRIPTION}

Figure 3.1 ullustrates the liquid piston ring concept, which is the subject of this report. A liquid ring is located above the top me allic piston ring to scrub ash particles from the path of the moving piston rings and piston skirt through relative motion of the labyrinth containing the llquid ring and cylinder liner. The clean liquid is supplied to a labyrinth seal area formed in the top of the piston. The clean liquild could be supplied above the top metal compression ring, as shown in Figure 3.2, and the contaminated liquid removed through the stationary liner rather than the moving piston if the pistcn were much longer (by appraximately the stroke of the engine). The piston rings are designert to prevent the contaminated liquid from leaking past the rings.

An analysis of the probable ash loading of the cylinder walls (see Section 5) and the amount of clean liquid renewal of the liquid ring required to maintain a low ash concentrati in indicates the possibllity of having the liquid ring discharge directly to the cylinder. where the ash and liquid would then be divinarged with the rest of the exhaust products. This variation of the corcept is shown in Figure 3.3. The advantage of the once-through system is that all of the cleanup is in the exhaust system and no separate liquici cleanup (or lube oll cleanup) is re " "tred. This also simplifies, and avoids problems with, the plumbing and valving.

The flow rate of liquid to the annulus is also dependent on the heai transfer from the combustion gas. The now rate must be high enough to prevent bolling. which would cause the loss of the liquid ring in the annulus.

The design of the labyrinth area through which liquid is purnped coritrols the scrubbing velocity at the liner surface and also controls the inertia of the liquid annulus moving with the piston. The inertic of the liquid annulus and the clearances between the labyrinth and liner and top ring and liner control the amount of liquid leaking into the cylinder during deceleration of the piston. Leakage of liquid down the piston past the rings is controlled by a secondary seal behind the top metallic compression ring. as shown in Figure 3.1.

The relative velocity of the liquid in the annulus is not only an important vartable in scrubbing ash particles off the liner wall but also controls the amount of heat transferred to the liquid from the hot liner and piston. If the liquid temperature becomes too high, bolling could occur, which would reduce the scrubbing elfectiveness and might lead to excessive loss of lluid into the cylinder. Since the llqutd ring operates at instantaneous cylinder pressure, bolling is suppressed during a substantial portion of the cycle. One positive aspect of the heat transferred to the liquid ring is that it should significantly reduce the cooling requirements of the piston and liner. 


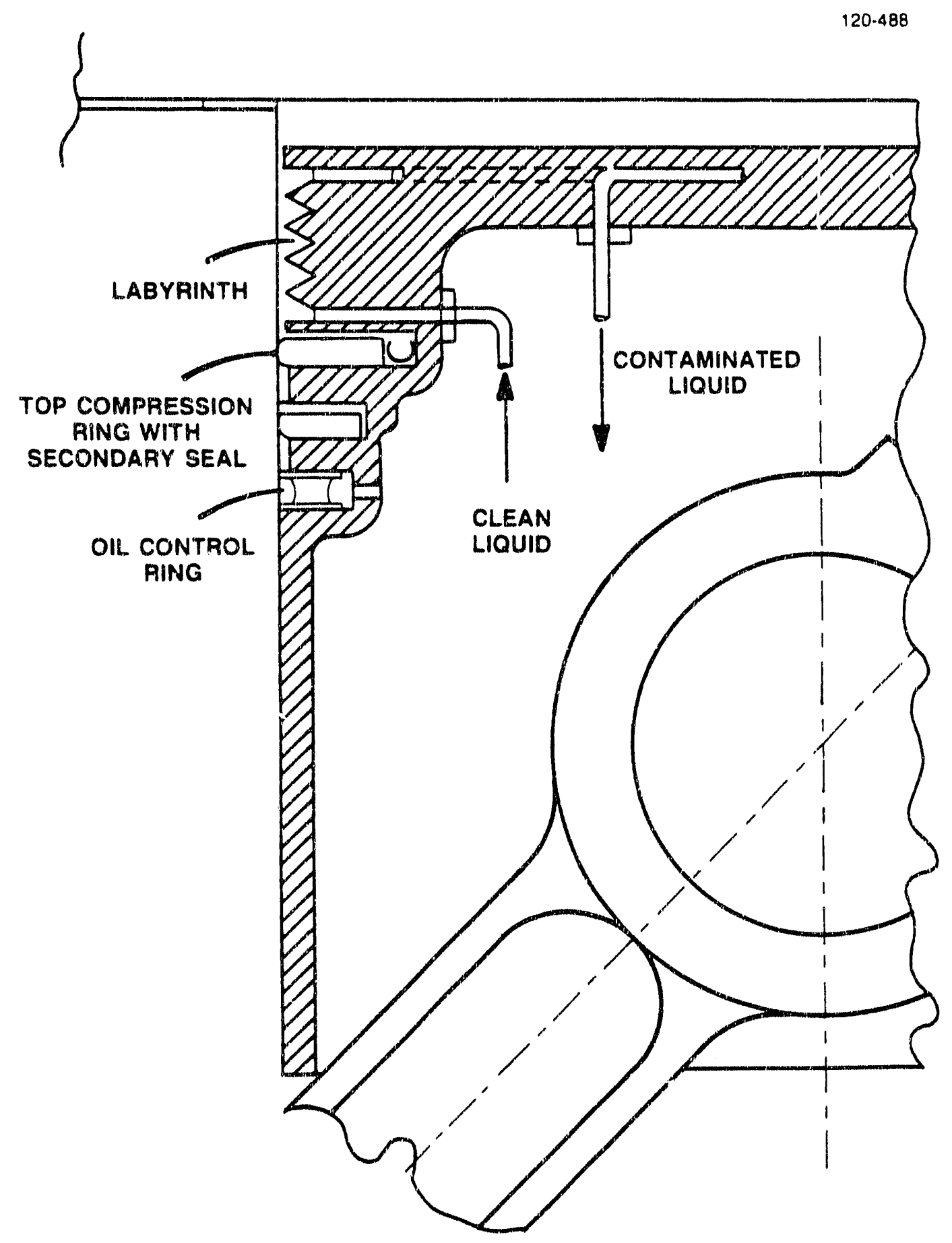

Figure 3.1 Liquid Piston Ring Concept Schematic (Liquid Recirculation Through Pistor) 


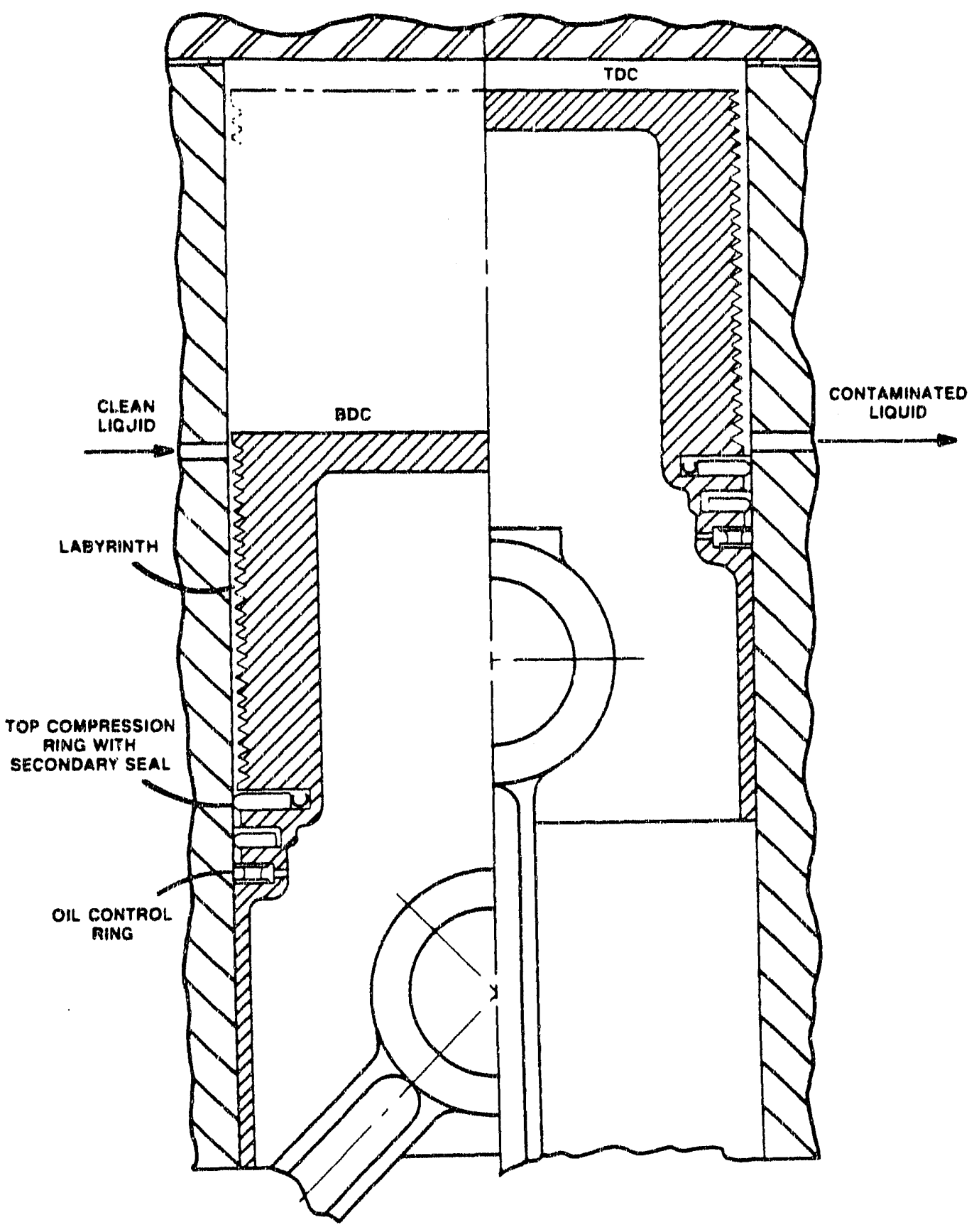

Figure 3.2 Liquid Piston Ring Concept Schematic (Liquid Recirculation Through Cylinder Liner) 


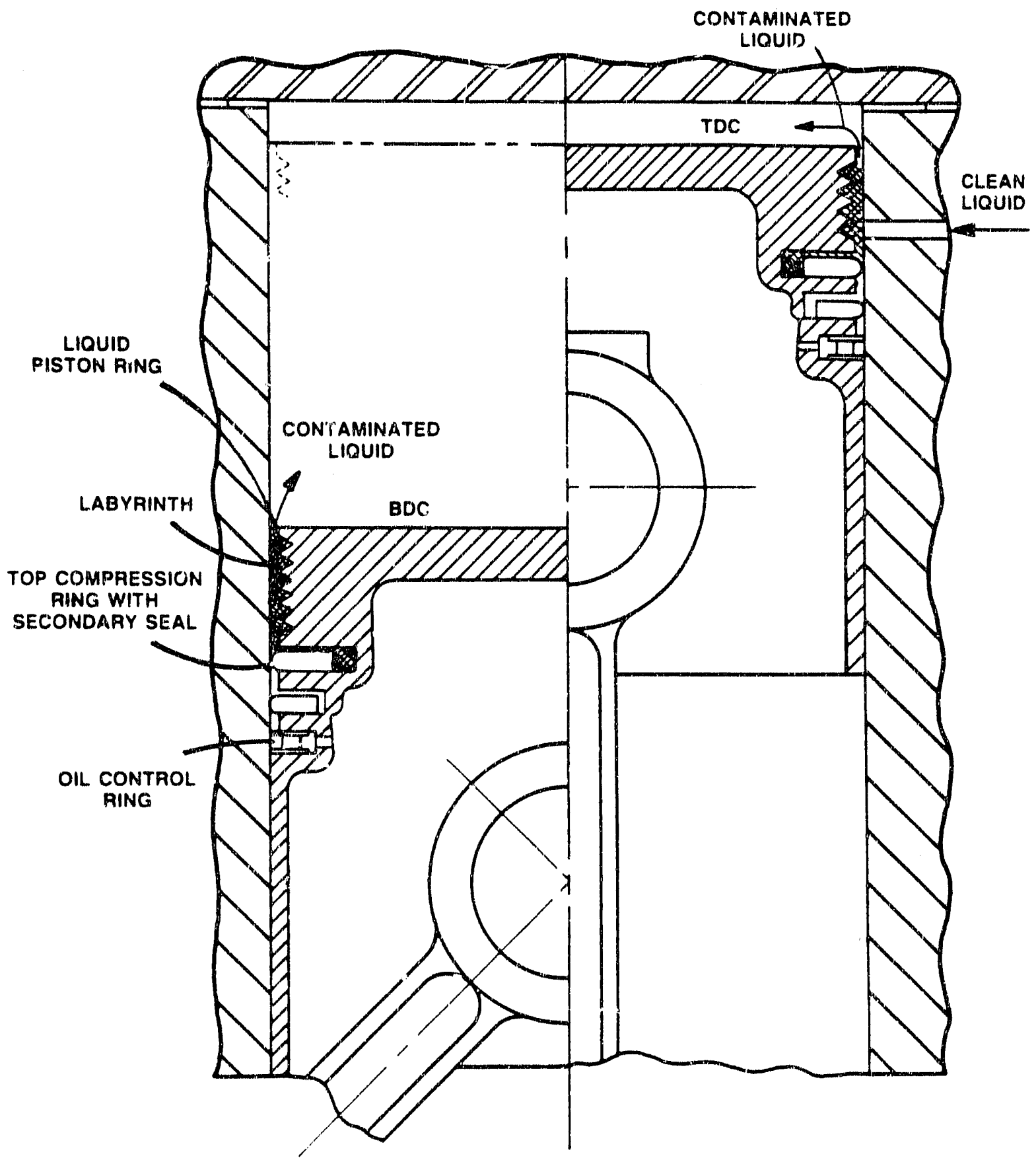

Figure 3.3 Liquid Piston Ring Concept Schematic (Once-Through System) 
The pump for clrculating the liquid through the liquid piston ring annulus could operate either at instantaneous cylinder pressure or at a lower pressure controlled by a system of check valves, since the liquid needs to circulate only during the exhaust stroke.

Following is a brief summary of the potential advantages of the concept.

- Wear-inducing particles can be prevented from reaching the engine sump. In approaches where the piston, liner, and piston ring assembly are designed to handle these particles with acceptable wear, the particles still find their way to the crankcase where they must either be removed frorn the lube oil before they splash onto a cam surface, for example, or every bearing system in the engine must be designed to tolerate them.

- Exotic materfals for ring, liner, and piston are not required.

- The top piston ring is protected from high temperature by the liquid ring. 


\section{PROGRAM DESCRIPTION}

\subsection{TECHNICAL, ISSUES}

The principal technical issues Involved in this concept are the acilevable effectiveness of removing particles from the walls; the control of leakage from the liquid piston ring annulus to both the engine cylinder and past the top piston ring to the inter-ring area; heat transfer to the liquid ring; and lubrication of the compression rings and piston skirt. A brief discussion of each of these issues follows:

- Particle Scrubbing - The basis for this concept is the assumption that liquid moving over the cylinder walls at high velocity will scrub ash particles from the wall. The obvious first step was to prove that this is. in fact, the case. Bench type tests were designed and performed to validate the concept and also provide design information about the effects of scrubbing velocity, particle stze, and labyrinth design on the efficiency of particle removal.

- Leakage - Some leakage to the cylinder is acceptable, since the fuel is presumably a coal/water slurry. Leakage will be controlled by the detall design of the labyrinth, the diametral clearance and height of the top piston land, and the deceleration of the piston. The labyrinth is critical, since it controls the scrubbing action, leakage to the cylinder, and buildup of ash deposits in the labyrinth itself. Analytical techniques were required to develop a model of the behavior of the labyrinth and to develop scaling laws so that proof-of-concept bench tests need not be full size.

In the once-through version of the concept (see Figure 3.3), a small amount of liquid would actually be displaced from the liquid piston ring labyrinth into the engine cylinder. The quantity of liquid injection would be determined by the particle loading of the cylinder wall and the destred concentration of particles in the liquid ring. For this concept to work. the leakage could not be large compared to the destred amount of liruid injected per cycle or to the total throughput of water In the slurry fuel.

Leakage of the contaminated liquir pasi the piston ring would cause the ash particles to be trapped between the piston ring and the cylinder wall. This would defeat the purpose of cleaning the abrasive particles of the wall with the liquid ring. The leakage ivould also allow the particles to enter the oil sump and cause wear of the bearings and cams. 
Therefore, controlling tise llquid leakage past the piston rings is an important factor in liquid piston ring effectiveness.

- Heat Transfer - Heat from the liner and piston is transferred to the liquid piston ring where it is dissipated through liquid leakage into the cylinder, evaporation and loss of liquid in the ring, or cooling of the recirculated liquid. If too much of the liquid ring is lost due to evaporation, its effectiver.sss in scrubbing the cylinder is reduced. An analysis was necessary to see if measures would have to be taken to reduce the heat transfer path from the pistor to the liquid piston ring. The liner could re cooled to a level that should preclude heat transfor to the liquid ring if necessary.

Buling of the iquid is suppressed whenever the cylinder pressure is elevated, since the liquid ring operates at instantaneous cylinder pressure. It may be that the effective saturation temperature 11 correspond to something like the mean effective pressure of the engine.

- Lubrication - Lubrication of the piston ring is of concern because the cylinder surface is exposed to luquid. There are several factors that help the lubrication of the piston rings. First, the surface is alternately exposed to oll and liquid. During the compression stroke, the piston ring moves into the zone prevlously scrubbed with liquid while oll is supplied to the surface below the ring. When the pressure load of the ring is the highest during the expansion stroke, the ring is moving onto the welllubricated surface. Second, since the piston ring does not scrape the surface completely free of oll during the downstroke, it is not llkely that the liquid will displace the thin layer of boundary oil away from the surface. Chemical additives may be used to further enhance the adherence of oll to the cylinder surface. Third, even if liquid mixes into the oll at the boundary, it may stlll provide adequate lubrication for the piston ring.

The technical issues discussed above were addressed in this program, and any barriers must be resolved before the technical feasibility of the proposed liquid ring concept can be established. To accomplish this overall goal, the following steps were taken.

\subsection{ANALYTICAL MODEL}

The analytical modeling of the system consisted of establishing the operating conditions and requirements for the liquid ring system, describing the flow sys em. 
and establishing the design crittria to meet the heat transfer and liquid leakage requirements. The approach taken in the modeling effort was that of minimum complexity to achleve these goals.

An analytical model was developed to gain an insi into the factors that affect the various functions of the liquid piston ring. The autulysis proceeded from simple, one-dimensional, single-phase treatment of the liquid piston ring and became more complex only as required to meet the objectuves. Three-dimensional unsteady, or boundary layer analyses were not considered unce it was shown that a simpler means of gaining a physical understanding of the system was adequate.

Similarly, the problem of understanding heat transier to the liquid piston ring did not begin with fintte element techniques.

Emphasis was placed on principles of similitude so that the bench rig procedures and results retain meaning when applied to the full-scale piston.

The operating conditions of the systern depend on the speed and the range of sizes of the engine, the power output, and the limitations in the engine design with respect to the coolant and lubrication system. The piston stroke and speed determine the acceleration and inertial force imposed on the liquid ring mass as the piston moves around the top dead center position. An analytical model of the liquid ring was developed to describe the motion and pressure variation in the liquid as a result of the inertial force generated by acceleration. the viscous drag on the liquid by the cylinder wall, and the pressure drop across each labyrinth. The object of the analysis was to establish the design criterta for minimal leakage of the liquid into the cornbustion space.

Heat transfer to the liquid ring is important, particularly in the once-through system. If heat transfer to the liquid ring were more than that required to evaporate the liquid at the supply rate. the liquid ring could not be maintained. An excessive rate of liquid now, on the other hand. is not desirable as it may affect the combustion of the coal slurry and lower the cycle efficiency.

\subsection{CYLINDER SCRUBBING BENCH SIMULATOR}

The scrubbing action to remove the particles from the cylinder wall due to nuid motion in the liquid ring is difficult to predict analytically. The flow pattern is unsteady due to the reciprocating motion of the piston. A bench simulation model was used to study the nutd motion in the annulus between the piston and the cylinder wall as the piston moved up and down. Since the effectiveness of scrubbing the particles off the wall is related to the flutd velocity and shear rate adjacent to the wall surface, it was the object of this study to develop the optimum labyrinth geometry for maximum now velocity and turbulence. 
The "Cylinder Scrubbing Simulator" is described in Section 6. The labyrinth in the piston is scaled up in size for visual observation cf the flow pattern by means of a videc camera with lighting in a narrow plane at an oblique angle to the camera. The motion of the piston was selected so that the Reynolds number duplicates that of the medium-speed diesel engines. Particles were introduced onto the surface of the cylinder wall so that their removal by the liquid ring could be observed. In addition to the scrubbing action. it is also important that the local fluid motion prevents deposition of particles anywhere in the arinulus. The parameters varied were:

- Liquid Ring Gap

- Total Ring Height

- Labyrinth Geometry - Shape, Tip Clearance, Pitch, Circumferential Partictons

- Reynolds Number

- Acceleration - Inertial Force

Because of the many geometrical variables, the piston was designed in a modular form to provide the nexibility to change the labyrinth geometry with minimum effort. The piston was moved by means of a crank mechanism driven with a vartable-speed motor. The results of these tests provided the data to design the single-cylinder bench test device.

\subsection{SINGLE-CYLINDER LIGUID PISTON RING TEST RIG}

To determine the eflectiveness in removing the solid particles from the wall and the wear characteristics of the liquid ring design, a single-cylinder wear rig was used. A single-cylinder englne was modified to provide easy replacement of the piston, ring. and cylinder liner, as described in Section 7. Liquid was supplied to the annulus ring through the cylinder wall by means of a timed injector. The unit could be motored over a range of speeds. This rig was used for verification of the labyrinth design and measurement of ring wear under varlous operating conditions. As a first step in determining the technlcal feasibllity of the liquid ring concept the test rig was designed to operate only at low pressure and temperature conditions. The results of this test determine whether or not to proceed to the next test in a firing engine.

The labyrinth configuration resulting from the bench simulation study was incorporated into the piston design for verdication of its eflectiveness in scrubbing the particles of the cylinder wall. To do this, particles were fed to the cylinder and water was continuously supplied and removed from the annulus space while the piston was reciprocated at the simulated speed. The surface of the cylinder wall 
and the piston were examined periodically to determine the effectivenes 3 of the labyrinth design. The leakage of water into the combus ion space was also determined.

The design of the piston rings, their elfectiveness in sealing against the leakage of contaminated water into the crankcase, and their resistance to wear were evaluated. Although this test rig did not provide the temperature and pressure conditions of a real engine, the behavior of the piston rings, the lubrication of the sliding surfaces, and the wear of the ring provided the information required to establish the feasibility $c$ f the liquid piston ring design with respect to the reduction of engine component wear for a directly coal-fired diesel engine. 


\section{SYSTEM ANALYSIS}

The system analysis consisted of studies in three areas. The first area defined the engine configuration, engine speed and output, the coal slurry characteristics, and the flow circuit for the liquid piston ring. This analysis provided the necessary information to determine the applicability of the liquid piston ring concept and its impact on the overall system of the coal-slurry-fired diesel engine. The second area of study was the dynamic behavior of the liquld piston ring as it moved with the piston in a reciprocating motion. The local flow pattern adjacent to the cylinder wall directly influenced the effectiveness of scrubbing the solid particles off the liner surface. However, the unsteady motion was not amenable to analytical modelling, and it was studied by means of now visualization on a large-scale bench simulator. The analysis therefore treated only the gross behavior of the fluid motion, which affected the pressure variations in the liquid ring as a function of the engine crank angle. This information helped to determine the tendency of liquid leakage into the combustion space as well as past the piston rings. The third area was the heat transferred from the combustion gas via the piston and liner to the liquid ring. It was important to determine whether or not the liquild ring could be maintained without bolling and what design changes were necessary to reduce heat transfer in order to maintain the liquid ring. Various aspects of the system analysis are presented in the following sections.

\subsection{RECIRCULATED LIGUID RING SYSTEM}

The rectrculated liquid ring concept is illustrated in Figures 3.1 and 3.2 for two different methods of introducing and discharging the liquid.

In Figure 3.1, the liquid entry and discharge are through the piston. This design has the advantage that the lquid entry and discharge points always remain the same relative to the liquid ring annulus. Therefore, by properly selecting the inlet and discharge ports, a now pattern can be established such that the clean liquid is always near the piston ring while the contaminated liquid is near the top of the piston. The major challenge in this design is the method of piping the liquid in and out of the piston which is in constant rectprocating motion. The following approaches are considered technically feasible.

- Telescopic pipes with sliding seals.

- Flexuble hoses.

- Pipe linkage with rotaling seal at joints.

The telescopic pipes have been used on low-speed cross-head type engines for bringing cooling water to the piston. However, in the liquid ring application. 
the return water contains particles of abrasive materials which may cause wear problems in the sliding seals. The pipe linkage arrangement with sealed joints could potentlally face the same wear problem at the seals when they are exposed to the contari.lnated liquld over a prolonged period of tlme. The flexible hose system requires selection of the proper material for long 1 fe and special design of the connections. The inertia of the hose and the liquid within it contribute to the dynamic behavior of the flexible hose system under reciprocating motion.

Figure 3.2 shows an alternate approach in which the liquid is introduced and discharged through the cylinder wall. This design eliminates the need to pipe the liquid through the moving piston. In this design. the height of the liquid ring section above the piston ring is greater than the stroke of the piston, so that both the injection and discharge ports remain exposed to the liquid ring at all times. When the piston is at top-dead-center the ports are at the bottom of the liquid ring and just above the piston ring. At bottom-dead-center, the ports are near the top of the piston crown. This arrangement can also establish a flow of liquid in the axial direction away from the piston ring if the injection of the liquid is timed to take place near top-dead-center while discharge of the liquid occurs near bottomdead-center. The added height of the piston has a significant impact on the overall dimensions of the engine as well as the static and dymamic force balance on the piston. A shorter liquid ring section is also acceptable if valves are provided to prevent the cylinder gas from discharging into the liquid system.

One advantage of the recirculated liquid ring system is the Mexiblity in selecting the liquid now rate. The flow rate of llquid affects the particle concentration in the liquid ring, which in turn allects the probabilly of the particles being trapped between the piston ring and the cylinder liner. The liquid now rate also determines the temperature rise of the liquid in the ring due to heat transferred from the combustion gas through the piston and the cylinder liner. High liquid flow rate can prevent the liquid from reaching the bolling point particularly if the pressure in the liquid ring drops below atmospheric pressure during the exhaust stroke of the cycle. This will be discussed later.

The recirculated liquid ring system involves a rather complex flow circuit exlemal to the engine cylinders (see Figure 5.1). The conlaminated liquid from the engine must be cleaned up with a filter or separator before the liquid is sent back to the engine. Liquid make-up is necessary as part of the liquid will be lost to the cornbustion space and also disposed with the solids. The pressure level of the liquid injection pump depends on the timing of the injection. For example. if continuous injection is desired, the liquid must be pumped to a pressure higher than the peak firing pressure in the cylinder. If one chooses to inject during intake and exhaust stroke when the cylinder pressure is low, then a low pressure pump 


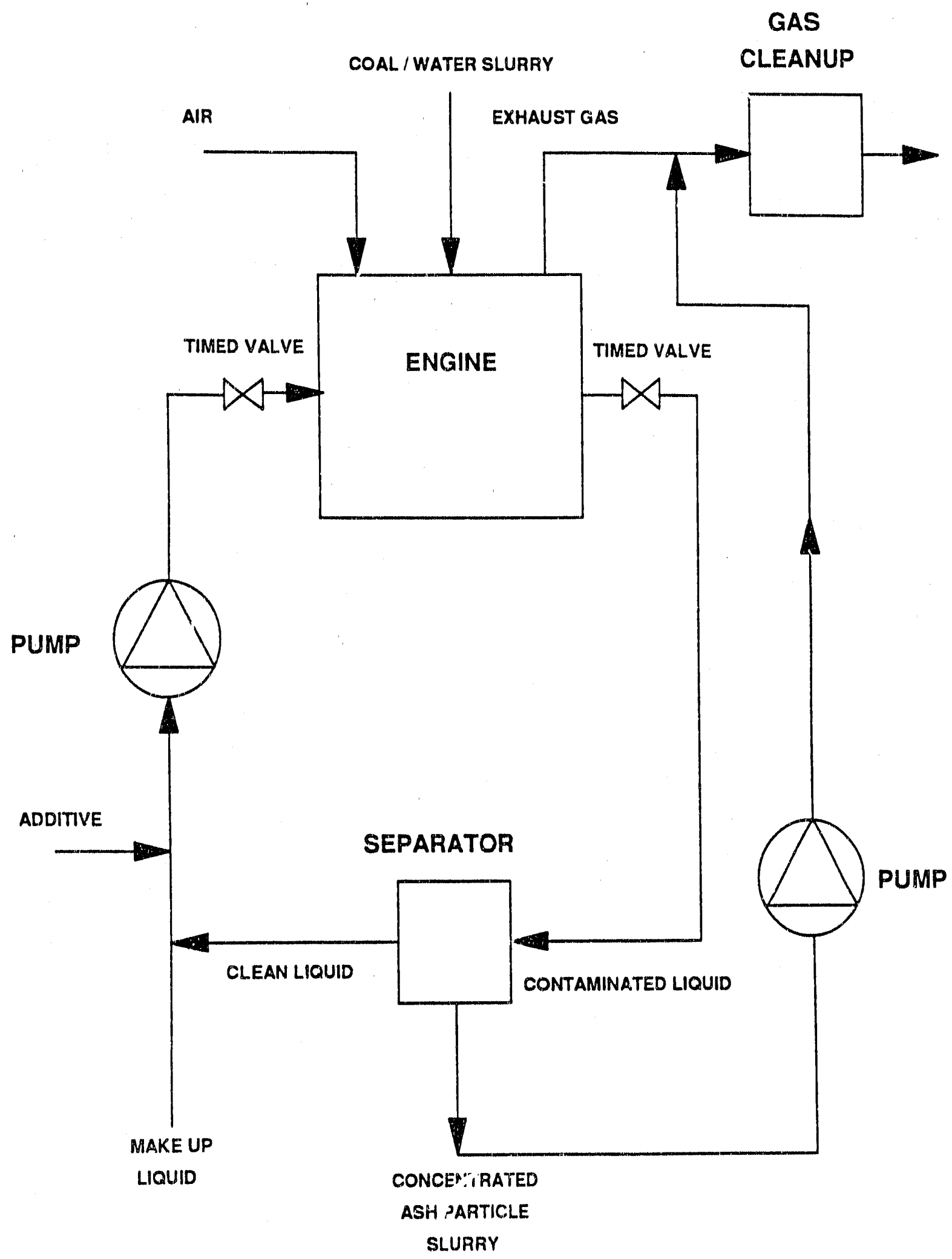

Figure 5.1 Flow Diagram for Recirculated Liquid System 
may be used in conjunction with check valves in the supply line to prevent back now. A timed valve would be operated according to the engine crank angle if a specific timed injection is destred.

The solid particles removed from the engine cylinder must be separated from the liquid and discharged from the system continuously. Since the particles could be in the submicron size range, a very efficient method of separation si required. The disposa' could be accomplished by discharging the concentrated slurry into the hot exhaust gas so that the liquid is evaporated and the solids captured in the exhaust clean-up system.

In general, the recirculated liquid ring system, in spite of its advantages in controlling the flow and temperature in the ring, is a less preferred approach due to the complexity of the overall system. A simpler system with once-through liquid feed is described below.

\subsection{ONCEITHROUGH IIGUTD SYSTEM}

The once-through liquid ring system, as shown in Figure 3.3. only has ports to admit clean liquid. The contaminated liquid is discharged direcily into the cylinder space where the ash particles and liquid are then discharged with the rest of the exhaust products. The advantage of the once-through system is that all of the cleanup is in the exhaust systern and no separate liquid cleanup is required (see the flow diagram in Figure 5.2). This simplifies, and avoids problems with, the plumbing and valving. The liquid inlet ports are located near the pistor. ring when the piston is at top dead center. Therefore. if the injection of liquid is timed near top dead center, the liquid flows away from the piston ring towards the top of the piston, thus keeping the contaminated liquid away from the piston ring area. Li. the case where the liquid ring height is less than the piston stroke, the tined injection valve is necessary to prevent the cylinder gas from flowing into the liquid supply system.

The once-through siystem is limited in the amount of liquid now to the ring and subsequently into the combustion space. The addition of the liquid into the combustion gas has two effects. First, large amounts of liquid addition to the coal slurry fuel cause the combustion rate to slow down and result in lower combustion efliciency and overall thermodynamic cycle efficiency. In the extreme case, it may cause engine misfiring. The limit of liquid flow rate is difficult to predict, because it is a function of the liyuld form. l.e., droplet size, and the time distribution of the liquid flow over the various parts of the cycle. For example. if the majority of the liquid is discharged into the cylinder during the exhaust stroke, there is little effect on combustion. The second effect is the addition of the liquid on the thermodymamic cycle efficiency. If the liquid is added to the fuel-air mixture and 
TF60-990

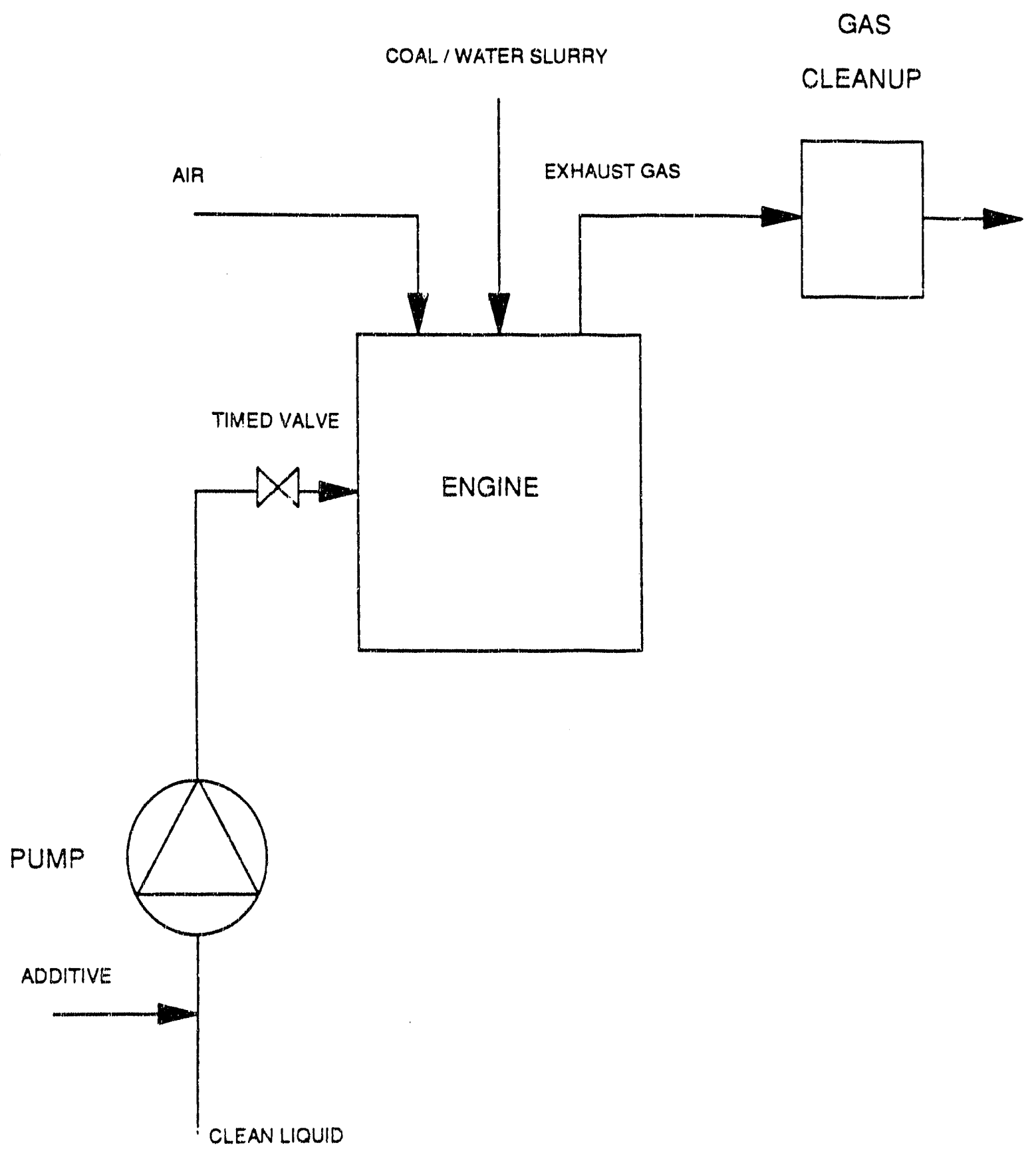

Figure 5.2 Flow Diagram for Once-Through Liquid System 
proceeds through the normal cycle of compression, evaporation, and expansion, it causes the flame temperature to drop, thus causing a reduction of thermal efficiency for the nomnal fuel-air charge. However, the added liquid also contributes to the total power output, and therefore the net result could be an increase in power and efficiency. Analysis and experiments made on inlet manifold water injection ${ }^{3}$ showed a slight improvement in fuel consumption up to a ratio of water to fuel of 1.25 for the case of stolchlometric gasoline-air mixture. Therefore, it is reasonable to assume that a liquid mass injection rate comparable to the fuel mass rate is acceptable for the once-through system.

\subsection{ASH SYSTEM PARTICLE LOADING}

The next ruestion for the once-through system is what would be the magnitude of ash concentration in the liquid ring if the liquid fow rate is limited to the fuel flow rate. Let us consider the following conditions.

\begin{tabular}{ll} 
Fuel Pruperties & \\
\hline Dry Coal & $50 \%$ \\
Molsture & $50 \%$ \\
Particle Size (Average) & $10 \mathrm{microns}$ \\
Ash Content & $0.53 \%$ \\
Lower Heating Value (Dry Coal) & $13.740 \mathrm{Btu} / \mathrm{lb}$ \\
Lower Heating Value (Slurry) & $6.750 \mathrm{Btu} / \mathrm{lb}$ \\
& \\
Engine Condilion (GE) & \\
\hline Bore & $9 \mathrm{in}$. \\
Stroke & $10.5 \mathrm{in}$. \\
Speed & 900 to $1200 \mathrm{rpm}$ \\
Power & 249 to $274 \mathrm{hp} / \mathrm{cyl}$. \\
BSFC & $6.500 \mathrm{Btu} / \mathrm{bhp}-\mathrm{hr}$
\end{tabular}

These figures yield the following estimates.
Coal Consumption
$0.473 \mathrm{lb} / \mathrm{bhp}-\mathrm{hr}$
Water Loading
$0.473 \mathrm{lb} / \mathrm{bhp}-\mathrm{hr}$
Ash Loading
$0.00251 \mathrm{ib} / \mathrm{bhp}-\mathrm{hr}$

If 10 percent of the ash from the coal is assumed to contact the cylinder wall and is held by the oil film, then the concentration of ash particles in a homogeneously mixed liquid ring can be detemined for a given liquid flow rate. Let clean liquid enter the ring at llow rate $m_{1}$, contaminated liquid at particle concentration $C$ leaves the ring, and particles deposit on the cylinder wall from the 
combustion gas at a rate of $\mathrm{m}_{3}$. To maintain a steady-state concentration of particles in the liquid ring, we have, for mass conservation,

$$
m_{s}=C\left(m_{s}+m_{1}\right)
$$

At a particle deposition rate of $0.000251 \mathrm{lb} / \mathrm{bhp}-\mathrm{hr}$

$$
c=\frac{0.000251}{m_{1}+0.000251}
$$

Therefore, at a liquid flow rate comparable to the water loading from the slurry fuel, 1.e., $m_{1}=0.473 \mathrm{lb} / \mathrm{bhp}-\mathrm{hr}$, the concentration of particles in the liquid ring is $C=0.00053$. This is a reasonably diluted slurry to be maintained in the ring. The concept of the once-through system is therefore considered feasible, and further investigation is warranted in view of its advantages over the recirculated system.

\subsection{DYNAMICS OF THE IIGUID RING}

The two major technical issues addressed in the system analysis are the following:

- Dynamlc behavior of the liquid ring, which cetermines the leakage of the liquid into the cylinder and the effect of the labyrinth geometry on that leakage.

- Heat transier from the cylinder liner and the piston to the liquid ring. which aftects evaporation and loss of liquid in the ring.

The heat transier consideratlons are discussed in Section 5.5 .

An analytical model to describe the dynamic behavior of the fluld ring was developed. The model includes the inertia force generated by the rectprocating motion as the liquid ring moves up and down with the plston. the viscous drag on the llquid due to its motion relative to the cylinder wall, and the pressure drop resulting from flow across the labyrinth. Although simplifying assumptions are nade regarding the flow pattern and the viscous drag, the model helps to identify the important design parameters for the liquid ring. 
For a simple annular ring model, as shown in Figure 5.3, the static pressure in the liquid at a depth $L$ from the top free surface can be expressed as a function of the liquid ring configuration and the instantaneous engine operating parameters:

$$
p-p_{0}=\frac{\mu C_{v} L v}{g h^{2}}+\frac{n k}{(\pi D C h)^{2}} \frac{m^{2}}{2 g p}+\frac{\rho L}{g}(a+g)
$$

where:

$$
\begin{array}{ll}
\mathrm{n} & =\text { number of labyrinths per inch } \\
\mathrm{L} & =\text { depth of liquid ring from top free surface } \\
\mathrm{h} & =\text { liquid ring thickness } \\
\mathrm{V} & =\text { piston velocity } \\
\mathrm{a} & =\text { piston acceleration } \\
\mathrm{D} & =\text { piston diameter } \\
\mathrm{m} & =\text { mass through fiow rate } \\
\rho & =\text { liquid density } \\
\mu \quad & \text { viscosity of liquid } \\
\mathrm{C}_{\mathrm{v}}, \mathrm{C}, \mathrm{k} & =\text { correction constants for assumed velocity profiles }
\end{array}
$$

The first term on the right hand side of the equation represents viscous drag resulting from the relative motion between the cylinder wall and the liquid ring. $\mathrm{C}_{v}$ is a correction factor for the assumed linear velocity gradient. This term varies in magnitude and direction during a cycle. The secorid term is the pressure drop due to the net now of the liquid across the labyrinths. It is assumed that the flow is constant and it is in the direction from the piston ring toward the top of the piston. The third term is the inertta of the liquid mass when it is moved up and down with the piston.

Figure 5.4 shows for a $9-1 \mathrm{n}$. bore $\times 10.5-1 n$. stroke engine the variation of pressure differental between the top and bottom of the liquid ring in one revolution of the engine and the eflects of the various design and operating parameters. When the ring thickness is larger than $0.0005 \mathrm{ft}$ in this medium-speed engine the ring height and engine speed are the only two major controlling parameters on the pressure in the liquid. When the ring thickness is reduced to $0.0002 \mathrm{ft}$. as shown in Figures $5.4(\mathrm{c})$. (d), and (e). the labyrinth pitch also becomes effective in controlling the liquid pressure. The liquid flow rate affects the pressure only when it is appreciably higher than that corresponding to the water loading in the coal slurry fuel even when the ring thickness is only $0.0002 \mathrm{ft}$.

It is important to note that for a cerlain geometry and engine speed the pressure at the bottom of the ring drops as much as 7 psi below the cylinder 


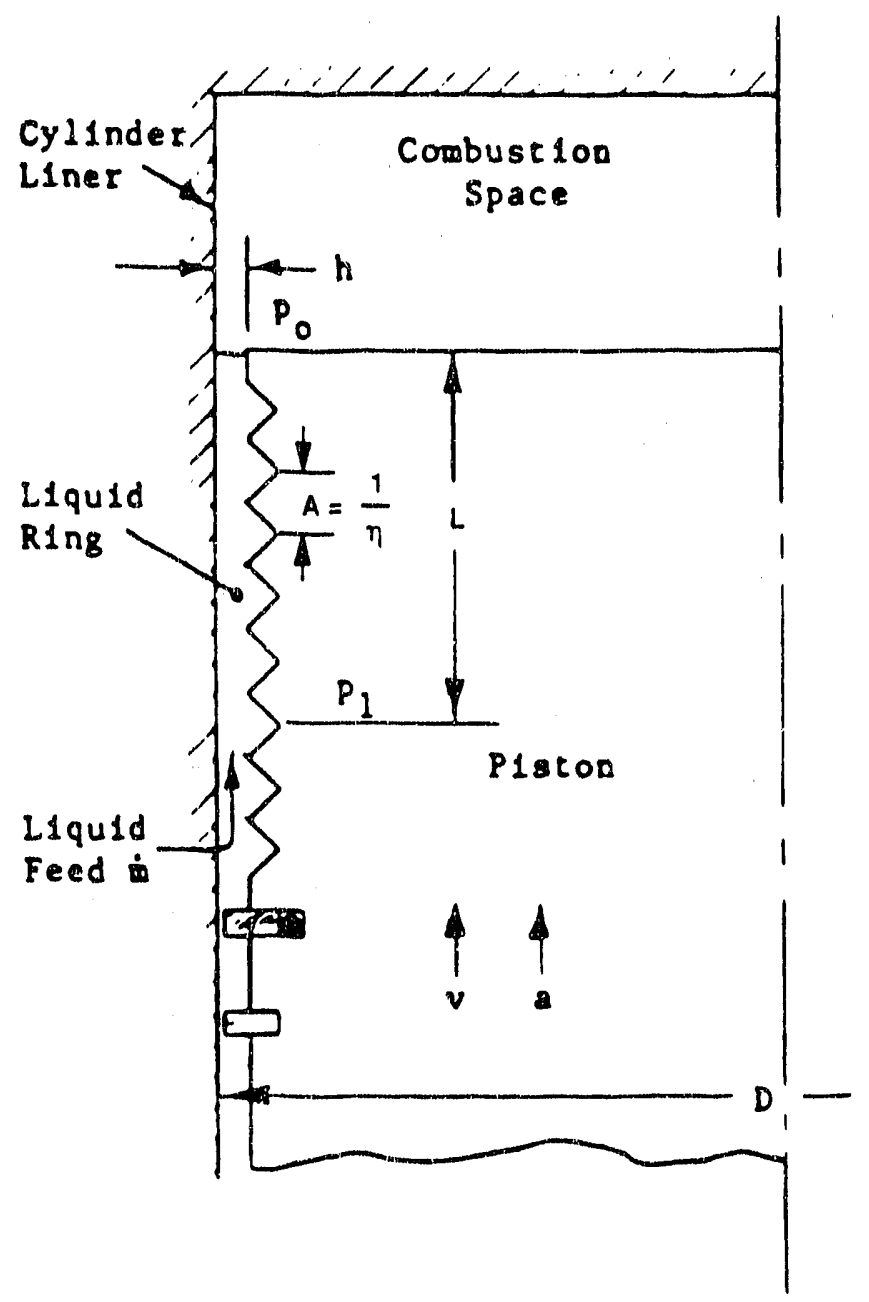

Figure 5.3 Model of Liquid Piston Ring 
(a) VARIABLE ENGINE SPEED

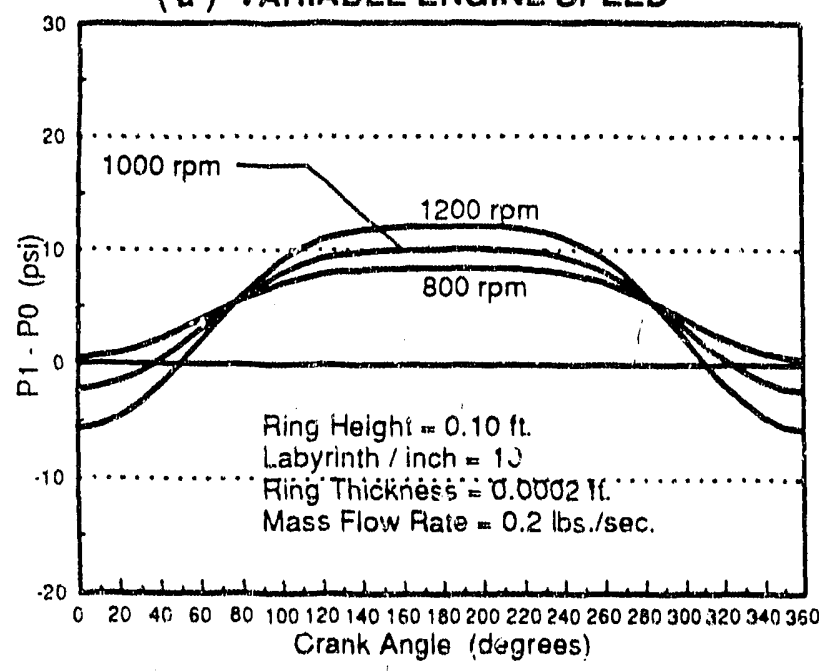

(b) VARIABLE RING HEIGHTS

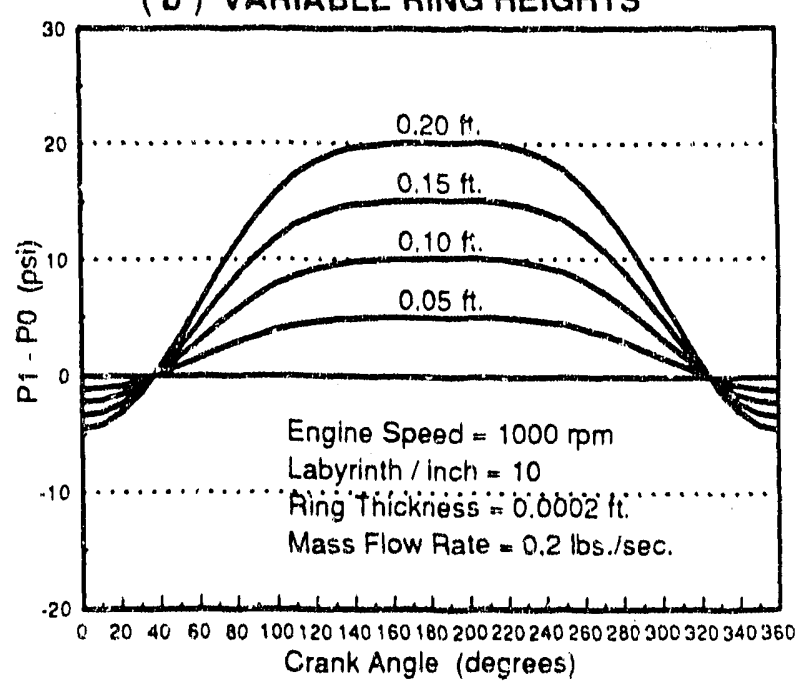

(c) VARIABLE LABYRINTH / INCH

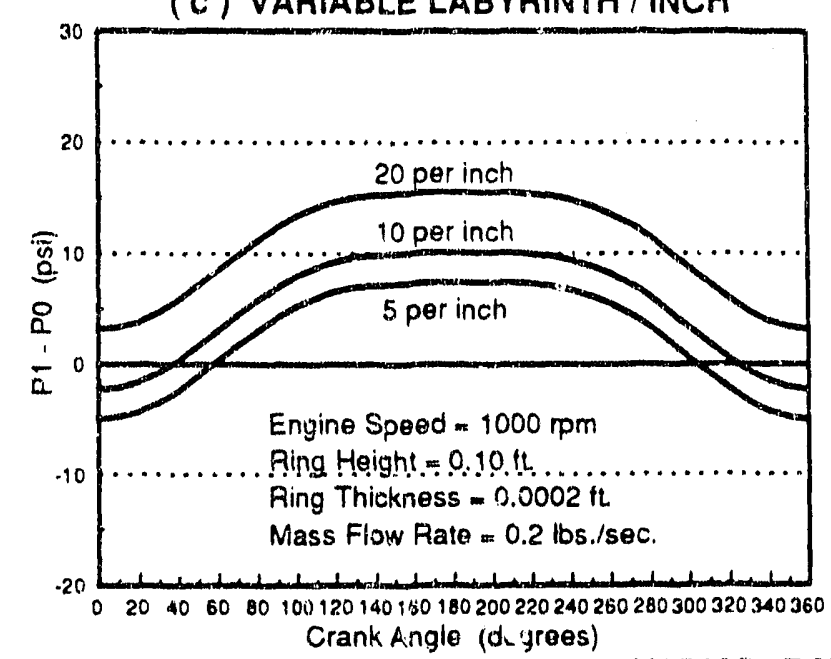

(d) VARIABLE RING THICKNESS

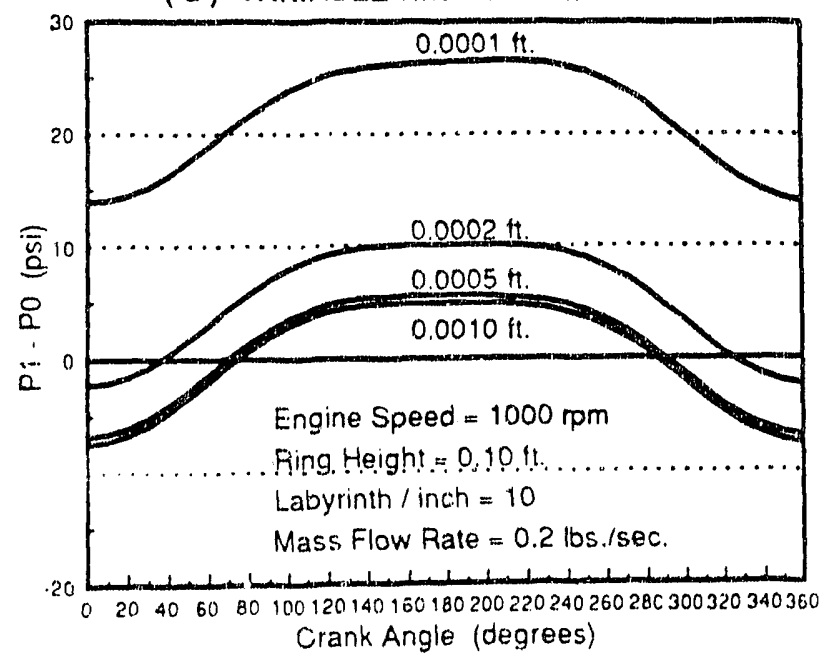

(e) VARIABLE MASS FLOW RATE

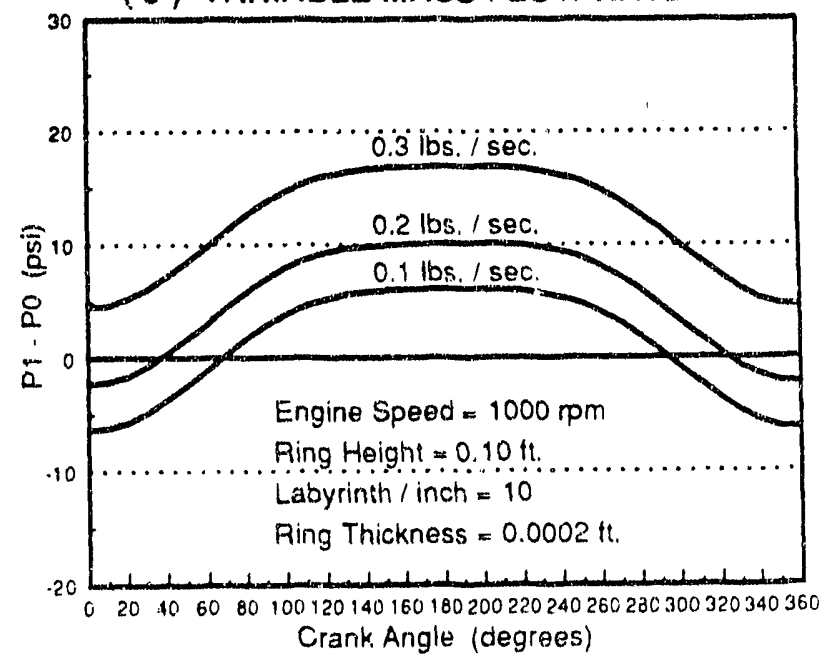

Figure $5.4\left(P_{1}-P_{0}\right)$ versus Crank Angle - Medium Speed Engine 9.0-in. Bore, 10.5-in. Stroke 
pressure when the piston is near top dead center. This suggests that, at the end of exhaust. and heginning of intake stroke, such a condilion may result in bolling oi the liquitd if its temperature is high enough to exceed the equllibrium condition. Therefore, for a gtven engine, the liquid flow rate, the heat transfer to the liquid ring through the piston and the cylinder liner: and the liquid ring geometry determine the integrity of the liquid ring. Bolling the liquid near the end of the exhaust stroke could be desiraole since the vapor generation helps to discharge the liquid and the suspended particles into the cylinder space and exhaust through the exhaust valves. Engine testing will be needed to determine whether or not bolling will help to scrub the wall and discharge the contamirated liquid. If so, the liquid ring can be designed to enharice the bolling condition.

Figure 5.5 shows the pressure variation for a typlcal low speed industrial stationary engine of 13 -in. bore $\times 16$-in. stroke. In this case, the inertia force is lower and therefore the pressure swing is lower than that in the medium-speed engine. Larger pressure depression, if desired to produce boiling effects, wan be achieved by increasing the height of the liquid ring.

Discharge of the liquid into the cylinder space can occur due to two different mechanisms. One mechanism is that when bolling occurs in the liquid ring near the piston ring, where the pressure drops below the vapor pressure corresponding to the liquid temperatures, the formation of vapor pushes the liquid above it out of the annulus space. The second mechanism is that when there is circumferential variation in pressure due to variation in liquid ring thickness, a flow pattern count be developed due to the axdal and ctrcurnferential pressure gradients such that the liquid flows out of the annulus over a portion of the circumference whils, over the other portion. liquid flows axially into the annulus. The tendency for this flow pattern to occur depends on the axial pressure gradient in the liquid ring. The higher the press'ire variations, the higher will be the tendency for the liquid to discharge into the cylinder space.

\subsection{EFFECT OF HEAT TRANSFER}

The integrity of the liquid piston ring depends on the temperature of the liquid and the pressure in the liquid near top-dead-center exhaust. The temperature of the liquid is a function of the rat: of liquid flow and its initial temperature and the heat transfer from the piston and the cylinder liner. The objective of this study is not to carry out a detalled heat transfer analysis from the combustion gas to the piston and the cylinder liner and thrcugh the metal structure to the liquid ring. This study is to establish the orter of magnitude of the heat transfer based on past studies in diesel engines and to determine what might be needed in terms of design modifications in order to reduce the heat transfer to the liquid ring. 
(a) VARIABLE ENGINE SPEEDS

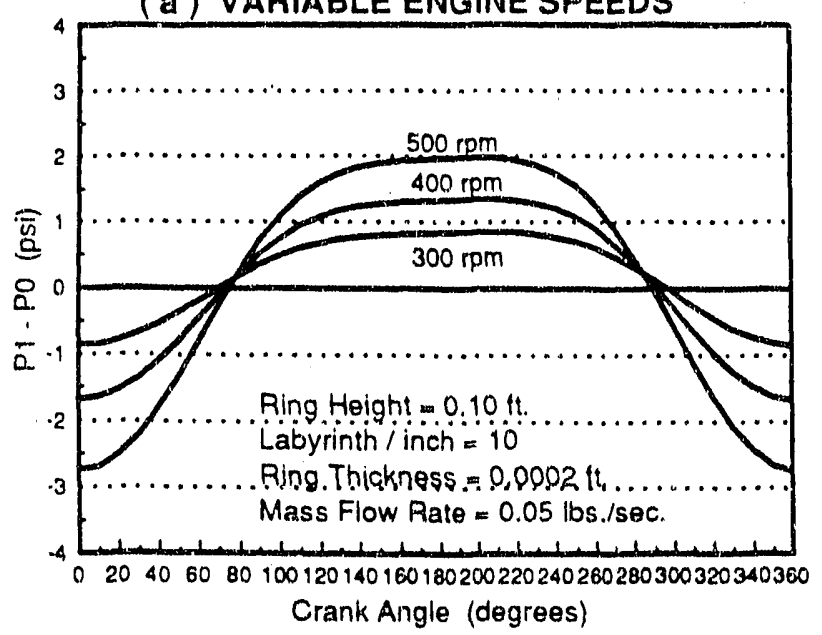

(b) VARIABLE RING HEIGHT

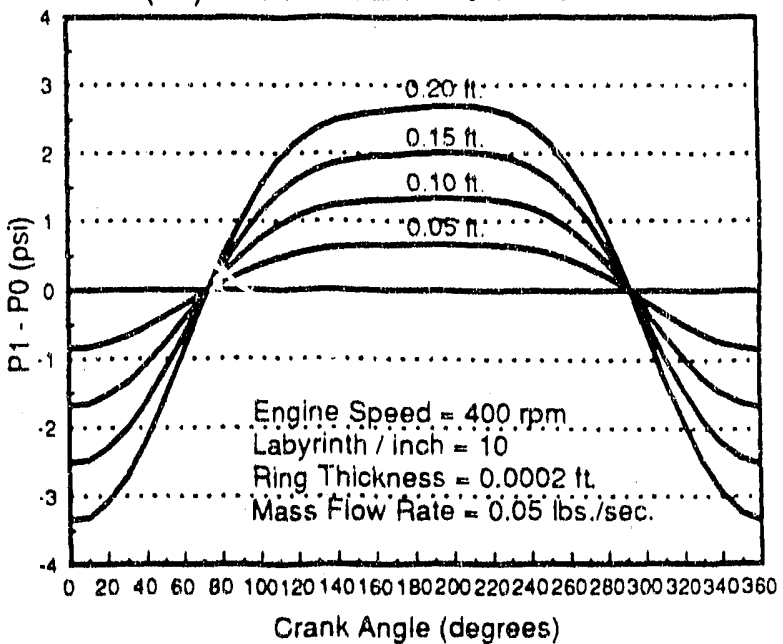

(c) VARIABLE LABYRINTH / INCH

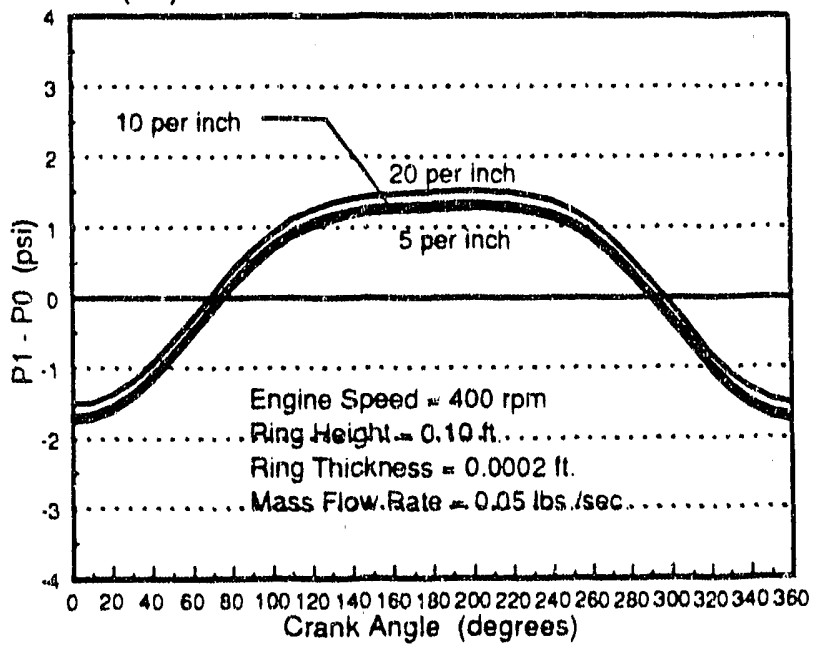

(d) VARIABLE RING THICKNESS

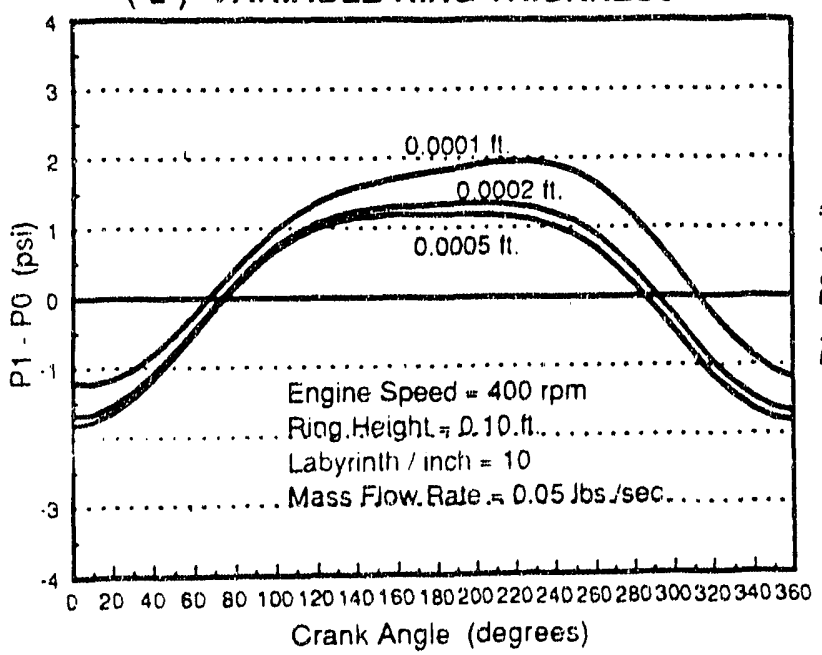

(e) VARIABLE MASS FLOW RATE

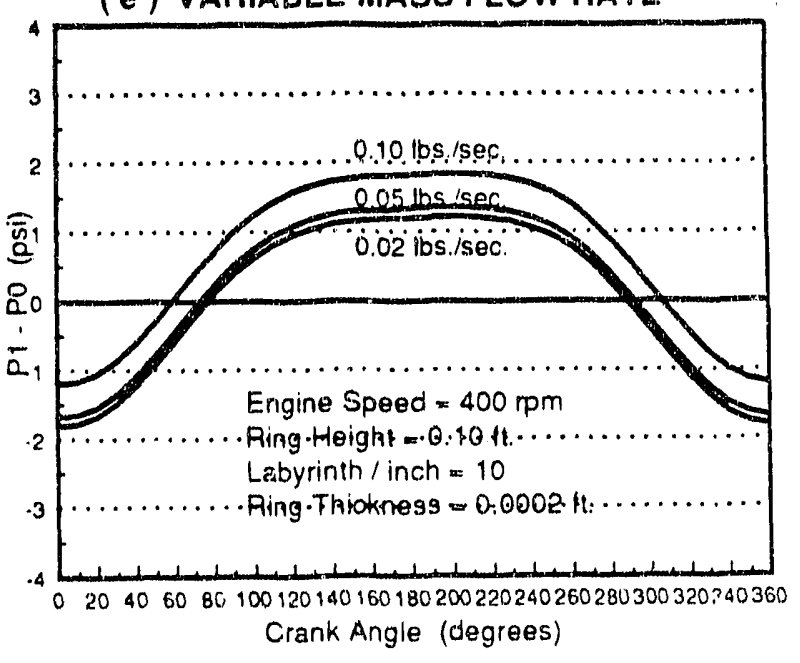

Figure $5.5\left(P_{1}-P_{0}\right)$ versus Crank Angle - Low Speed Engine 13-in. Bore, 16-in. Stroke 
Heat transfer from the combustion gas to the piston was measured previously in diesel engines, ${ }^{4-8}$ and the heat $\mathrm{flux}$ ranged between 55,000 and $150,000 \mathrm{Btu} / \mathrm{ft}^{2} \mathrm{hr}$. Heat flux to the cylinder liner was averaged at $40,000 \mathrm{Btu} / \mathrm{ft}^{2} \mathrm{hr}$. If we take the example of the medium-speed engine, 9 -in. bore $x$ 10.5-in. stroke, and estimate the total heat transferred to the liner and the piston, we have:

Total Heat Transfer into the Piston $=24,300$ to $66,330 \mathrm{Btu} / \mathrm{hr}$

Total Heat Transfer into the Liner $=82,500 \mathrm{Btu} / \mathrm{hr}$

Assuming for the once-through system a water feed rate of $118 \mathrm{lb} / \mathrm{hr}$ at $249 \mathrm{bhp}$ and specific water feed rate of $0.475 \mathrm{lb} / \mathrm{bh}_{\mathrm{h}} \mathrm{h}-\mathrm{hr}$, it is seen that the total heat input required to vaporize the water, including sensible and latent heat, is comparable to the totai . ueat transfer from the combustion gas. This means that one can design the piston to maximize or minimize the heat conduction to the liquid ring depending on whether or not boiling the liquid in the ring is beneficial to the reduction of piston ring and liner wear. Similarly, by controlling the temperature of the engine coolant in the liner jacket the net heat input to the liquid ring can be changed to control the bolling. If the pressure in the liquid ring drops to $7.5 \mathrm{psia}$ at TDC exhaust, the liquid in the ring must be held below $180^{\circ} \mathrm{F}$ to prevent boiling. In this case, the temperature of the coolant in the engine facket must be kept below $180^{\circ} \mathrm{F}$ to allow heat transfer from the liquid ring to the jacket.

Unless the system is actually tested in an operating engine (which was not within the scope of this project) it cannot be determined whether allowing the liquid to boll in the ring is desirable from the standpoint of piston ring and liner wear. The bolling action helps to discharge the llquid into the combustion space and also to create high velocity liquid movement and agitation to enhance the scrubbing of the ash particles from the liner wall. However, it is clearly not possible to boll the liquid near the piston ring and push out and empty the liquid ring on every revolution of the engine. It is easy to show that in the once-through systern it takes a large number of revolutions to fill the liquid ring annulus when the feed rate is limited to the amount comparable to that in the coal-slurry. This means the liquid ring cannot be established within one cycle, and consequently the metallic piston ring will not be protected by the liquld ring at all times. Therefore, we may conclude that the control of heat flux to the liquid ring and the extent of bolling are important factors to consider when judging the system's wear reduction capabilities. 
The following are some of the methods to control the heat transfer to the liquid ring.

- Design the piston such that the load is transmitted to the wrist pin through structural members instead of the cylinder forming the inside wall of the liquid ring so that the thickness of the cylinder can be reduced to cut down the longitudinal heat conduction to the liquid ring.

- Use a two-piece piston design that includes a heat dam at the corner between the piston crown and the labyrinth section of the liquid ring. as shown in Figure 5.6. Oil is injected between the two pieces for piston cooling. Heat transfer from the oll to the liquid ring can be controlled by oll temperature.

- Separate the coolant clrcult for the cylinder jacket from that for the cyinder head. This would permit the control of the jacket coolant temperature and heat transfer to the liquid ring without affecting the cylinder head temperature.

In general, even though this study does not identify the heat transfer conditions needed to operate with the liquid ring system, we can conclude that the control of heat transfer to the liquid ring is technically feasible. 


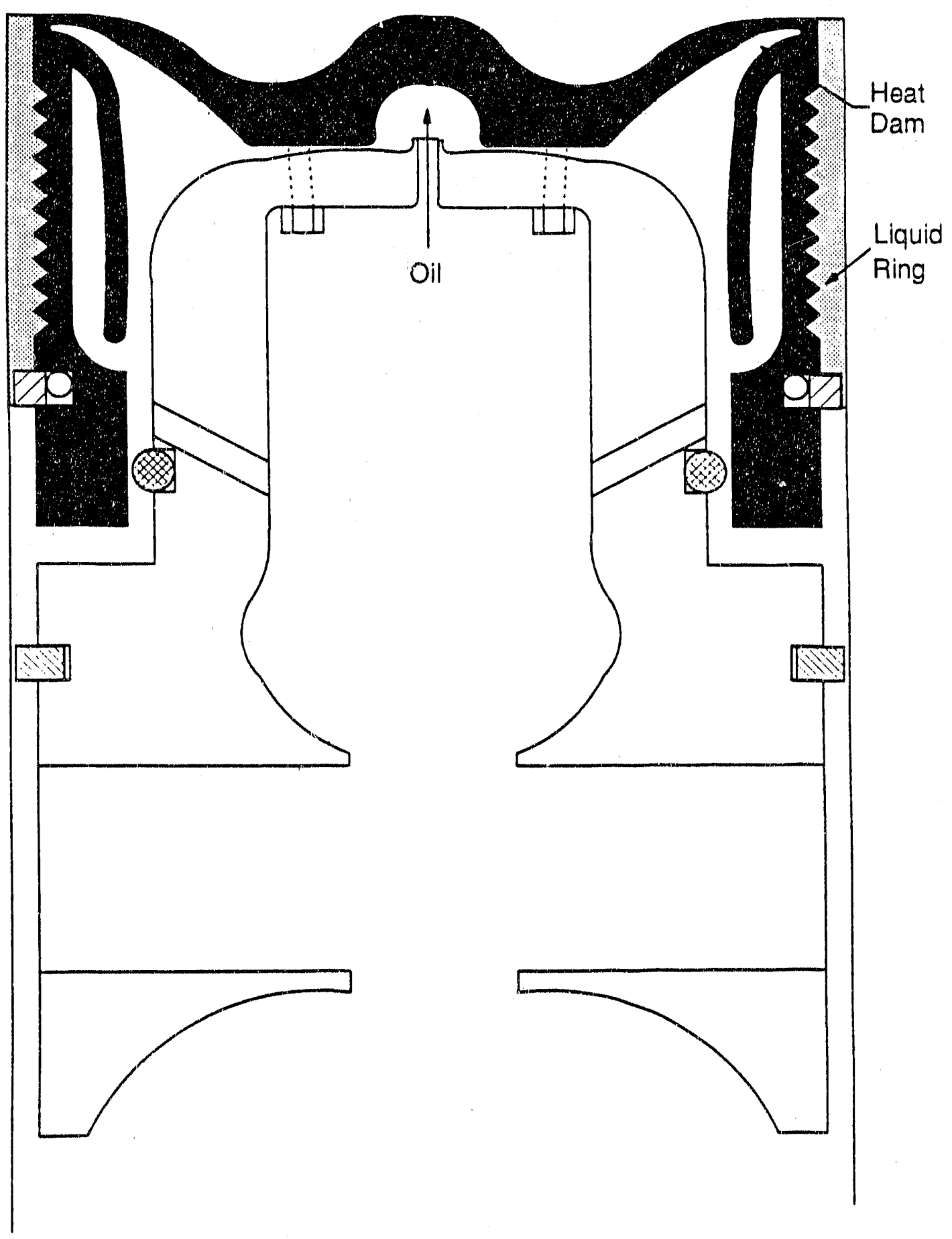

Figure 5.6 Two-Piece Piston Design with Thermal Barrier to the Labyrinth 


\section{BENCH SCRUBBING SIMULATION STUDY}

\subsection{LABYRINTH GEOMETRY}

The liquid piston ring concept for reducing wear of the piston ring and cyllnder liner is based on the premise that the ash particles deposited on the wall can be lifted by the liquid ring so that the piston ring in relative motion with the liner surface would not come in contact with the particles. The effectiveness of the liquid ring system for wear reduction is therefore dependent on how effectively the particles can be scrubbed by the motion of the liquid ring. The concept of using a labyrinth geometry was to promote the shear rate and turbulence adjacent to the surface. The bench simulation model was designed to study the fluid motion in the liquid ring annulus as the plston moves up and down. The test results were used as a guide to selection of the labyrinth geometry for testing in the single cylinder test rig.

The selection of the labyrinth geometry was based on two criteria. One was to maximize the shear rate and turbulence at the surface of the liner wall, and the other was to maintain agitation throughout the annulus at all times so that the particles would not have a chance to settle down and become agglomerated and eventually plug up the entire annulus ring. The geometries of the labyrinth selected for testing were also limited to the simple shapes that were considered practical from the standpoint of machining. Two basic geometries were selected for the simulator test - reclangular and saw-tooth grooves - as shown in Figure 6.1. For the rectangular configuration, the width to depth ratio of the groove was varied. For the saw-tooth case only a $90^{\circ}$ saw-looth was tested.

\subsection{BENCH SCRUBBING SMMULATOR}

To select the labyrthth geometry for maxdmum effecttveness in scrubbing the particies of the wall, a large-scale simulator was designed and built for the purpose of studying the flow patterns in the labyrinth region. The labyrinth was scaled up in size for ease of visual observation. The required piston speed to duplicate the Reynolds No. was reduced. which made the operation of the stmulator and visual observation of the flow field easier.

The characteristic Reynolds No. for the flow field in the liquid ring, which is induced by the relative motion bitween the piston and cylinder wall, may be expressed by:

$$
\operatorname{Re}_{h}=\frac{\rho_{w} V_{p} h}{\mu} \text { or } \operatorname{Re}_{a}=\frac{\rho_{w} V_{p} A}{\mu}
$$


TF61-990
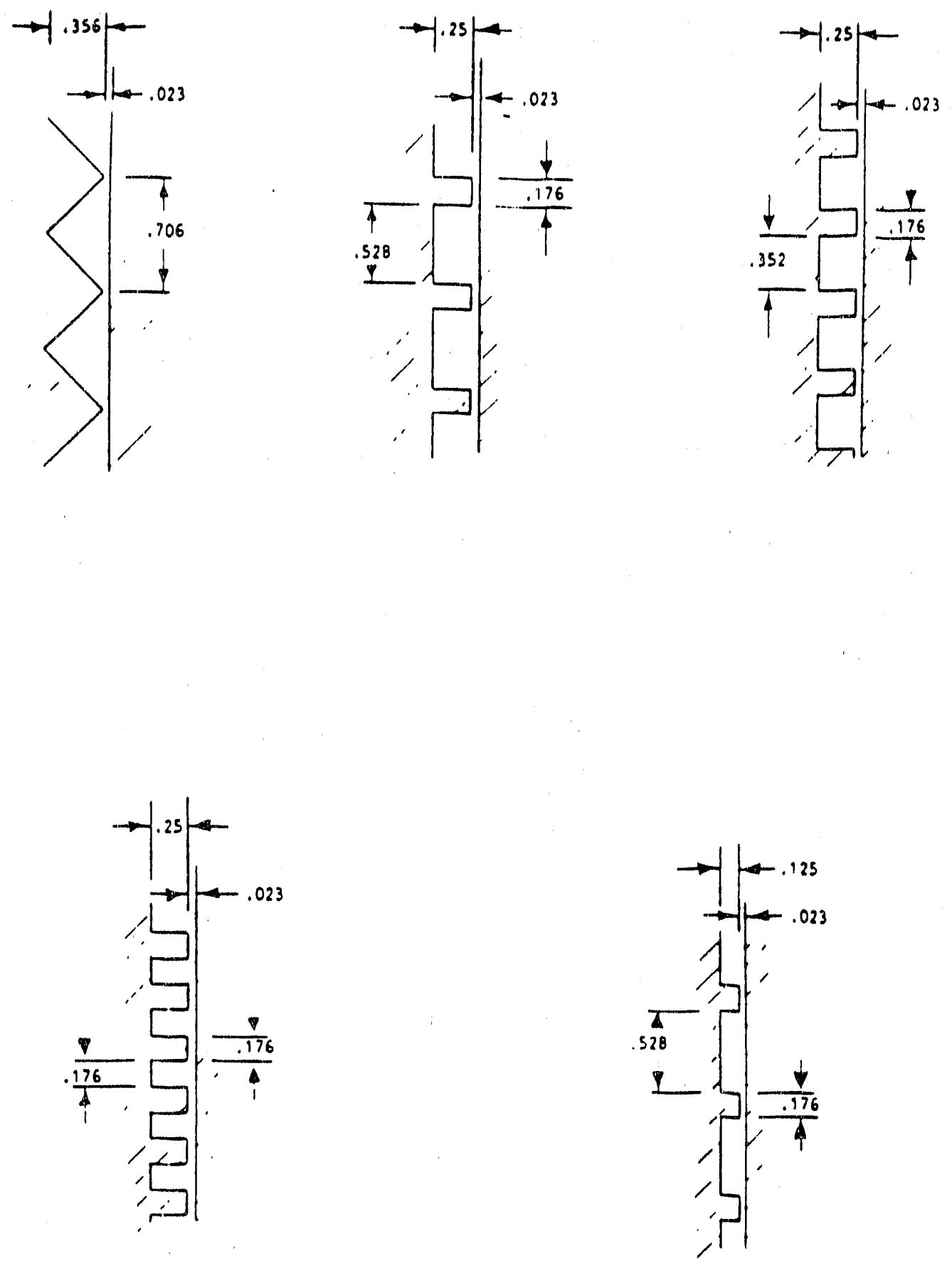

Figure 6.1 Labyrinth Geometry 
where $\rho_{w}$ is the densily of the liquid, $v_{p}$ is the piston velocily, $h$ is the clearance between the up of the labyrinth and the cylinder wall. $A$ is the pitch of the labyrinth teeth, and $\mu$ is the viscosity. If the labyrinth in the simulator is scaled up with the tip clearance, then for a constant Reynolds No. we have

$$
\begin{aligned}
v_{p} h & =v_{p s} h_{s} \\
\text { and } v_{p s} & =v_{p} h / h_{s}
\end{aligned}
$$

where the subscripts designate the simulator. A tip clearance of approximately $0.025 \mathrm{in}$. was chosen for the simulator to allow sufficiently large passage for the polystyrene spheres used for flow visualization to move from one labyrinth tooth to the next. This clearance is roughly 10 times that in a real engine if a $0.0025 \mathrm{in}$. clearance is used.

It should be noted that the simulator did not fully simulate the transient phenomena due to the variation of the piston velocity and acceleration over the cycle. Since the flow pattern in the liquid ring varied with time, the time avallable for the development of the flow pattern would affect the magnitude of the velocity at a given time. To fully simulate the system, a very long stroke was required for the simulator, which was impractical. Since we were looking for qualitative information as a guide to evaluating geometrtes, a 4.33-1n. stroke was accepted for the simulator.

The simulator is a piston wilh labyrinth in a plexiglass cylinder, as shown in Figure 6.2. The piston was bullt up with a stack of machined rings of the desired geometry. This construction allowed flexiblity to change the geometry, particularly in the rectangular tooth configuration. The piston was attached to the top of the piston of a single-cylinder 4.33-in.-stroke diesel engine which was used to provide only the required reciprocating motion. The engine was driven by a variable-speed motor through an in-line speed reducer. A simllar arrangement was used for the single-cylinder test rig, and a more detalled description of the drive system is given in Secilon 7. Figure 6.3 shows the overall setup of the simulator system.

During operalion the cylinder was filled with water up to a level approximately $1 / 2 \mathrm{inch}$ above the piston. An "O" ring was provided at the bottom ring to prevent water from leaking down. A fow visualization system was developed to provide visual observation of the flow pattern as well as video recording so that in high speed operation, the flow paltern could be viewed by playing back in slow molion. 
TF62-990

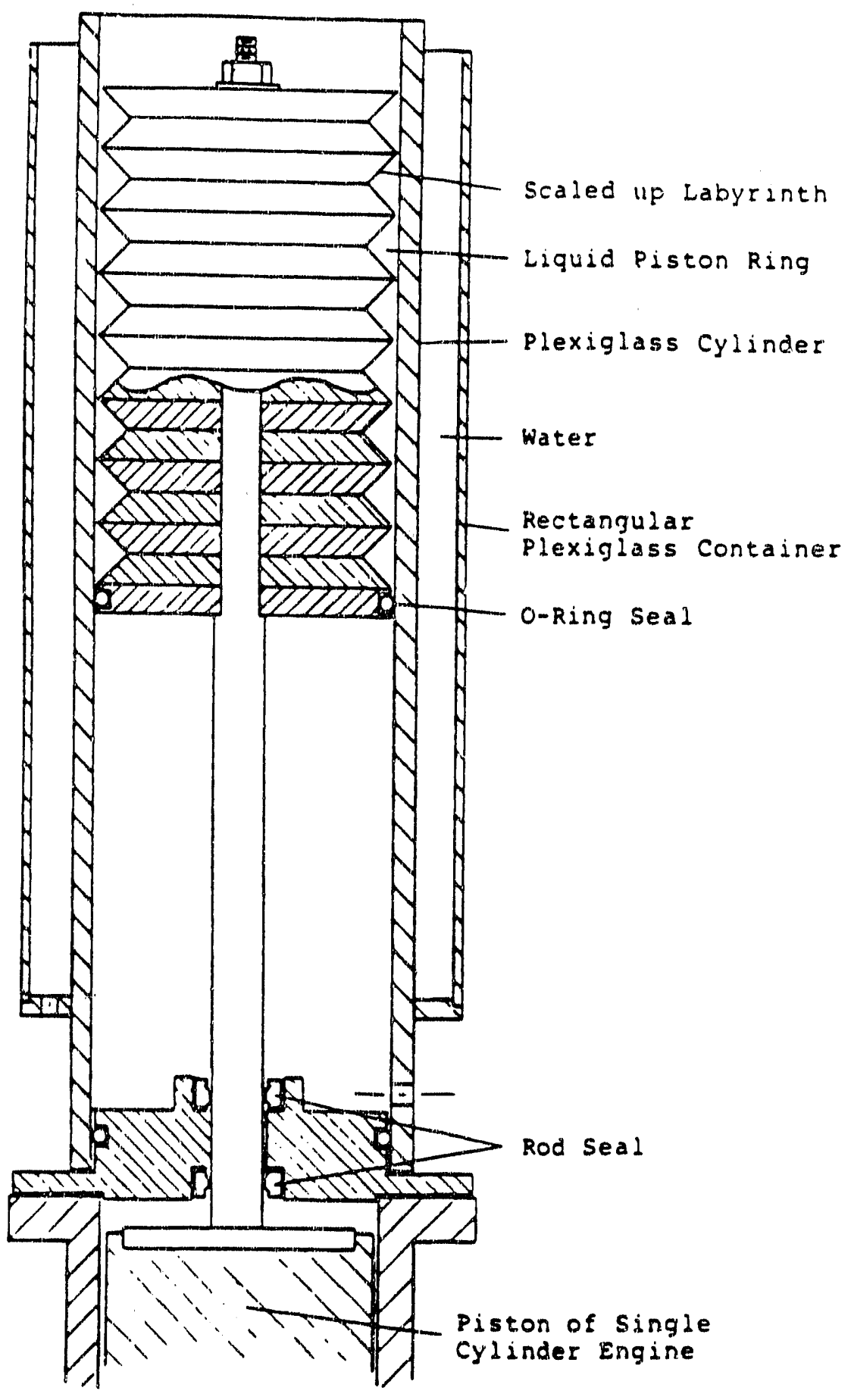

Figure 6.2 Bench Scrubbing Simulator 


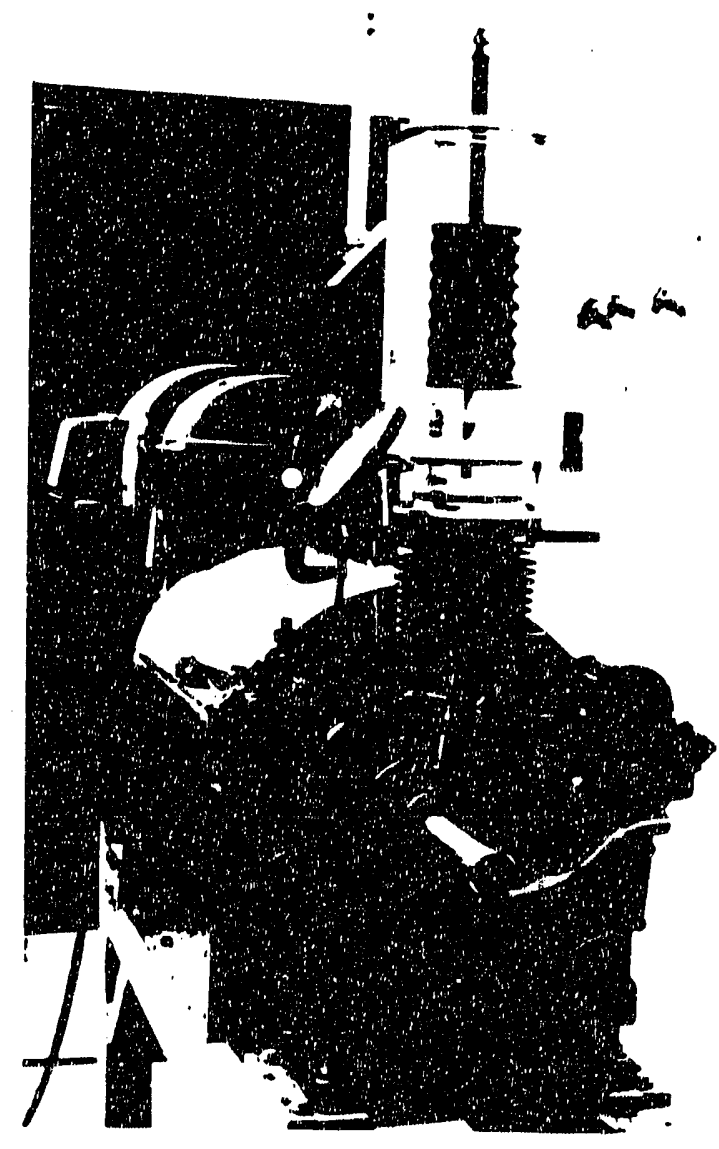

Figure 6.3 Bench Scrubbing Simulator 


\subsection{FLOW VISUALIZATION SYSTEM}

The flow visualization was accomplished by using polystyrene tracer beads in water with properly controlled lighting. The beads have a specific gravity slightly higher than water, but they followed the streamline quite well because of the relatively low water velocity of about $1 \mathrm{ft} / \mathrm{sec}$. To facllitate vewing and to cut down reflected light, the labyrinth surface was painted with a non-reflective black paint. Lighting was provided from the side through a 1 -in.-wide slit parallel to the piston axis so that only a narrow circumferentlal segment of the liquid ring was illuminated. A direction approxdmately 70 degrees from the viewing direction gave the best illumination. Because of distortion of the view due to the transparent cylinder, a square plexiglass box was built around the cylinder and filled with water. This arrangement completely eliminated the distortion when viewing from the flat side of the box. The flow visualization system is shown in Figure 6.4.

Since the piston and the liquid ring move up and down. It was not possible to vlew the flow pattern unless the viewer or the camera moved up and down with the piston. A relatively simple system (as shown in Figure 6.5) was designed with mirrors that permitted the camera to be stationary. The drawback of this arrangement was that the effective distance between the object and the viewer varied with time, which caused a slight variation in the sharpness of the picture due to changing focus. Nevertheless, it provided a sufficiently clear view of the flow pattern in the labyrinth for examination. The video record was played back at reduced speed for ease of viewing the transient flow development as the piston and the liquid ring reciprocated in relative motion to the stationary wall.

\subsection{TEST RESULTS}

Seven diflerent labyrinth geometries were tested, tncluding one $90^{\circ}$ sawtooth shape and five rectangular shapes. The depth and width of the channel were varied as shown in Figure 6.1. For each geometry the simulator was operated at dilferent speeds up to $100 \mathrm{rpm}$. Above $100 \mathrm{rpm}$, dificulty was encountered when the water in the simulator tended to splash and be thrown out of the cylinder. A typical view of the flow pattern in the labyrinth region is shown in the timed exposure picture in Figure 6.6. Due to the unsteady nature of the flow pattern, the observation is represented in the form of a qualitative description, as shown in Figure 6.7(a) through (g).

In the saw-tooth configuration, a major vortex was developed quickly in the trailing corner of the triangular channel, while a secondary vortex was situated at the middle of the channel. Since the formation of the rnajor vortex was in the opposite corner from the existing vortex of opposite direction, the time to start the 


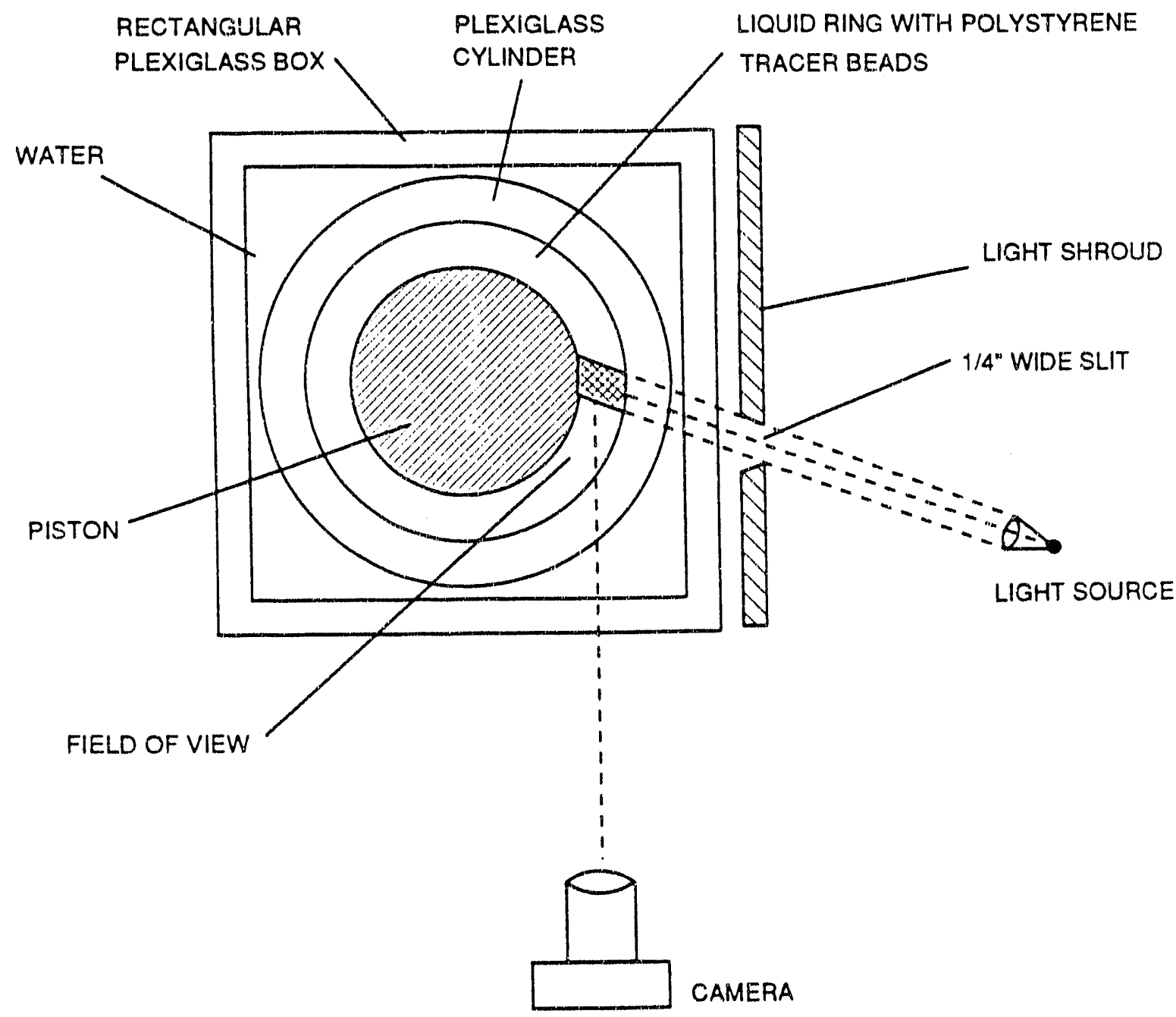

Figure 6.4 Flow Visualization Lighting System 


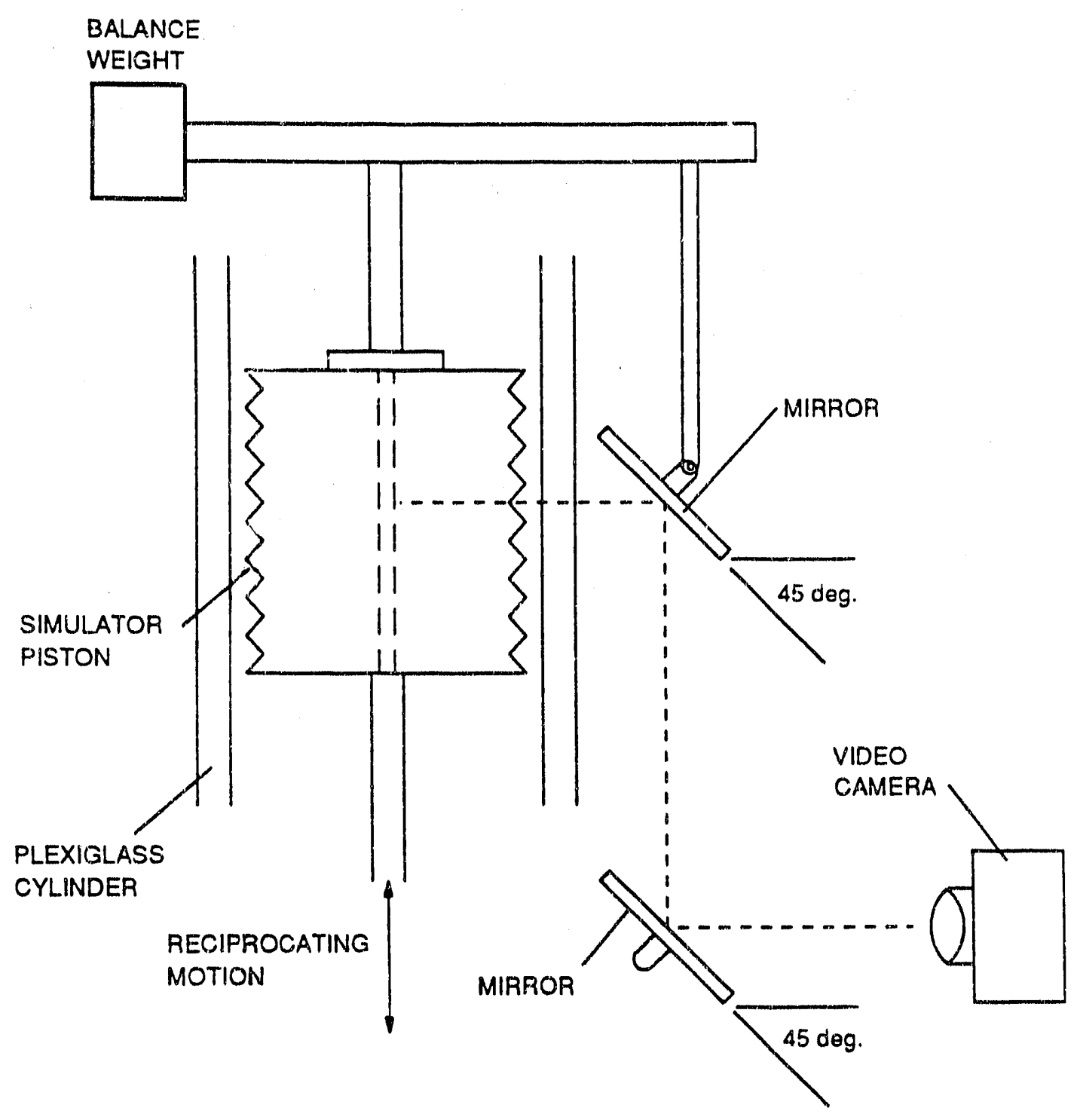

Figure 6.5 Flow Visualization System for Stationary Camera 


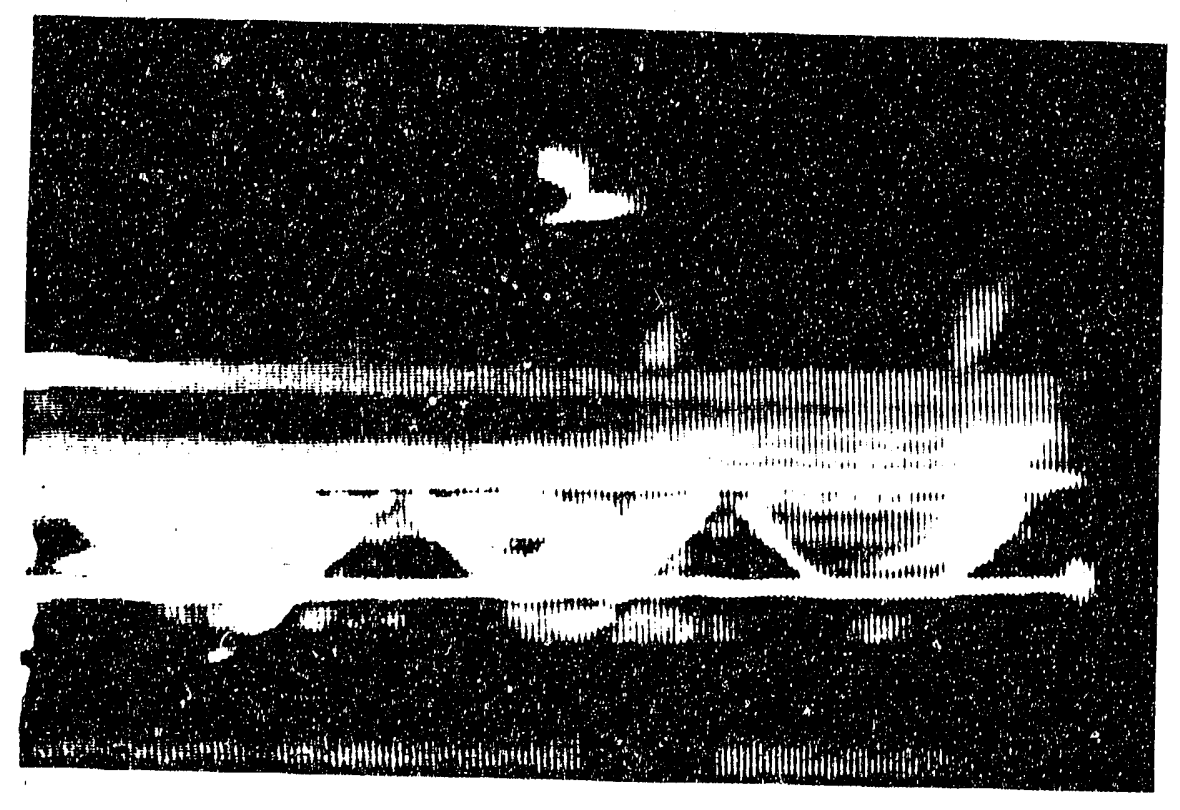

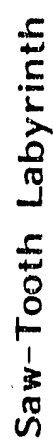
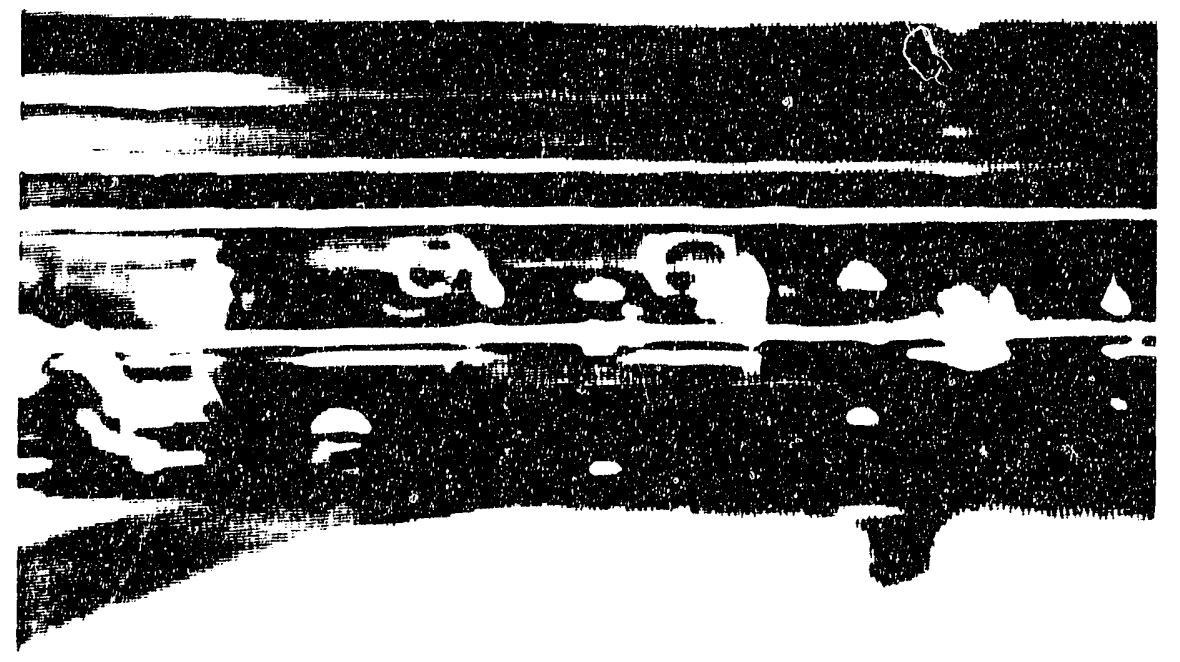

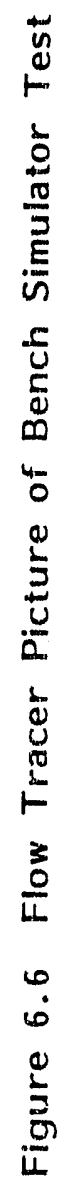


Plctuies 1llustrate typlcal fluld motion at 30 rpm durlang the upstroke Existence: Engine speed at wich vortex exlats

Size: Relationahip between vortex size and englne speed

Formation: Distance frow BDC to when vortex becomes visible (approximate)

Deterioration: Distance vortex remalns visible into the domstroke (approxltate)

Center: Locatiun of vortex center

(a) Configuration analyzed at $10-100 \mathrm{rpm}$

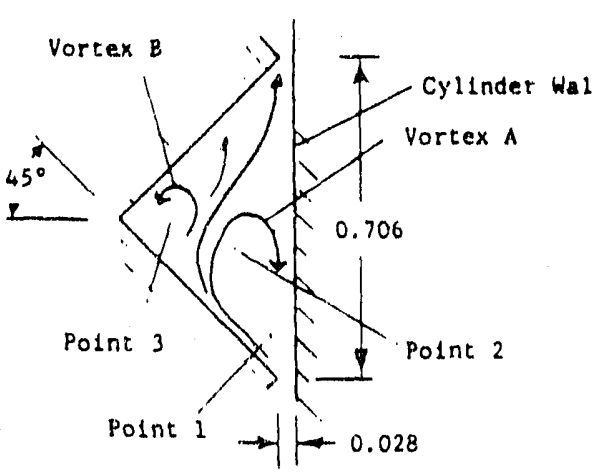

Upstroke

Vortex $A$

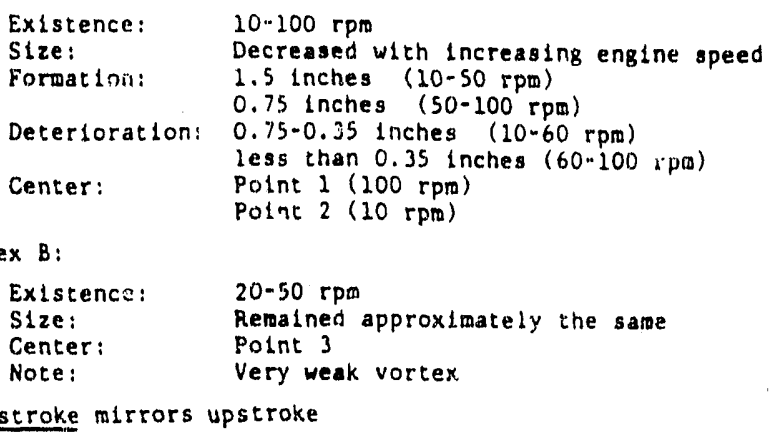

(b)

Configuration arialyzed at 10-60 rpw

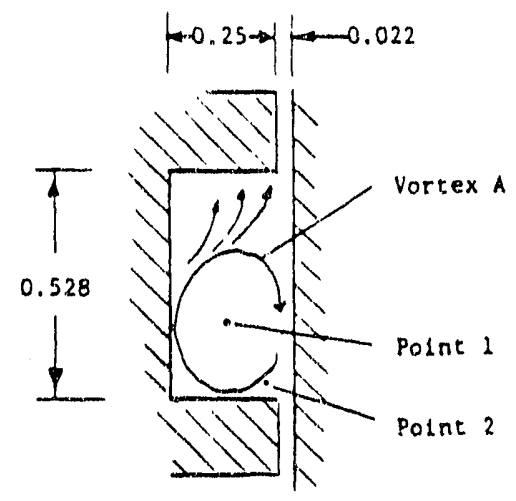

Downstroke mirrors upstroke

\section{Upstroke \\ Vortex A: \\ Existence: $\quad 10-60 \mathrm{rpw}$ \\ S1ze: Does not change with engine speed \\ Formation: $\quad 1.5-2.5$ inches $(10-60 \mathrm{rpm}$ respectively) \\ Deterioration: 1.5 inches \\ Center: Point 1 \\ Hote: Above 30 rpm vortex began small (with \\ center at polnt 2) and grew to normal \\ slze approximately half way through \\ the stroke.}

Downstroke mirtors upstroke (a)l dimengtons are in lnches) (c) Configuration analyzed at 10-60 rpso

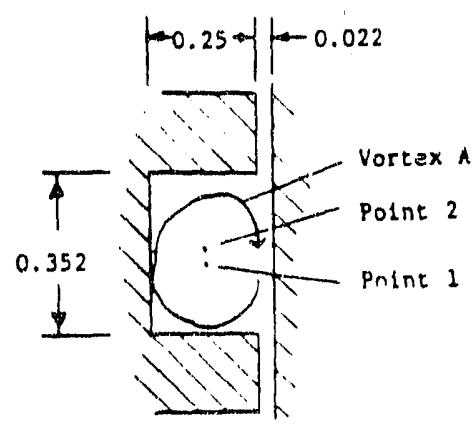

Upstroke

Vorcex $A$ :

Existence: $\quad 10-60 \mathrm{rpt}$

Size:

Formation:

Deterioration:

Increases $t$ engline speed

$1-1.5$ inches $(10-30 \mathrm{rpm})$

Somet lmes would not form $(40-60 \mathrm{rpm})$

$0.5-1$ Inches $(10-30 \mathrm{rpm})$

Sowetimes did not deterlorace $(40.60 \mathrm{rpm}$;

1.e. vortex would not change direction

Center:

when stroke changed direction

Point i $(10-30 \mathrm{rpm})$

Point $2(40-60 \mathrm{rpm})$

Downstroke m1rrors upstroke $(10-30 \mathrm{rpm})$

Figure 6.7 Observation of Flow Pattern in Labyrinth Channels 
(d) Conflguration analyzed at 10-60 rpm

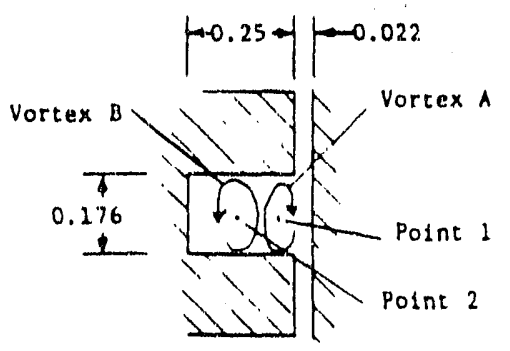

Upstroke

Vo:tex A:

Existence: $\quad$ 10-4,0 rp

Size: Helght of vortex remalned the same

but width became thinner with

but width

Formation: $\quad 0.35-1$ inch $(10-40$ spm reapectively)

Deterloration: $0-1$ inch $(20-40 \mathrm{rps}$ respectively)

Center: Polnt 1 whlch woved closer to the

cylinder wall with increasing

Vortex B:

engine speed

Ex1stenca: $\quad 30-60 \mathrm{rpm}$

Size:

Becase slightly smaller with increasing

englne speed

Moved from point 2 towards point 1 with Increasing eng Ine speed

Downstroke mirrors upatroke (e) Configuration analyzed at 10-60 rpo

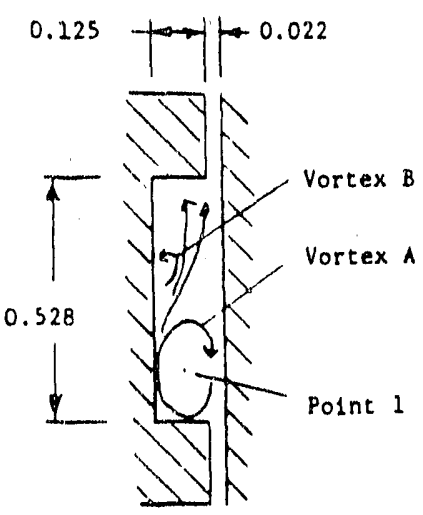

Upstroke

Vortex A:

Ex1stence: $\quad 10-60 \mathrm{rpm}$

Size:

Formation:

Deterloration:

Stays approximately the sase

$0.75-1.5$ Inches

$0-0.75$ inches

Point 1

Vortex B:

$$
\begin{array}{ll}
\text { Fistence: } & 20-40 \mathrm{rpw} \\
\text { Note: } & \text { Very weak vortex }
\end{array}
$$

Dounstroke mirrors upgtroke

(f)

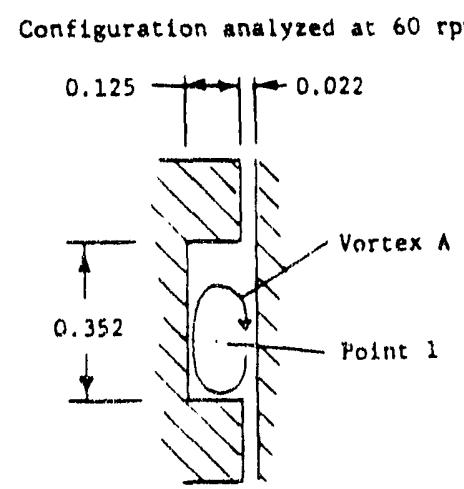

Upstroke

Existence

Size:

Formation: $\quad 1.5$ inches

Deterloration: Less than 1 inch

Center:

Point 1

Dounstroke mirrors upstroke.

Figure 6.7 Observation of Flow Pattern in Labyrinth Channels (cont'd) 
(g) Configuration analyzed at 35-60 rpw

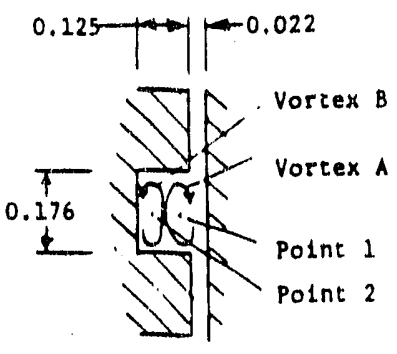

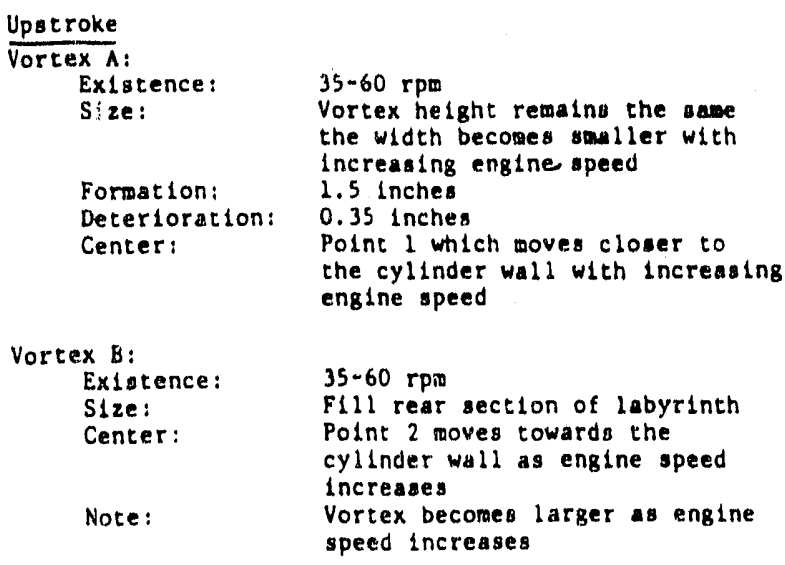

Vortex B:

\begin{tabular}{|c|c|}
\hline $\begin{array}{l}\text { Existence: } \\
\text { Slze: } \\
\text { Center: }\end{array}$ & $\begin{array}{l}35-60 \text { rpw } \\
\text { Flll rear section of labyrinth } \\
\text { Polnt } 2 \text { moves towards the } \\
\text { cyllnder wall as englne speed } \\
\text { increases }\end{array}$ \\
\hline Note: & $\begin{array}{l}\text { Vortex becores larger as engine } \\
\text { speed increases }\end{array}$ \\
\hline
\end{tabular}

Downstroke m1rrors upstroke

Figure 6.7 Observation of Flow Pattern in Labyrinth Channels (cont'd) 
vortex was short and the vorlex grew in size as the opposite vortex decayed. The lluid in the channel appeared to be sufficiently agltated everywhere to prevent settlement of particles. Based on qualitative reasoning, one might conclude that the maximum shear rale occurred during the first half of the piston stroke when the fully developed vortex from the previous stroke was being deceleraled.

With rectangular channels, the development of the vortex was generally slower because the stze of the vortex was dictated by the channel depth and width. In the case shown in Figure $6.7(\mathrm{c})$ where the width is only slightly larger than the depth, the vortex filled the entire cavity. The vortex developed in the previous stroke had to be fully decelerated belore a new vo-tex of opposite direction could be generated. This is why at higher engine speeds the vortex did not consistently reverse on each stroke. When the width to depth ratio was high and the depth was small, as th the case of Figure 6.7(e), the vortex formed on the tralling side and the development of the vortex was relatively fast. However, the vortex was small and it also deteriorated quickly. The major drawback of the rectangular shape was that the now activity in the corners was low. Consequently, polystyrene beads tended to collect in the lower inside comer. This condition would cause accumulation of ash particles and eventually could have led to total plugging up of the labyrinth.

Based on the above results, it was concluded that the saw-tooth geometry can provide the high huld shear at the cylinder wall and constant agitation in the labyrinth channels to prevent solld particies frorin settling. Therefore, the saw-tooth geometry was selected for testing in the single-cylinder test rig. 


\section{SINGLE-CYLINDER TEST RIG}

\subsection{DESCRIPTION OF TEST RIG}

Figure 7.1 shows the single-cylinder test rig in a schematic fashion while Figure 7.2 is a photograpll of this same facllity. The test rig was bullt up around a commerclally available Petter single-cylinder diesel engine of the following dimensions:

$$
\begin{aligned}
& \text { Bore }-3.4 \mathrm{ln} . \\
& \text { Stroke }-4.3 \mathrm{ln} .
\end{aligned}
$$

The engine was driven by a variable-speed-drive system.

The cylinder head and valve gear were removed from the engine and the piston was modified to become a cross-head piston for the liquid ring piston and cylinder liner. This arrangement is shown in detall in Figure 7.3. It should be noted that the use of a cross-head was an expedient to allow evaluation of the performance of the liquid ring. (All of the present DOE coal-fired diesel engine contractors are following a trunk type piston approach.) A second piston for the same diesel engine was modified to carry the liquid piston ring labyrinth, and a second cast-Iron cylinder liner was used as the kest cylinder liner. Hence the liquid piston ring test cylinder had the same bore and stroke as the diesel engine.

\subsubsection{Liquid Ring Feed System}

The diesel engine injection pump was used to introduce clean fluid to the liquid ring area. The governor of the pump was disconnected to allow independent control of the quantity of liquid injected, and the system was calibrated at various speeds and rack settings. The injection pump was capable of supplying the liquid at high pressure. but for the test rig the high pressure was not needed since the cylinder pressure at the time of injection was only about $20 \mathrm{in} . \mathrm{H}_{2} \mathrm{O}$ above atmospheric pressure. Liquid was supplied to the pump from a reservoir and through a standard fuel filter, as shown in Figure 7.1.

Liquid was injected at a single point near the bottorn of the labyrinth with the piston at top dead center. There was a single injection every other revolution when the piston was near lop dead center. Liquid was removed from a port opposite the injection port and near the top of the labyrinth, as shown in Figure 7.3. 


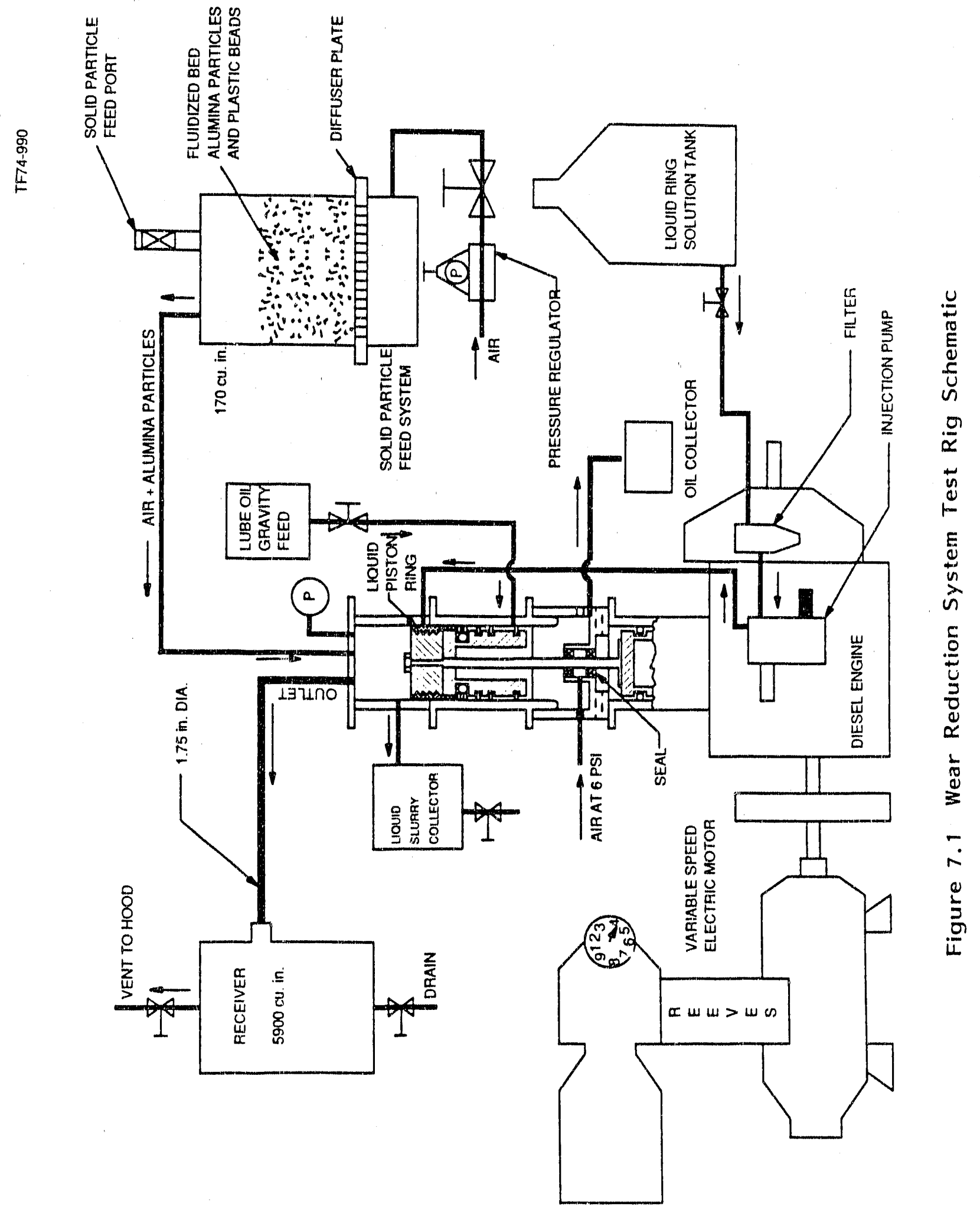



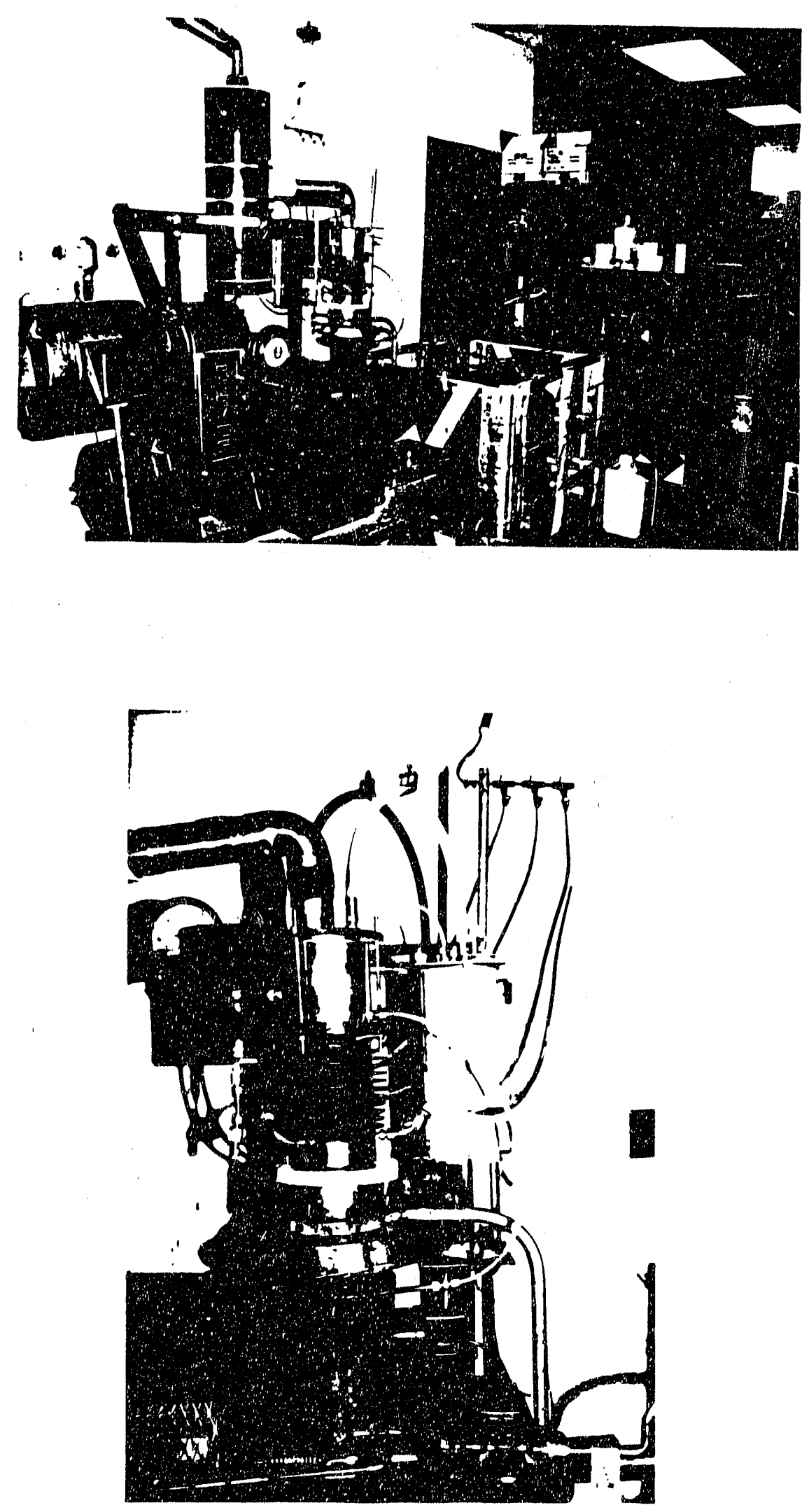

Figure 7.2 Single-Cylinder Test Rig 

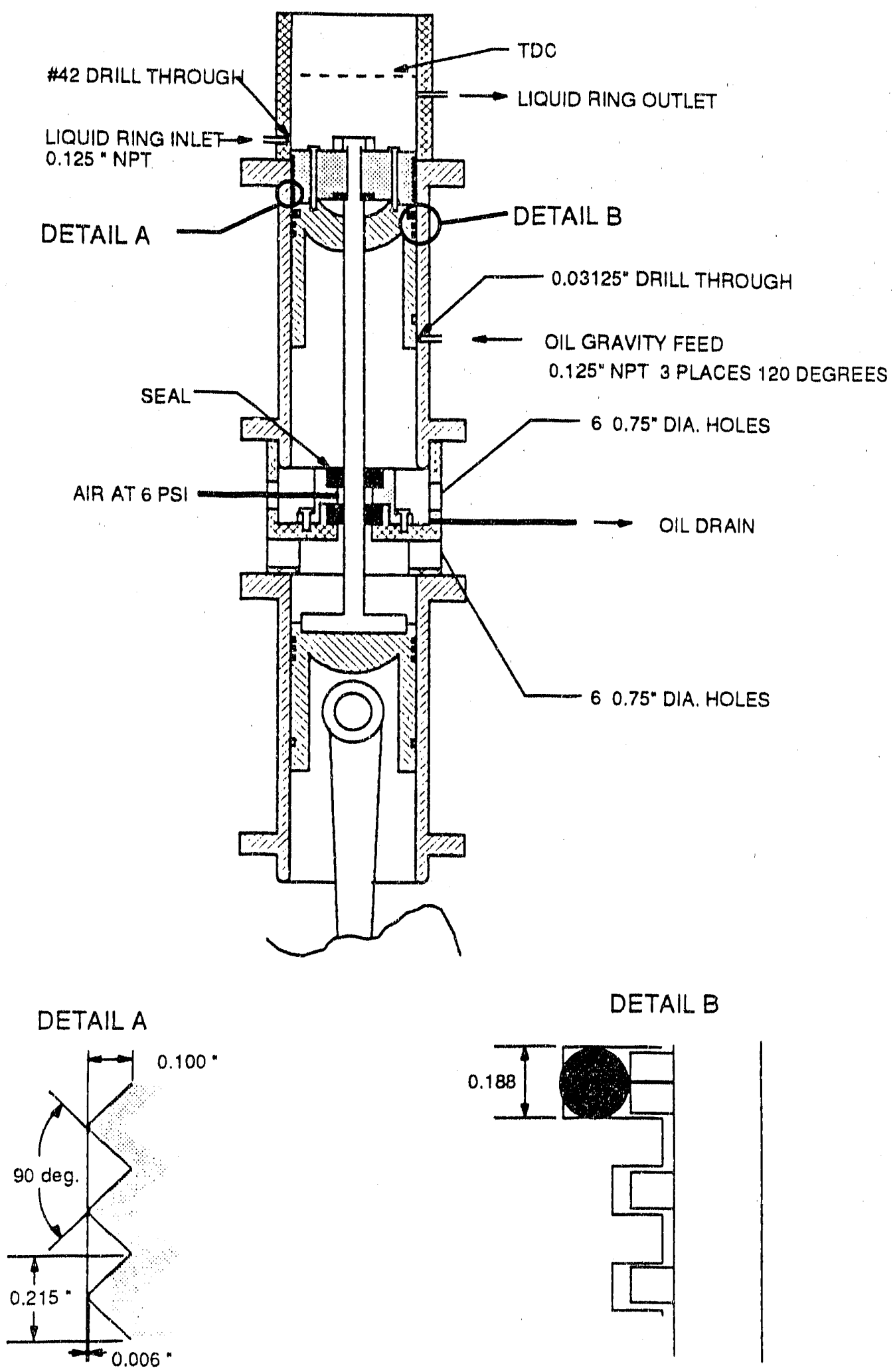

Figure 7.3 Piston/Cylinder Arrangement for Wear Reduction Test Rig 46 
A collection tank for the contaminated liquid/slurry mixture was connected to the liquid ring outlet on the cylinder liner, as shown in Figure 7.1. Since the pressure fluctuated more in the cylinder than in the collector, the pressure differential between the cylinder and collector near top dead center helped to discharge the liquid at the top of the liquid ring into the collector. Most, but not all. of the liquid and alumina introduced was trapped in this collector and in the large recetver plumbed to the test cylinder head.

\subsubsection{Solld Particles Feed System}

To determine the relative wear rate of the piston rings and cylinder liner with and without the liquid piston ring, an abrasive material was used for the singlecylinder rig test. Alumina particles with an average size of 3 microns 10.8 to 8.0 microns) were used. The particles were carried continuously by an atr stream into the test cylinder. A portion of the particles was deposited on the cylinder wall and the remaining were discharged from the cylinder along with the alr. The deposited particles were either mixed with the lube oll or scrubbed of the wall and discharged along with the water in the liquid ring.

Feeding of the particles into the air stream was not straightforward because of the small particle size and their poor flow characteristics. A fluidized bed system was developed for the feeding of the alumina particles, which gave a reasonably constant rate over the short test duration. The fluldized solid feed system is shown in Figure 7.4. It consisted of a 4.25-ln. O.D. plexiglass cylinder for ease of observation with a diffuser plate separating the plenum chamber and the fluidized bed. The diffuser plate was drilled with a square array of 0.042-tn.-dlameter holes at 0.25 -in. center spacing. The system operated at a pressure above atmospheric that was dictated by the rest of the flow system through the test cyllnder and the exhaust. A solid feed hopper was provided at the top of the bed, which was pertodically sotated manually into position in line with an opening to allow a batch of solids to drop into the bed. The alrborne solids were fed through a 0.5-in. I.D. flexdble tube into the test cylinder.

Inftial attempts to fluldize the alumina particles in the bed were not successful. At low alrfiow, the bed was fixed. As the atr flow-rate was increased. a portion of the bed suddenly became fluidized while the remaining area stayed fixed. The rate at which the solid particles were carried out with the atr was high and uncontrollable. This phenomenon was caused partly by the low pressure drop across the diffuser plate at the low fluidization velocity and partly by the tendency of the small particles to cake up. 


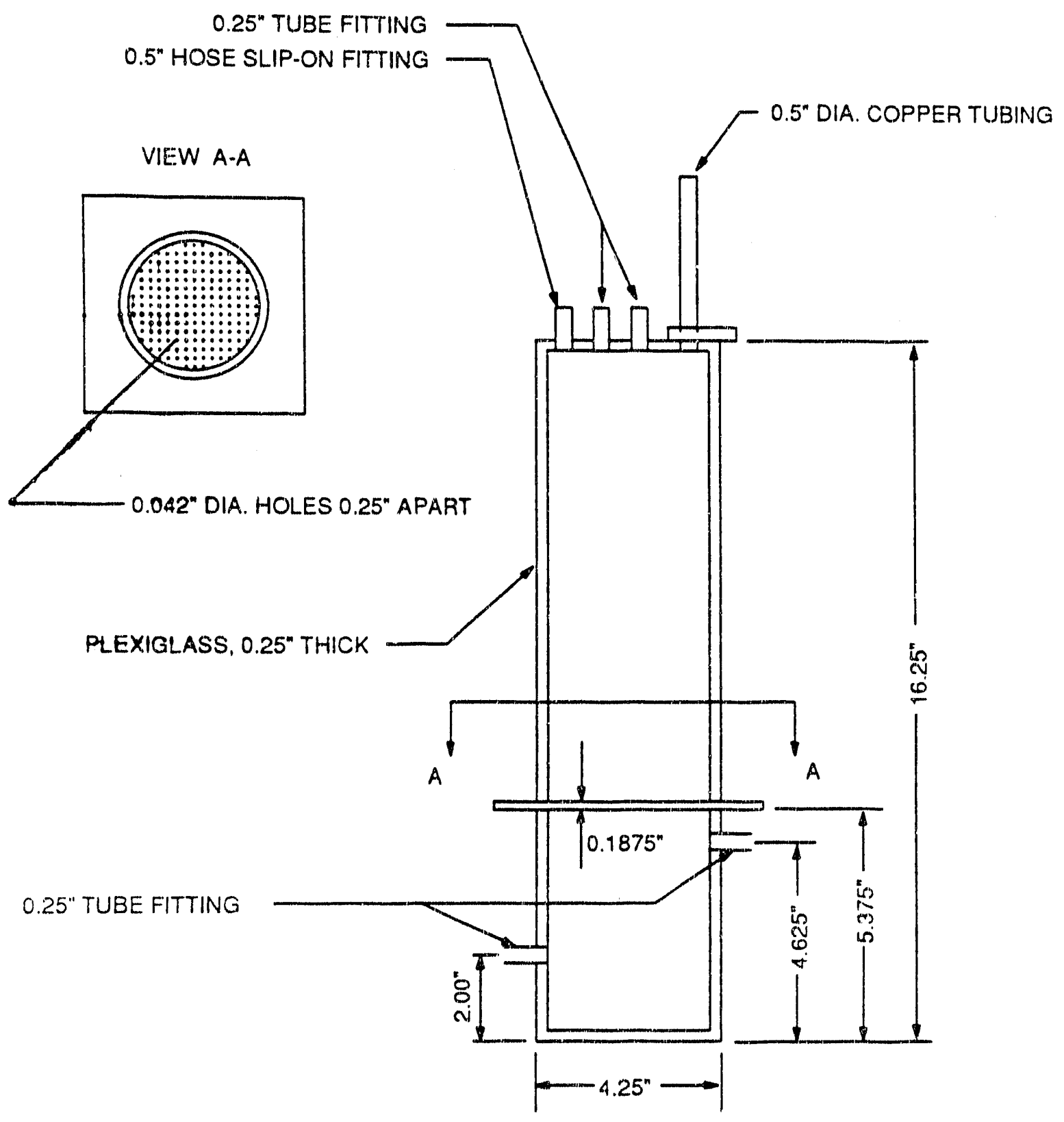

Figure 7.4 Particle Feed Apparatus for Wear Reduction System Test Rig 
To overcome the problem, a solld feed system was developed which consisted of a fully fluldized bed of polystyrene spheres of approximately $0.008 \mathrm{in}$. to $0,0016 \mathrm{in}$. diameter into which the alumina particles were fed. The alumina particles formed aggregates of larger particles which were heavier than the plastic beads and therefore would sink to the bottom of the bed. The vigorous motion of the fluidized plastic beads would impact and rub on the alumina aggregates to free the particles from the aggregate surface. Once the individual alumina particles were separated from the aggregate they became fluldized and were lifted out of the bed by the air stream. Although the above described process was not actually observed. It appeared to be a logical explanation of the slow release rate of the solld particles from the bed after a batch of alumina parlicles was added to the bed. The sollds discharge rate from the bed was initially high and gradually decreased with time. Bench lests showed that over a 40-minute period from the time a batch of solids was added, the solld discharge rate decreased gradually from 100 percent to 25 percent of the initial rate in a consistent and repeatable manner. For the purpose of the comparauve wear rate tests in the test rig, the repeatability of solids feeding to the test cyllnder over the test period is more important between one test. and another than achleving constant feed rate. Therefore, this flutdized feed system was accepted for the test rig.

\subsubsection{Exhaust System}

Excess air and alumina particles supplied by the feed system were allowed to discharge from the test cylinder through a 1.75-in. pipe to a 5900-cubic-inch recetver, where some of the particles and lquid were separated out. The remaining air/alumina/water mixture was vented through a standard chemical hood.

The size of the line and the volume of the recetver were arrived at by trial and error to maintain pressure fluctuations in the test cylinder due to piston motion at a level that would not upset the consistency of delivery of the particle feed system. This pressure fluctuation was \pm 10 inches of water column at $1.000 \mathrm{rpm}$. The average pressure was maintained slightly above 10 inches of water so that the minimum system pressure stayed above atmospheric pressure. This was done so that the collected liquid could be drained during the test.

\subsubsection{Test Cylinder Lube Oil System}

While the lower part of the test rig was lubricated by the lube oll system. which is a part of the engine, the test cylinder had to be lubricated as well. This was accomplished by a simple gravity system, as shown in Figure 7.1. Oll was introduced at several points on the circumierence of the liner at points near the bottom of the piston skirt with the piston at top dead center. The top piston ring and the llquid piston ring did not override the lube oil ports.

Detalls of the test piston, labyrinth, and piston ring arrangement are given in the following section. 


\subsection{TEST CONDITIONS}

Four comparative tests were selected for the single-cylinder test rig. the results of which provided the necessary information to draw some preliminary conclusions on the technical feasibility of the liquid piston ring concept. These four tests were as follows:

- Conventional piston ring without liquid ring above, air with alumina particles - baseline case.

- Liquid piston ring with water, atr with alumina particles.

- Liquid piston ring with water and surfactant, air with alumina particles.

- Liquid piston ring with water and surfactant, no alumina particles in air.

Specific test conditions selected for the test rig are described below.

\subsubsection{Liquid Piston Ring}

Based on the observation of flow patterns from the bench stmulator tests, the $90^{\circ}$ saw-tooth labyrinth was selected for the liquid piston ring test in the singlecylinder rig. The tip clearance of the labyrinth was chosen to be $0.006 \mathrm{in}$. so that at $1.000 \mathrm{rpm}$ and $4.33 \mathrm{-1n}$. stroke the Reynolds No. would be comparable to the medium-speed engine with a 0.0025 in. labyrinth tip clearance and 10.5-in. stroke operating at $1,000 \mathrm{rpm}$. The dimension of the labyrinth is shown in Figure 7.3. The height of the labyrinth section was $1.50 \mathrm{in}$. with 7 teeth. The Reynolds number. $\mathrm{Re}_{\mathrm{a}}$, in the test rig was about three times that in the simulator, which was $\operatorname{Re}_{\mathrm{a}}=6,600$. This should have provided higher turbulence in the labyrinth cavities and more effective scrubbing of the wall.

\subsubsection{Solids Particle Feed Rate}

Based on the ash loading of $0.00251 \mathrm{lb} / \mathrm{bhp}-\mathrm{hr}$ for the medium-speed engine described in Section 5.3, the total ash loading per cyllnder at $1.000 \mathrm{rpm}$ and $257 \mathrm{hp}$ was $0.645 \mathrm{lb} / \mathrm{hr}$. Since wear was a function of ash density on the cylinder wall, the relevant parameter to simulate was the average ash loading per unit cylinder surface area. Assuming 10 percent of the ash entering the cylinder deposited on the cylinder wall, the ash deposittion rate per unit cylinder wall area was $0.000217 \mathrm{lb} / \mathrm{hr}-\mathrm{in}^{2}$. For the same deposition rate in the test rig of $3.44 \mathrm{in}$. bore $\times 4.33-$ in. stroke, the solid feed rate to the cylinder should be $0.102 \mathrm{lb} / \mathrm{hr}$ ( $46 \mathrm{gm} / \mathrm{hr}$ ), again assuming 10 percent of what entered the cylinder deposits on the wall. The solid feed rate was established pror to the test by setting the air supply pressure at 50 psig and adjusting the micrometer valve at the inlet to the lluidized bed plenum. However. it was found after the test that the solid feed rate was 
somewhat higher than the set rate. The explanation for this deviation was that the pressure fluctuation in the fluldized bed resulting from cyllnder pressure Iluctuatlons caused cycllc variation of now rate in the bed and consequently a higher rate of solids discharge.

\subsubsection{Liquid Piston Ring Flow Rate}

Since the engine fuel pump was used to inject the liquid near the top dead center position, the liquid feed rate to the ring was limited by the maximum capacity of the fuel pump. At $1,000 \mathrm{rpm}$. the mean injection rate was approximately $2.700 \mathrm{ml} / \mathrm{hr}$ (or $5.94 \mathrm{lb} / \mathrm{hr}$ ). At a solid deposition rate of $0.0102 \mathrm{lb} / \mathrm{hr}$, the average concentration of solids in the liquid ring was 0.17 percent. This was considered a reasonably low concentration to avoid settling of the particles due to a change in the flow characteristics of the slurry.

\subsubsection{Water/Surfactant Mixture}

The surfactant used for the test was DeSonic LFB-65 supplied by Deseto, Inc. The amount of surfactant added to the water was established through bench testing. The test procedure was to wipe the inside surface of a glass test tube with a thin layer of oll, dust a small amount of ash particles onto the surface, partially fill the tube with a prepared solution of water and surfactant. and shake the tube and observe the ash captured on the oll film. The test showed that with 1 percent or higher concentration of the surfactant, the ash and oll film were effectively removed from the glass surface. Therefore, a water solution of 1-percent surfactant was selected for the last two tests.

\subsubsection{Top Piston Ring Design}

The differences between the conditions in the test rig and in a conventional engine are the temperature and pressure in the cylinder and the conditions the top piston ring is subjected to during an engine cycle. In the conventional engine, the piston ring is pressure-energized against the bore to effect the sealing of the high pressure gas in the cylinder. The end gap of the piston ring causes only a small amount of gas leakage. For the test rig. the cylinder pressure was only slightly above atmospheric. Therefore, an "O" ring was used behind the piston ring (see Figure 7.3) to provide the necessary force to keep the ring in contact with the bore. However, the contact pressure of the ring on the bore was significantly lower than that in a conventional engine during the combustion process. The " $O$ " ring also served the function of sealing the liquid from leaking through the path behind the piston ring. In the case with a llquid piston ring, the end gap of the piston ring would cause the liquid to leak into the crankcase. To minimize this problem, two 
piston rings, one on top of the other, were used with the gaps of the two rings oflset 180 degrees. It should be understood that although this piston ring configuration provided a comparative test for the different conditions, it by no means represented the optimum design for each situation. More detalled discussion will be given later on this subject.

\subsubsection{Cylinder Pressure}

The average cylinder pressure was set for all tests at 10 -in. $\mathrm{H}_{2} \mathrm{O}$ by adjusting the vent valve downstream of the exhaust recelver. The pressure was set above atmospheric pressure to assure drainage of water from the slurry collector. As mentioned earlier, the test rig was not designed to duplicate the operating temperature and pressure conditions in a real engine. The receiver and exhaust pipe were sized to reduce the compression ratio of the test rig to minimize the pressure fluctuation in the cylinder due to the compression action of the reciprocating piston. The measured pressure swing in the cylinder was reduced to $\pm 10-\ln . \mathrm{H}_{2} \mathrm{O}$ from the average.

\subsection{TEST RESULTS AND DISCUSSION}

There were a total of five test runs, of which the first two were under the same baseline condition without the liquid piston ring. In Test 1, the labyrinth section for the liquid ring was attached to the top of the piston. After the test, it was felt that the labyrinth section may have caused a paste mixture of alumina and oil to collect in the labyrinth section and contribute to the wear of the piston ring and liner. In Test 2 the labyrinth section was removed and the piston was more representative of a conventional design. Test 3 was the water ring test with alumina feed. Test 4 was the same as Test 3 except surfactant was added to the water. Test 5 had the same liquid as in Test 4 with the alumina feed.

The duration of the tests varied between 0.5 to 1.67 hours. The duration was limited to this short time, because the wear rate of the piston ring and liner was so high that additional testing time would cause the piston ring to lose the contact pressure exerted by the " $O$ " $\mathrm{ring}$.

During the test, measured quantlties of alumina particles were added to the fluidized bed at fixed time intervals. The total bed material was weighed before and after the tests to determine the total amount of solids fed to the test cylinder.

Liquids were collected and measured in three locations; namely, the liquid slurry collector, the exhaust receiver, and the oil collector. (See Figure 7.1.) The unaccounted liquid was assumed to have discharged with the air. 
All the piston rings and the cylinder bore were measured before and after the test. The wear of the piston ring was expressed in terms of the increase in end gap when the O.D. of the ring is held constant. Liner wear rate was expressed in terms of radial increase, averaged over the ctrcumference of the bore and four points along the axds of the bore.

The results of the wear tests are summarked in Table 7.1.

\subsubsection{General Inspection}

After completion of each test, the cylinder was disassembled for inspection. The following are the specific observations made for the different cases.

- In the baseline case, a relatively thick mixture of oll and solid particles accumulated on the entire outer surface of the piston. See the photographs in Figures 7.5 through 7.8. In Test 1, this mixture also accumulated in the labyrinth section above the piston.

- The thick mixture of oll and solids became diluted at the lower part of the cylinder where fresh oll was injected. The diluted mixture flowed down and drained into the oll collector. In an actual engine, this mixture would be dralned into the crankcase.

- With the water ring, the liner and piston surfaces were relatively clean. but a mixture of oll and sollds was stull present here and there. Because water was mixed into the oll, the solid/oll/water mixture appeared to be more fluld. Photographs of the components are shown in Figures 7.9 through 7.11 .

- Water collected in the slurry collector contained solids and oll. This was an indication that solids and oll were scrubbed by the water ring.

- When surfactant was added to the water, the piston and cylinder surfaces were practically free of sollds except in the upper part of the cylinder above the travel of the labyrtnth section. The liquid collected from the various points contained suspended solids. In this test. a significant amount of liquid leaked past the piston rings and was collected in the oll drain. Photographs of the components after the test are shown in Figures 7.12 through 7.14 .

- The sollds generally appeared black instead of the white for the feed alumina. This was due to wear material from the piston ring and the cast-tron liner. 
0
9
0
1
00
0
11

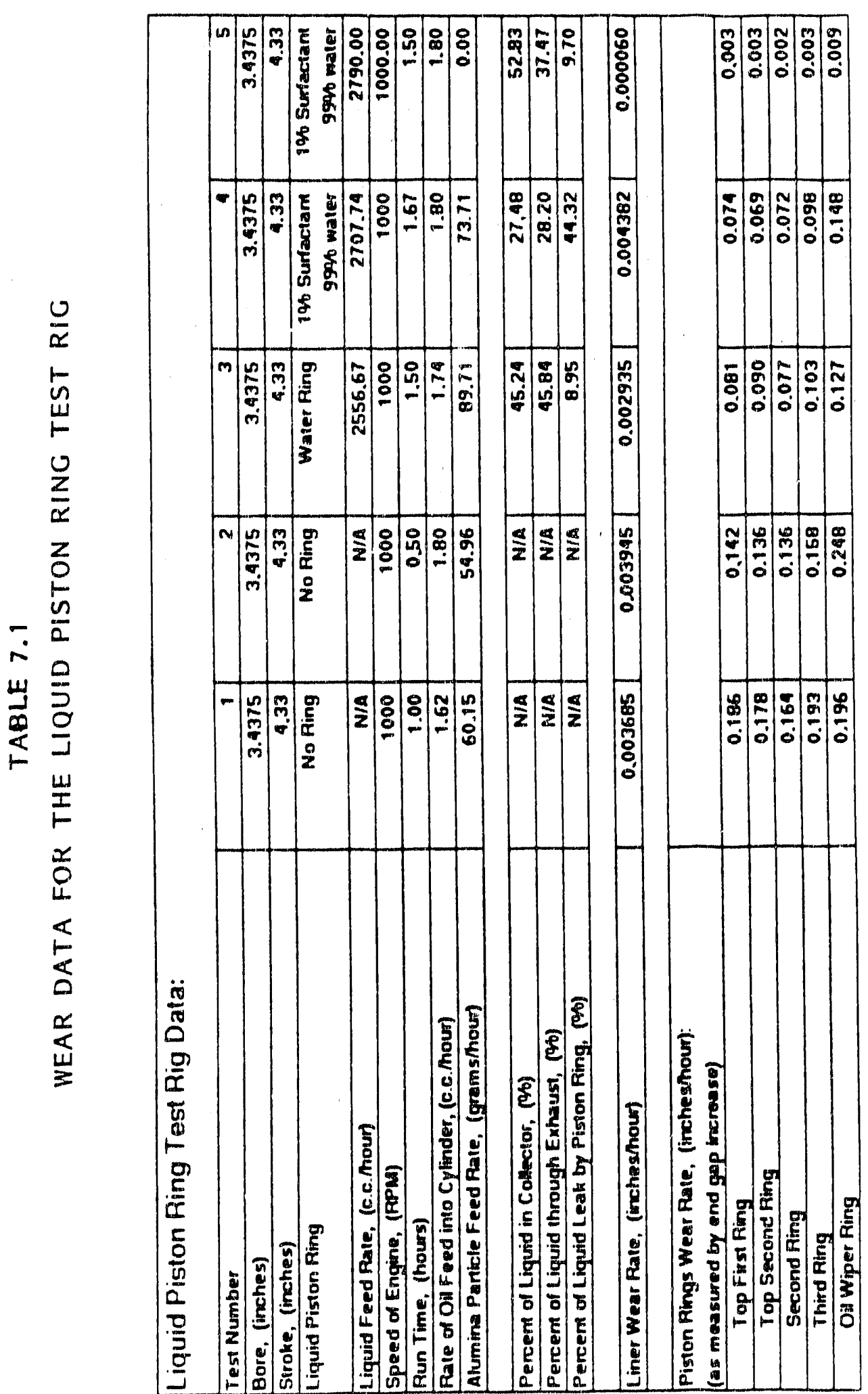



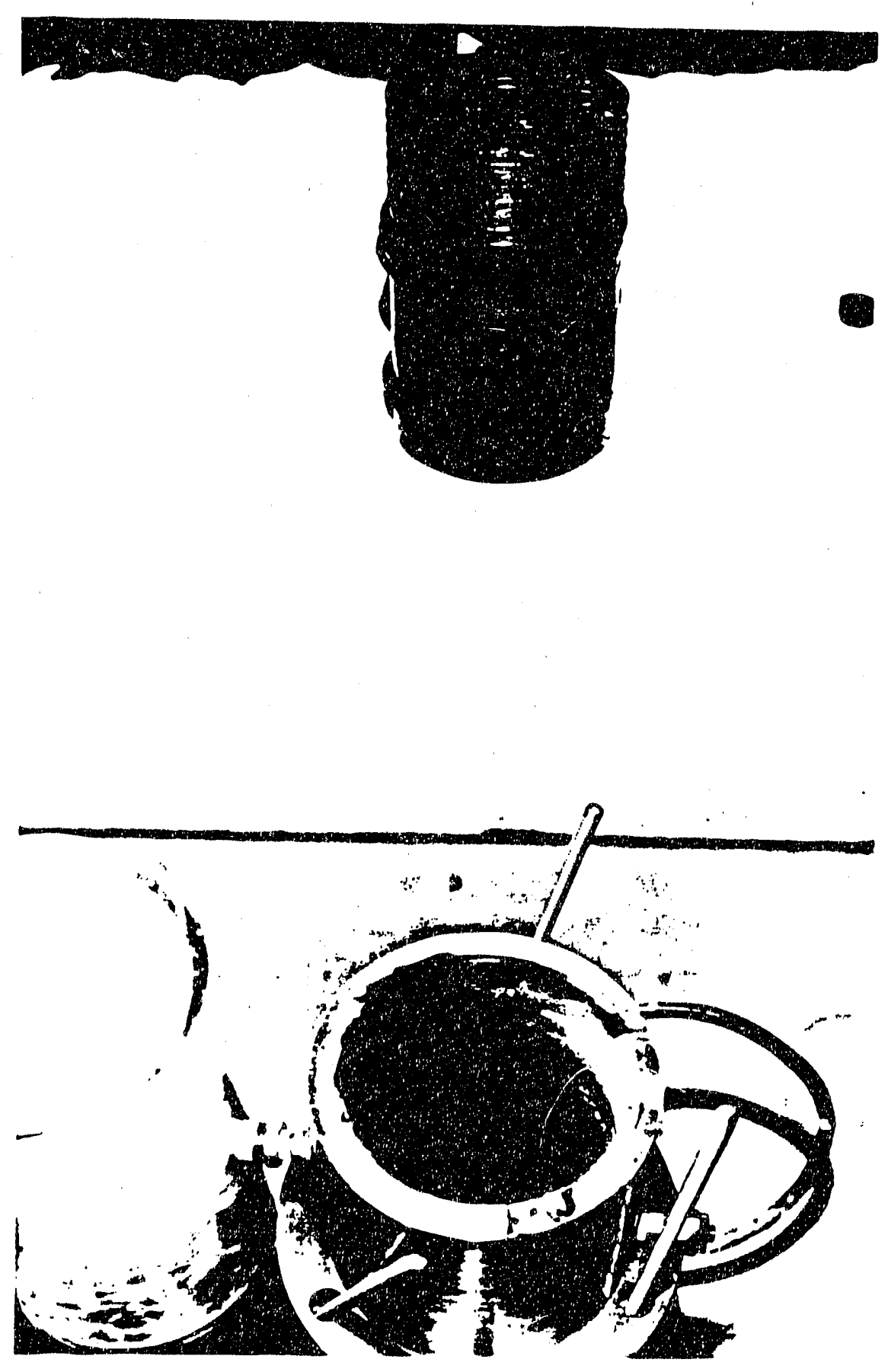

Figure 7.5 Test Components After Test 1 

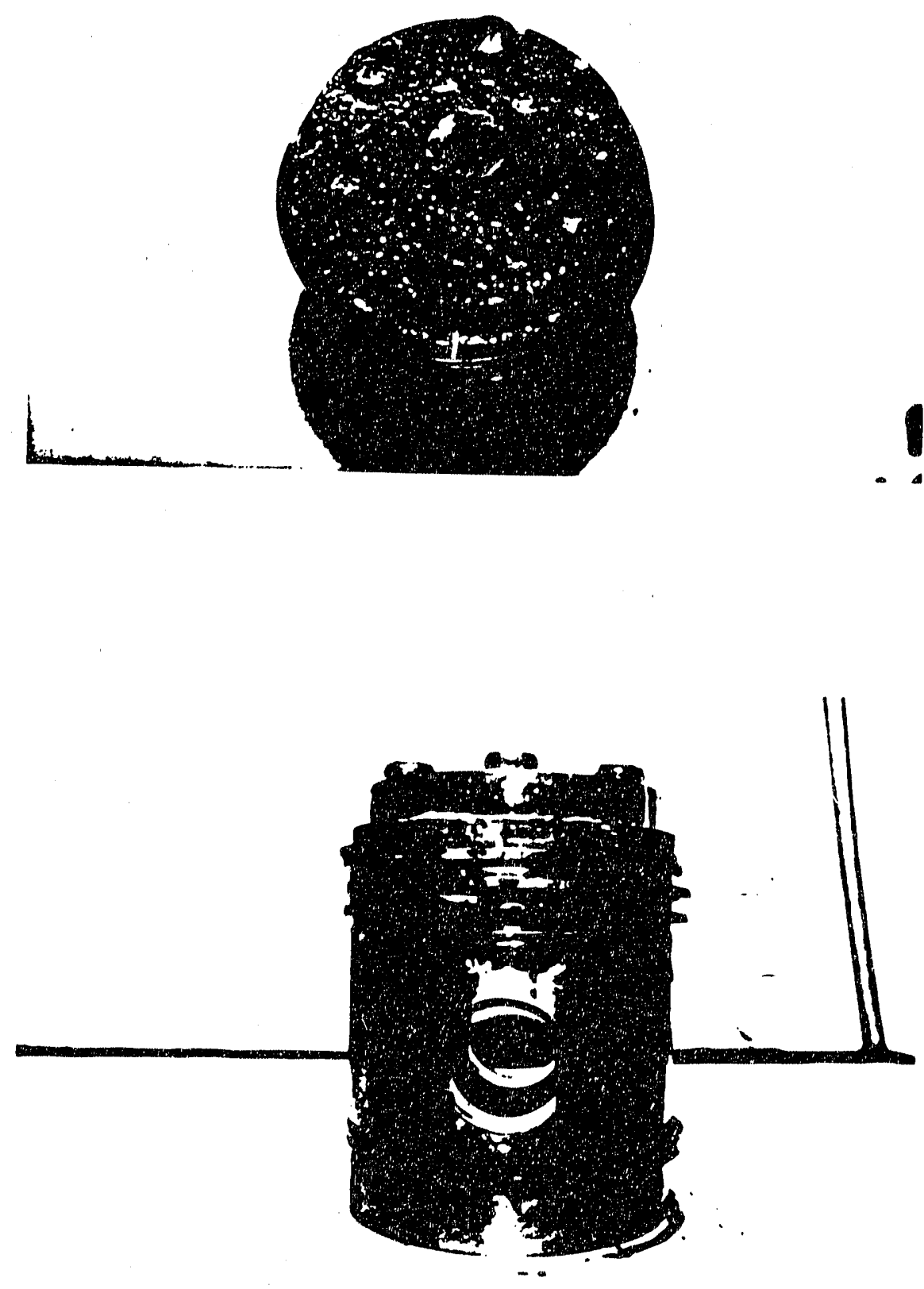

Figure 7.6 Test Components After Test 2 

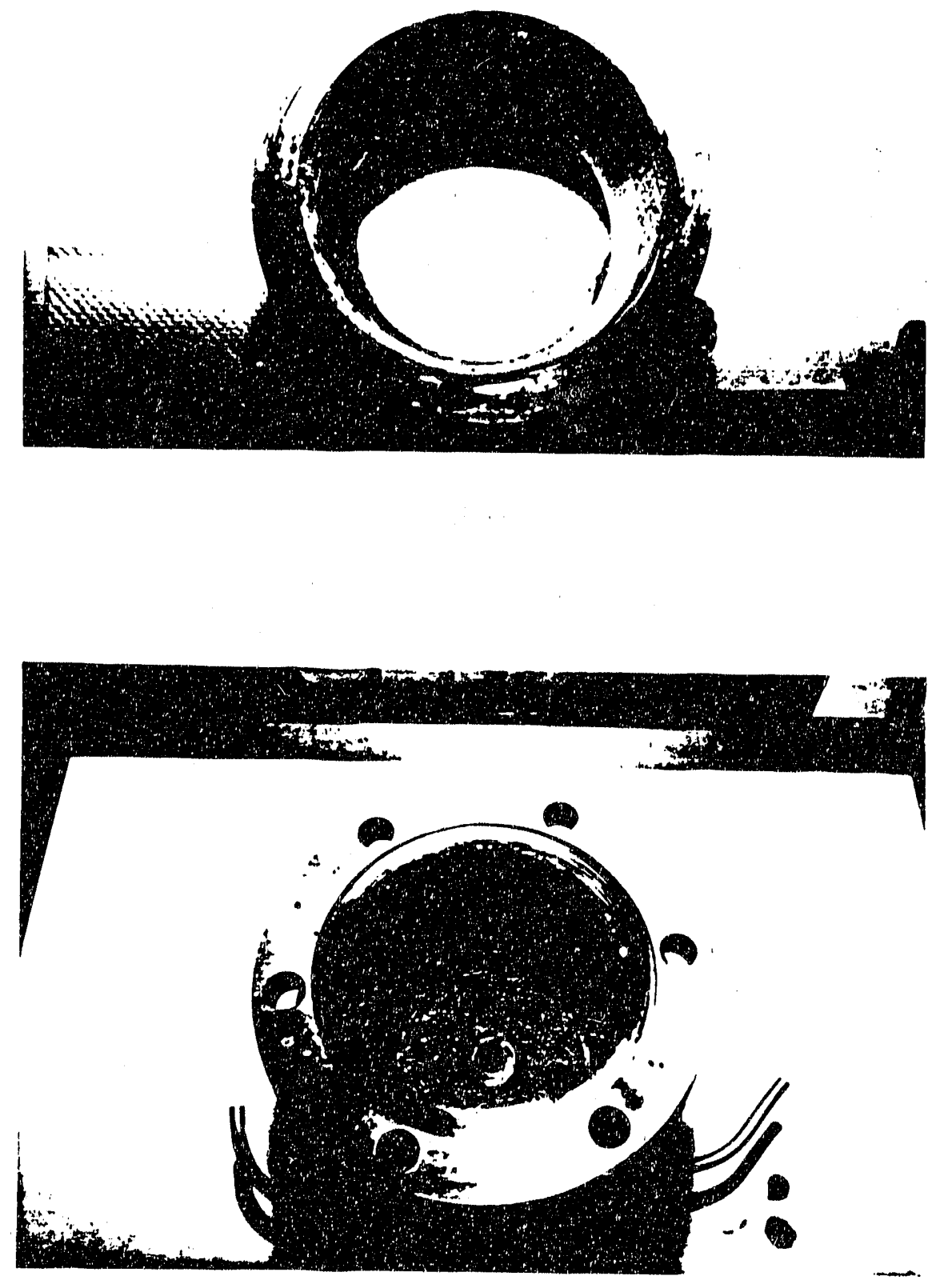

Figure 7.7 Test Components After Test 2 


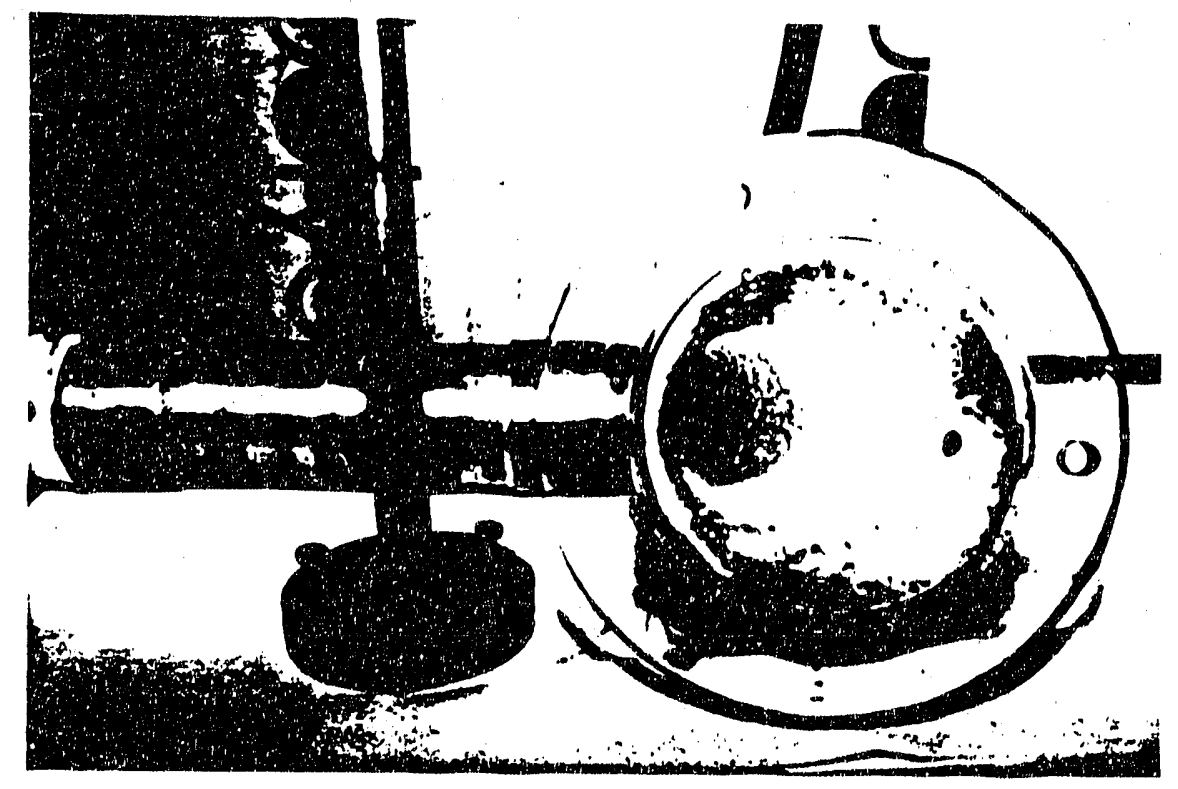

Figure 7.8 Test Components After Test 2 


$$
\text { Hi }
$$



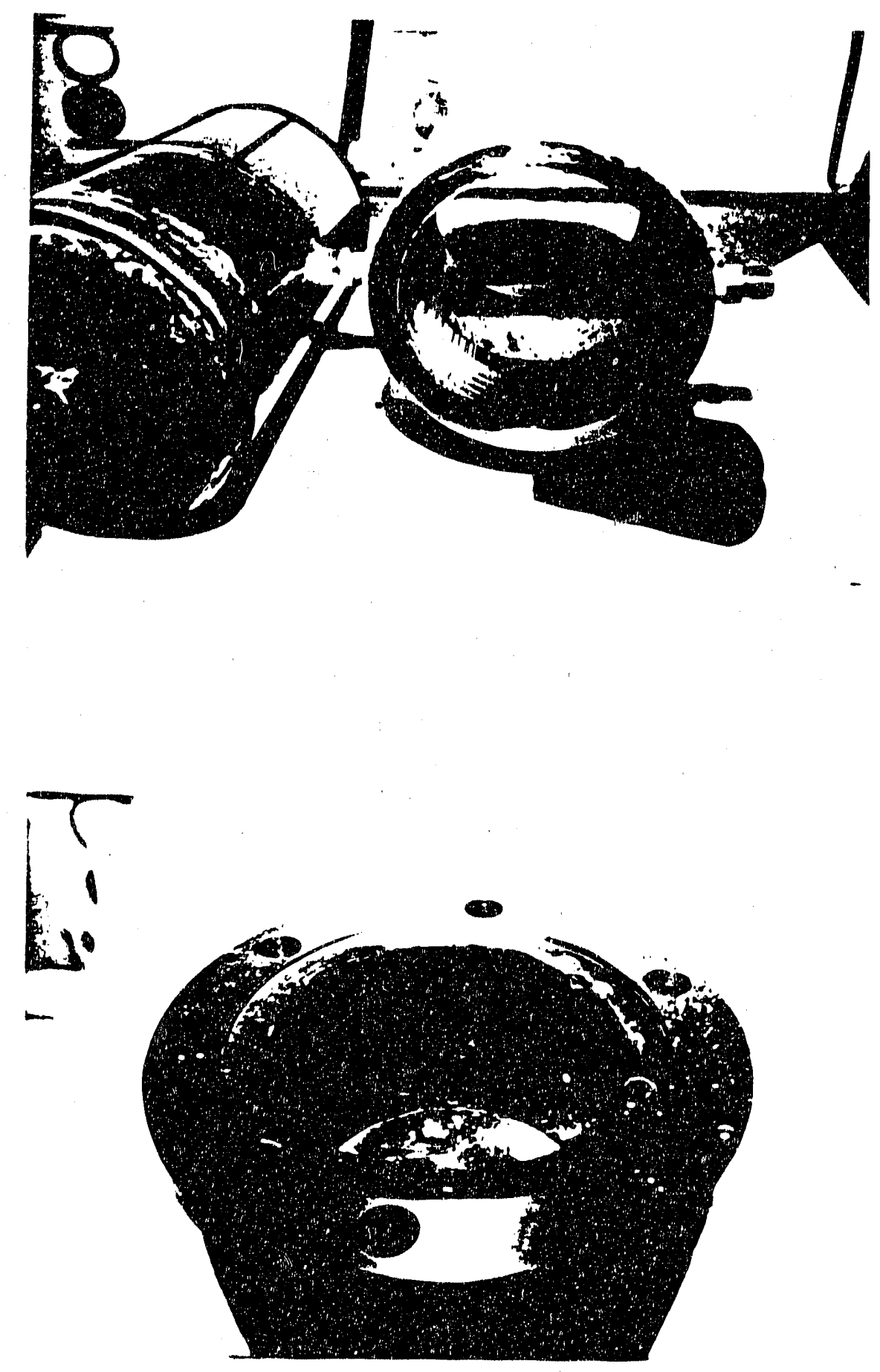

Figure 7.10 Test Components After Test 3 


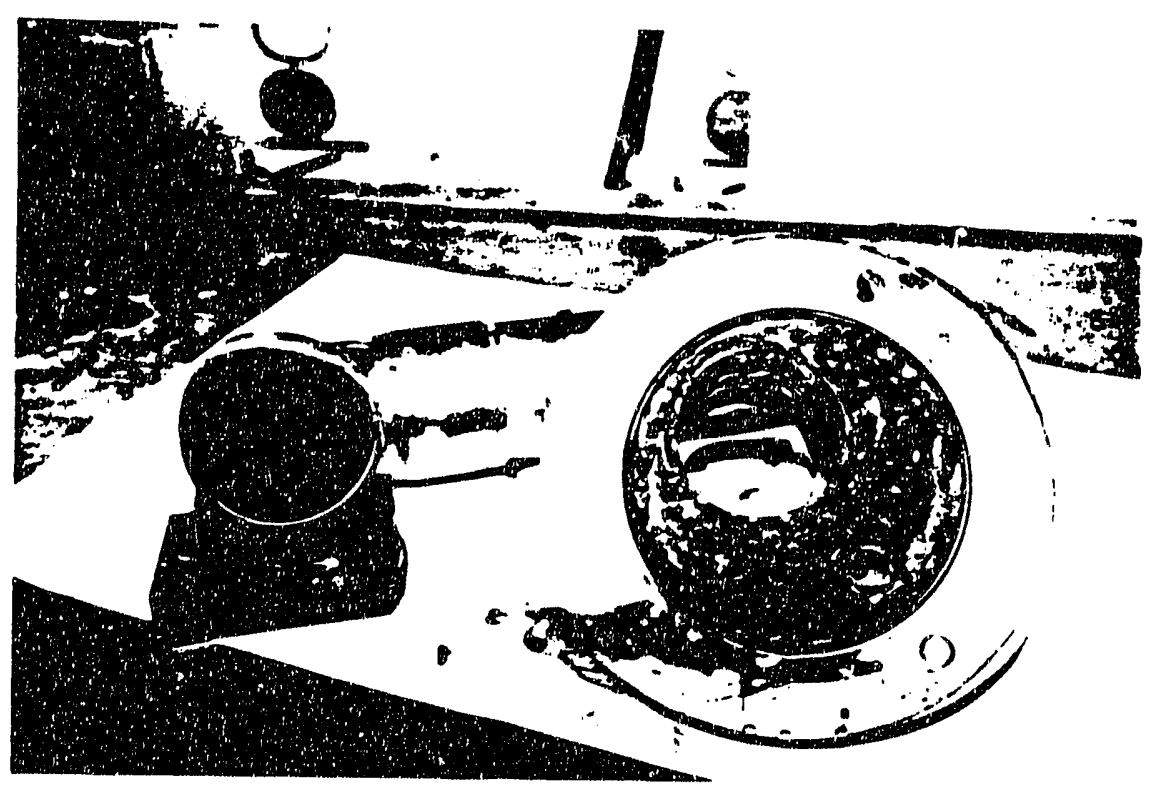

Figure 7.11 Test Components After Test 3 

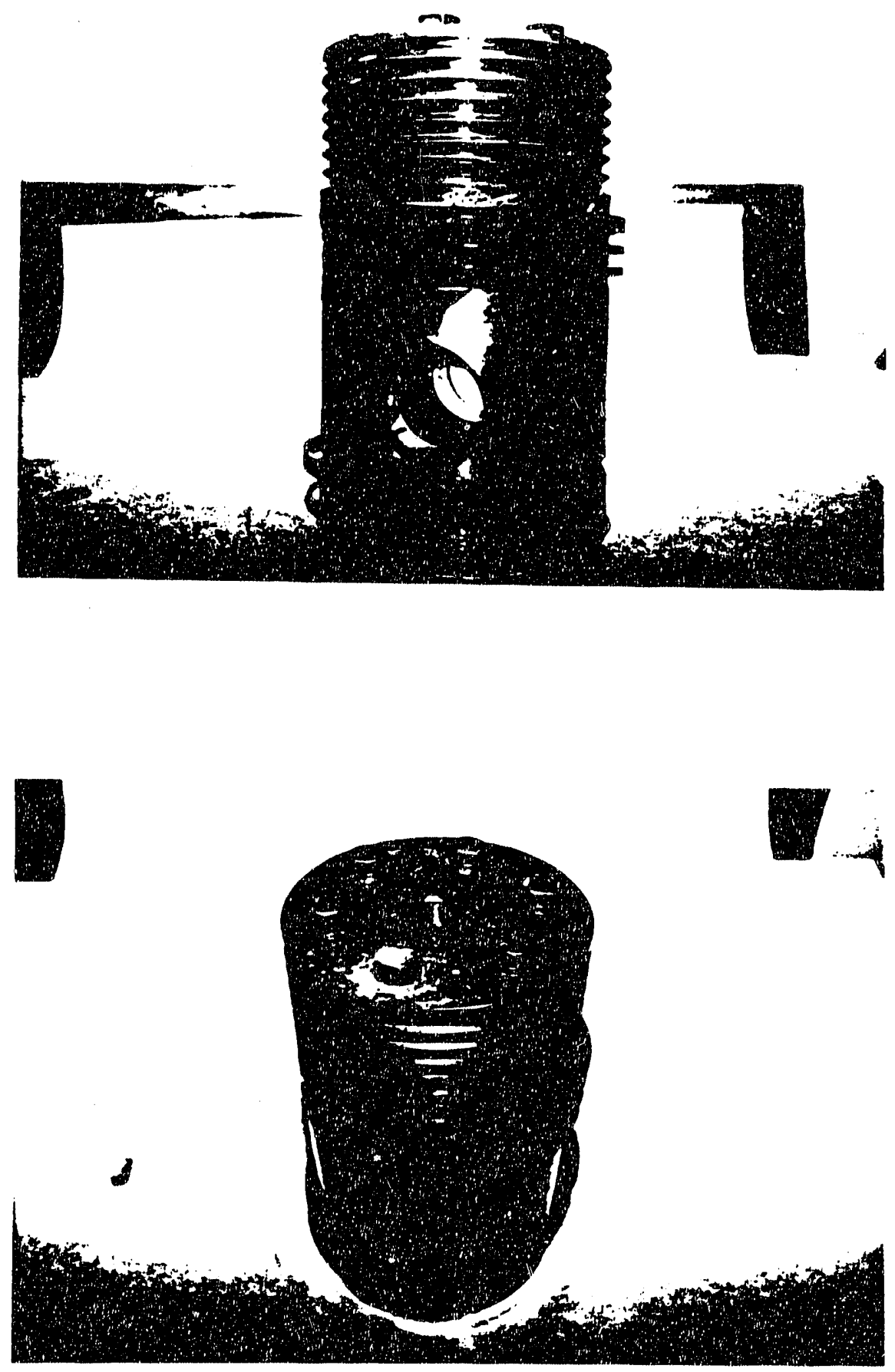

Figure 7.12 Test Components After Test 4 

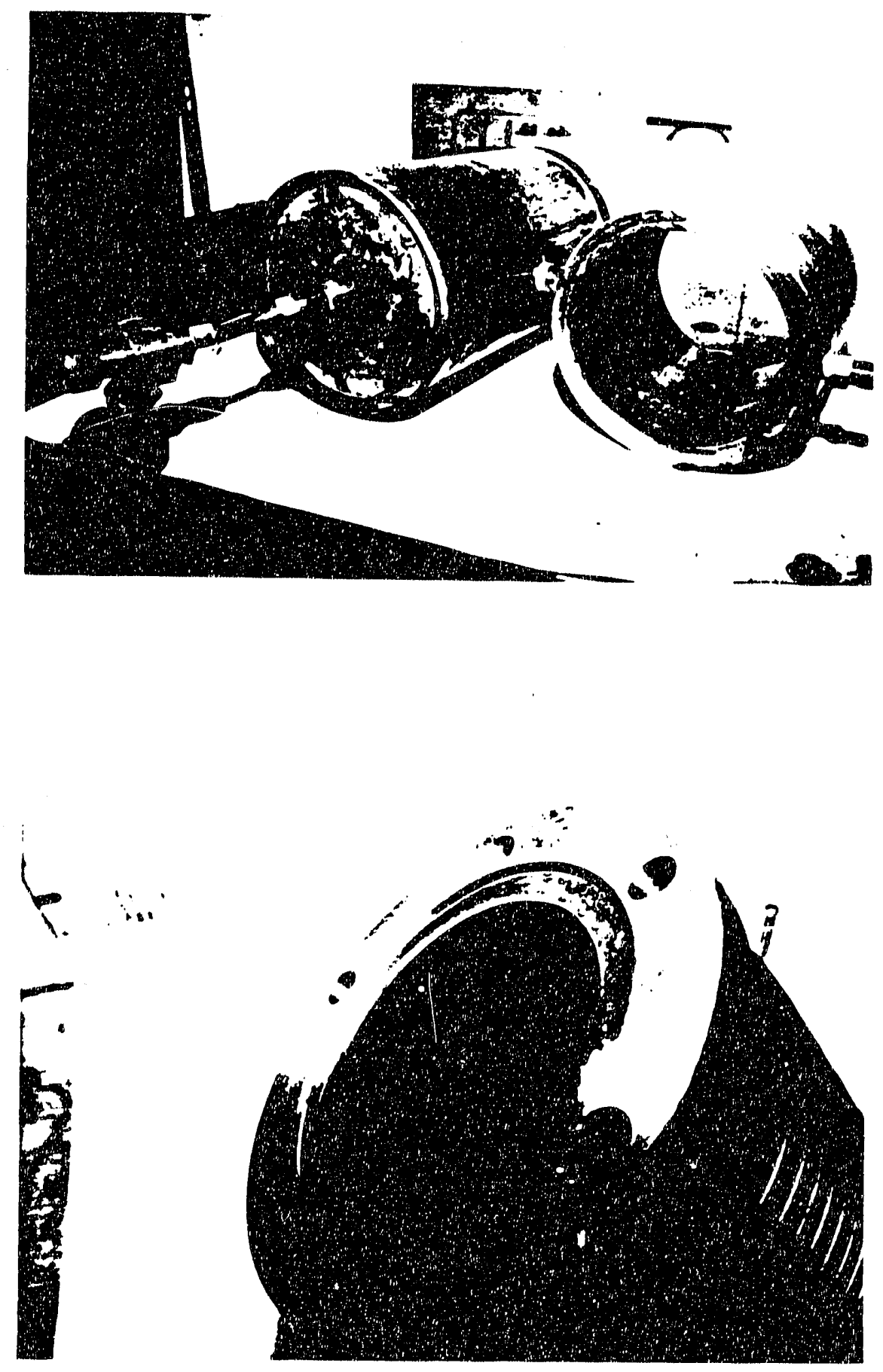

Figure 7.13 Test Components After Test 4 


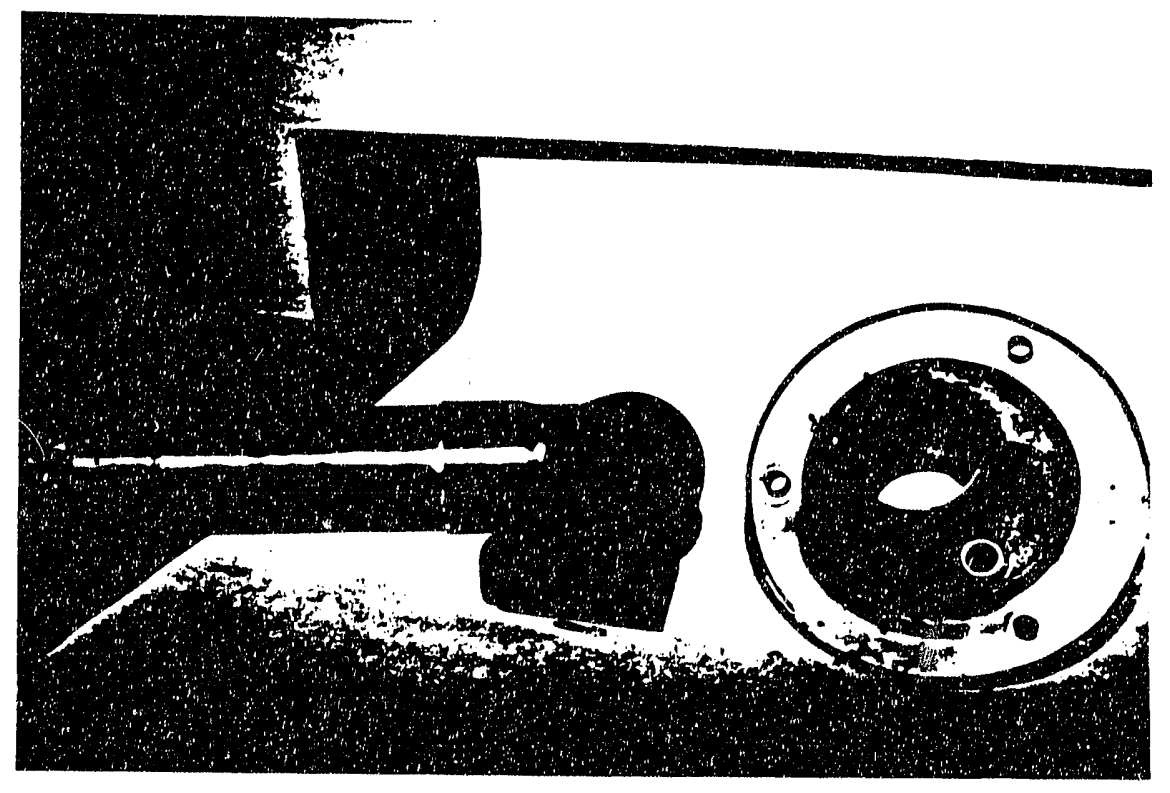

Figure 7.14 Test Components After Test 4 
- When solids were not introduced and surfactant was added to the water, the ptston and liner were clean. The liner surface appeared polished as opposed to the dull appearance after all other tests.

- In all tests with solids, the piston rings were visibly worn. The amount of wear on the radial thickness of the piston rings was uneven around the circumference. This could be a result of uneven deposition of particles due to the port arrangement or the urievenness of the radial pressure applied from the "O" ring behind the piston rings.

\subsubsection{Piston Ring and Liner Wear}

The wear rates of the piston rings and cylinder liner were very high in all cases when solid particles were introduced to the cylinder. Tests 1 and 2 were different in that the labyrinth section was attached to the piston top in Test 1 and not in Test 2. These results indicate that the presence of the labyrinth section and the accumulation of oil/solid mixture in the labyrinth section did not contribute significantly to the wear of the parts.

With the liquid ring, the wear rate was reduced by a factor of 2 , as shown by comparing Tests 3 and 4 with Tests 1 and 2. This clearly indicates that the liquid ring did remove particles from the wall to a degree sufficient to affect wear. However, visual observation of the parts in the two tests with water and the water/surfactant ring suggested that the mechanisms of how the solld particles became trapped between the piston rings and the liner wall were different. In Test 3 , the water ring helped to reduce but not eliminate the oil/solid mixture on the surfaces. The presence of the sollds on the wall would suggest that the mechanisms of wear in the case of water ring were simllar to the baseline case. As the piston ring slides on the liner surface, it rides over the oll/solid layer as it is supposed to do in a normal engine, thus causing the solids to be pushed and trapped between the rubbing surfaces. The reduced wear rate with the water ring reflected the reduced amount of solids on the wall.

For the case with the water/surfactant ring (Test 4), the surfaces were free of alurnina particles, and therefore the piston ring would not slide over the particles suspended in water. A reasonable description of the mechanism was that the leakage of the liquid past the piston ring caused the suspended alumina particles to be accumulated in front of the ring and eventually run over by the ring. Trapping the particles between the piston ring and the liner surface would open up the gap and cause more liquid to leak, as evidenced by the large fraction of liquid collected from the oll drain, and would consequently bring more particles to the front of the piston ring. 
The photographs of the piston ring surface for the various cases are shown in Figure 7.15 through 7.17 . They all show similar wear marks parallel to the piston axis.

Test 5 was designed to simulate the ideal condition in which a water ring with surfactant addition was established above the piston ring such that the solids contaminated portion of the liquid ring was kept near the top of the liquid ring and the piston ring contacted only the clean water/surfactant mixture. The test showed a potential reduction in wear by a factor of 50 over the baseline case. The water leakage past the piston rings was signtficantly different in Test 5 (compared with Test 4). This supported the postulated mechanism that the accumulation of solid particles between the piston ring and the cylinder liner due to leakage of the contaminated liquid caused the leakage io increase further.

Based on the analysis of the test results, we concluded that the liquid piston ring was effective in scrubbing and reducing the amount of particles held by the oil film on the wall. When a proper amount of surfactant was added to the water the movement of the liquid ring during the up-stroke effectively removed from the wall the solid particles that were deposited on the wall during the down-stroke of the piston. The wear of the piston ring and liner under this condition was not the result of the reduced all fulm on the wall due to the surfactant. The wear resulted from the leakage of the contaminated liquid past the piston ring, which caused the solid particles to accumulate and become trapped between the piston ring and the liner surface. It became clear that, in addilion to cleaning the solid particles of the wall surface, preventing the contaminated liquid from leaking past the piston ring was equally important for the liquid piston ring concept. The liquid piston ring concept for wear reduction in a coal-slurry-fired diesel engine is therefore technically feasible provided that an improved piston seal iting system is developed to prevent leakage of the contaminated liquid past the piston rings.

Since this study has shown the feasibility of cleaning the wall with a liquid ring, the next $R \& D$ step should be focused on the improvement of the sealing system to prevent leakage of the liquid past the piston ring. There are two steps in the development of an improved liquid ring system. The first step is to improve the liquid sealing of the pision ring system. The second step is to design a liquid supply' system in which the liquid is supplied through the gap between the piston ring and the bore from a buffer zone below the ring. The flow of liquid through the gap will continuously fush the particles away from the zone immediately above the piston ring. With the presence of the liquid ring. the piston ring will not be subjected to high temperalure. Special malerials including state-of-the-art plastic materials currently used for seals in compressors and pumps can be considered. in recent years, considerable interest has been raised in the subject of high 

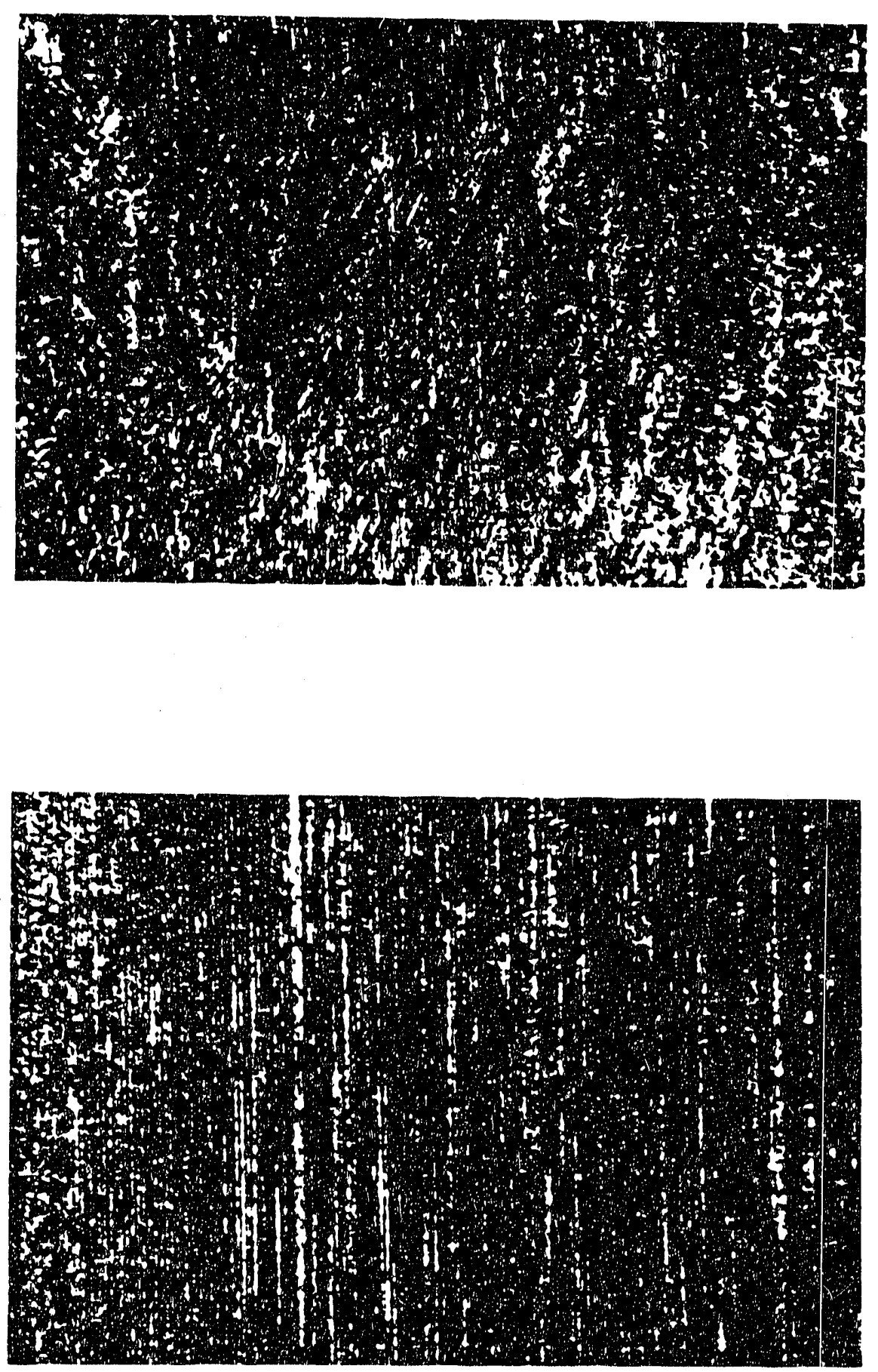

Figure 7.15 Magnified View of Top Ring Surface 

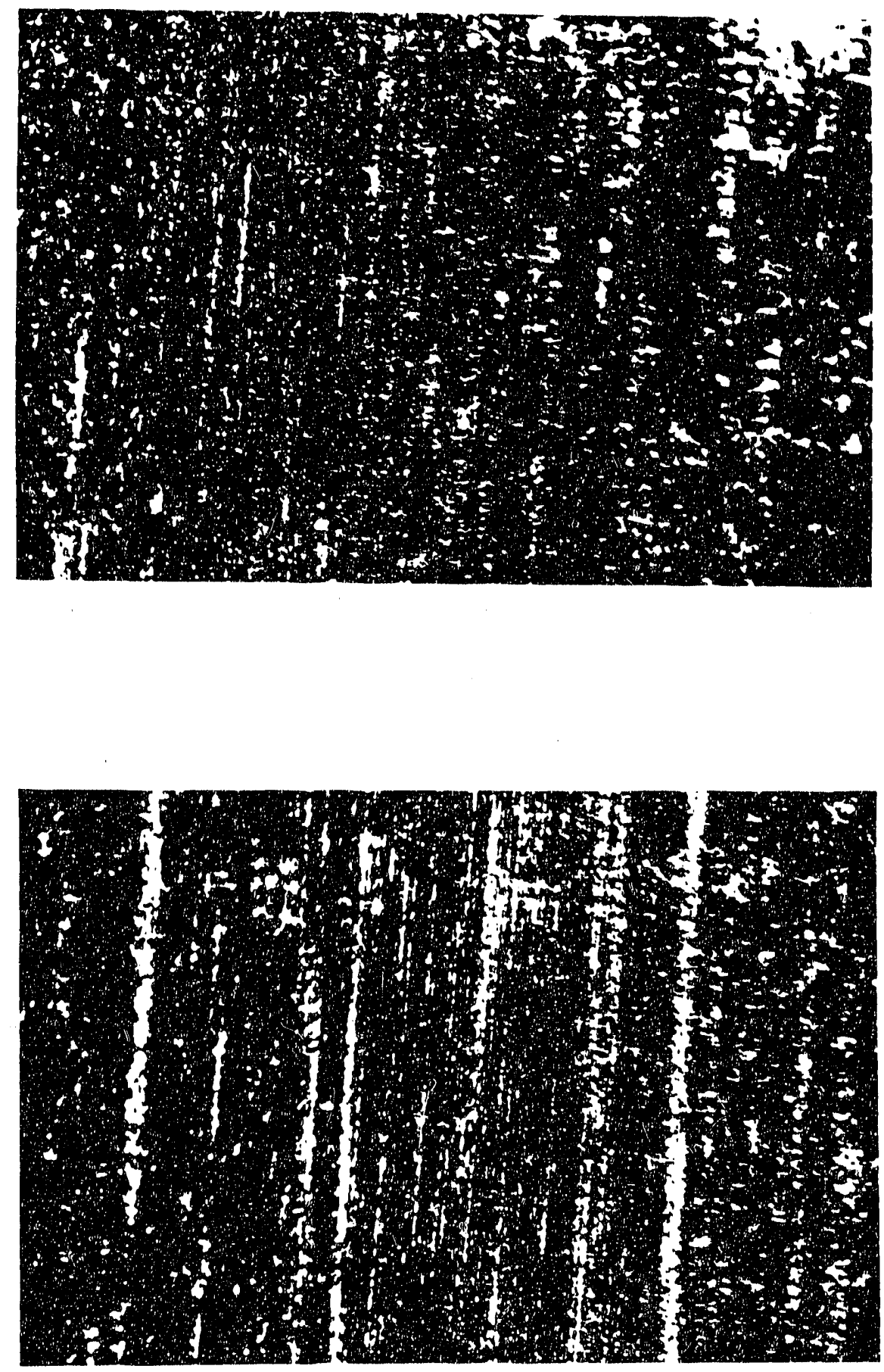

Figure 7.16 Magnified View of Top Ring Surface 


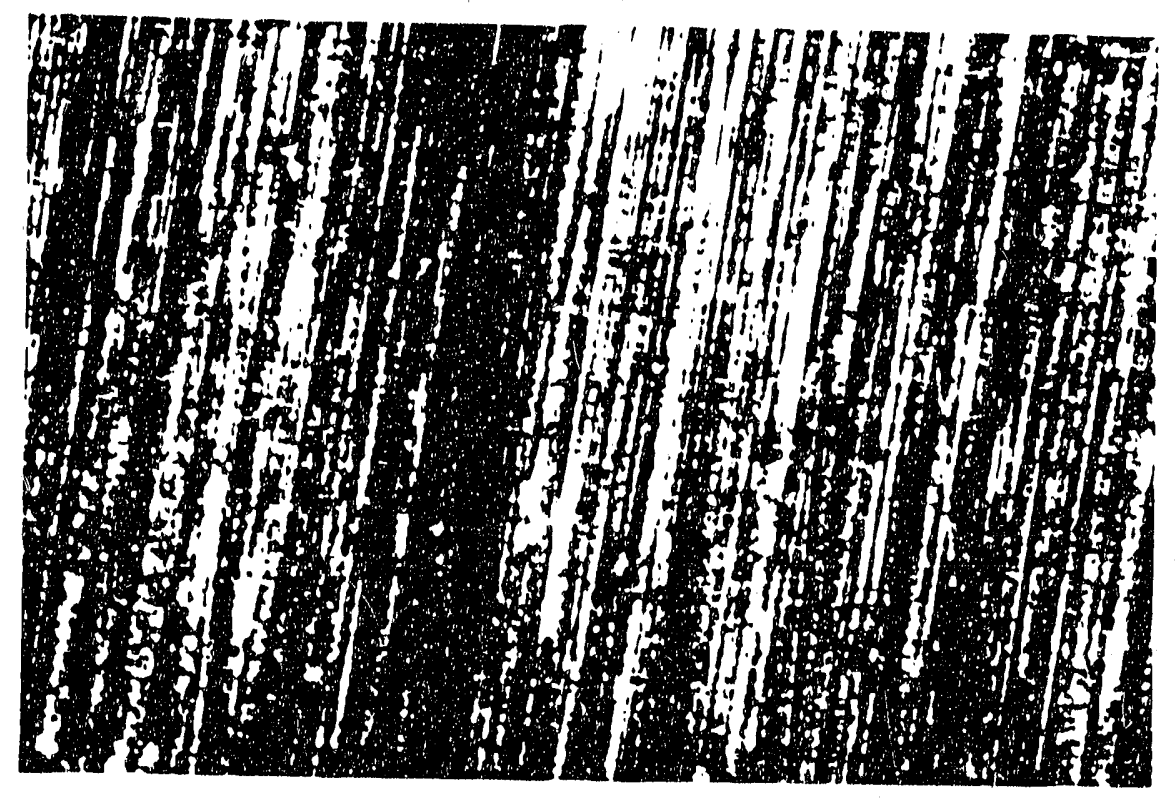

Figure 7.17 Magnified View of Top Ring Surface 
pressure slurry pumping for plpeline transport of minerals and coal slurries. Advancements have been made in the development of plunger pumps and their seal systems. New technology developed for seallng rectprocating plunger pumps should be applied and modified as needed for the engine system. 


\section{CONCLUSIONS AND RECOMMENDATIONS}

The following conclusions summarize the significant results obtained as the program progressed from modeling, to the fow visualization bench test, to the single-cylinder test rig where actual wear measurements were made.

- Baseline testing in the single-cylinder test rig with alumina particle feed and no liquid ring showed that the particles mixed with the oll to form a solid/oll mixture on the cylinder wall which caused high wear of the piston ring and liner. The solld/oll mixture also leaked past the piston ring into the space below the piston.

- A water ring with a saw-tooth shaped labyrinth effectively reduced the amount of solld/oll mixture on the cylinder wall, thus reducing the wear rate by a factor of 2 .

- A water ring with surfactant addition was most effective in keeping the solid particles from adhering to the cyllnder wall. However, the piston ring and liner wear rate was comparable to that with the water ring. The leakage of the contaminated liquid with suspended solids past the piston ring caused the sollds to be accumulated and trapped between the piston ring and the cylinder wall, thus producing the wear effect.

- Preventing leakage of the contaminated liquid past the piston ring was identified as one of the major factors in the liquid piston ring concept and should be the subject for the next R\&D program.

- Based on the flow visualtzation study on a bench simulator, a liquid ring with a $90^{\circ}$ saw-tooth labyrinth provided high shear rate at the cylinder wall and constant agitation in the labyrinth channels, which preverated sollds accumulation.

- The once-through version of the liquid ring concept is the most destrable from the standpoint of system simplictty. The once-through system was tested in the single-cylinder test $\mathrm{ug}$ and the problems identified are not easter to solve with the other versions of the concept.

- Liquid supply rate to the once-through system to maintain low particle concentration is sufficlently low so that no detrimental effects on engine thermal performance would be expected. 
- Heat transfer to the liquid ring through the piston and liner must be limited to prevent bolling away the liquid ring. Conceptual piston designs for minimizing this heat transfer are presented.

- A dynamic analysis of the liquid ring including viscous drag, inertia, and labyrinth pressure drop effects was carried out which showed large static pressure variations in the liquid ring during a complete engine cycle. These pressure vartations could allow significant loss of liquid in the ring if heat transfer was not limited.

- The pressure fluctuations in the ring were shown to be a strong function of ring height and engine speed, and a weak function of the liquid flow rate to the labyrinth and the number of labyrinth teeth when the labyrinth clearance is small.

Based on these results and conclusions, the following steps could be taken to continue exploration of the liquid ring concept.

- Select several concepts for reducing liquid ring leakage past the top ring. Establishing a liquid buffer zone with controlled leakage to the labyrinth seems most promising.

- Test one or more concepts in the single-cylinder test rig.

- Design a bench-scale piston incorporating the liquid piston ring and reduced heat transfer concepts.

- Conduct firing tests of the liquild ring concept in a single-cylinder test rig. 


\section{REFERENCES}

1. Nydick, Dr. S.E., "Development of a Coal/Water Slurry-fueled Diesel Engine for Industrial Cogeneration." Final and Summary Report, Report No. DE-ACO282CE40539-06, NTIS, February 1987.

2. Flynn, Paul L. and Hsu, Bertrand D. (GE Transportation Systems), "Coal Fueled Diesel Developments," SAE Paper 881159, 1988.

3. Nicholls, El-Messiri, and Newhall, "Inlet Mandfold Water Injection for Control of Nitrogen Oxudes - Theory and Expertment," SAE Paper 690018, 1969.

4. French and Hartles, "Thermal Loading of Diesel Engines," I. Mech. E., London, Proceedings 1964-65, Vol. 179, Part 3C, p. 126.

5. Butler, "Water-Cooled Pistons: Construction and Heat Transfer," I. Mech. E., London, Proceedings 1964-65, Vol. 179, Part 3C, p. 168.

6. Enomoto, Y. and Furuhama. S., "Heat Transfer into Ceramic Combustion Chamber Wall of Internal Combustion Engines," SAE Paper 861276, 1986.

7. Furuhama, S. and Enomoto, Y.. "Heat Transfer into Ceranuc Combustion Wall of Internal Combustion Engtnes," SAE Paper 870153, 1987.

8. Morel, T. and Keribar, R. "A Model for Predicting Spatially and Time Resolved Convective Heat Transfer in Bowl-in-Piston Combustion Chambers," SAE Paper 850204. SAE Congress, Detrolt. 1985. 

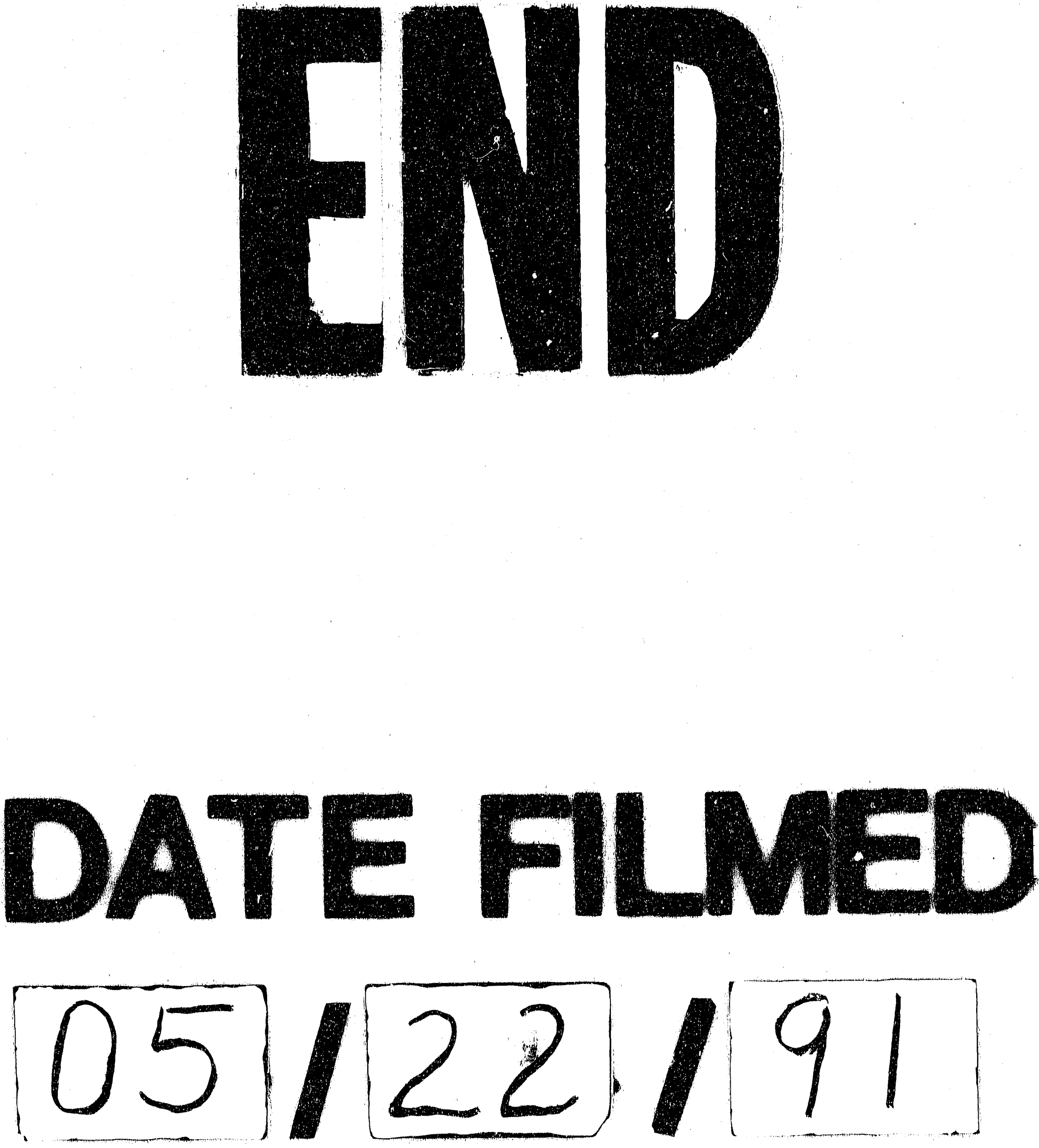